\title{
"Ligandless" pentafluoroethylation of unactivated (hetero)aryl and alkenyl halides enabled by the controlled self-condensation of $\mathrm{TMSCF}_{3}$-derived $\mathrm{CuCF}_{3}$
}

\author{
Jordi Mestre, Sergio Castillón, and Omar Boutureira* \\ Departament de Química Analítica i Química Orgànica, Universitat Rovira i Virgili \\ C/ Marcel·lí Domingo 1, 43007 Tarragona (Spain) \\ *E-mail: omar.boutureira@urv.cat
}

\section{Table of Contents}

1. Optimization of the preparation of $\mathrm{CuCF}_{3}$ and $\mathrm{CuC}_{2} \mathrm{~F}_{5}$ from $\mathrm{TMSCF}_{3} \quad \mathrm{~S} 2$

2. Stability of $\mathrm{TMSCF}_{3}$-derived $\mathrm{CuCF}_{3} \quad \mathrm{~S} 4$

3. Composition of $\mathrm{TMSCF}_{3}$-derived $\mathrm{CuCF}_{3}$ and $\mathrm{CuC}_{2} \mathrm{~F}_{5}$ in solution $\mathrm{S} 5$

4. ${ }^{19} \mathrm{~F}$ DOSY NMR experiments $\quad$ S8

5. ESI-MS experiments $\quad$ S12

6. Optimization of pentafluoroethylation of iodinated heterocycles $\quad$ S13

7. In situ reaction monitoring of the pentafluoroethylation of $\mathbf{1 d} \quad \mathrm{S} 14$

8. Conformational analysis of $\mathbf{2 a} \quad \mathrm{S} 15$

9. Optimization of the pentafluoroethylation of halogenated (hetero)arenes $\quad$ S15

$\begin{array}{ll}\text { 10. NMR Spectra } & \text { S18 }\end{array}$

$\begin{array}{ll}\text { 11. References } & \text { S48 }\end{array}$ 


\section{Optimization of the preparation of $\mathrm{CuCF}_{3}$ and $\mathrm{CuC}_{2} \mathrm{~F}_{5}$ from $\mathrm{TMSCF}_{3}$}

Within a glovebox: a two-neck round-bottom flask was charged with dried $\mathrm{CuX}(1 \mathrm{mmol})$, KF ( $1 \mathrm{mmol})$ and a magnetic stir bar. The corresponding dry solvent was added, the flask was capped with a rubber septum, brought out of the glovebox, and was vigorously stirred for 10 min. $\mathrm{TMSCF}_{3}(1 \mathrm{mmol})$ was slowly added via a syringe while the reaction mixture was stirred at the indicated temperature. After $3 \mathrm{~h}$, the flask was brought back inside the glovebox, an exit needle was then injected to release internal pressure, and 1,3bis(trifluoromethyl)benzene (BTB, $0.5 \mathrm{mmol}$ ) was added. After mixing well the components, the stirring was stopped and the reaction was left undisturbed until all solids settled on the bottom of the flask. An aliquot $(0.7 \mathrm{~mL})$ of the supernatant was transferred to a NMR tube, capped with a rubber septum, brought out of the glovebox and analyzed by quantitative ${ }^{19} \mathrm{~F}$ NMR.

Without a glovebox: $\mathrm{KF}(1 \mathrm{mmol})$ and $\mathrm{CuBr}(1 \mathrm{mmol})$ were dried under vacuum overnight at $150{ }^{\circ} \mathrm{C}$ and $80^{\circ} \mathrm{C}$, respectively. The solids and a magnetic stir bar were added into a twoneck round-bottom flask with PTFE stopcock and the system was evacuated under vacuum and refilled with argon three times. The corresponding dry solvent was added under argon and the mixture vigorously stirred for $10 \mathrm{~min}$. $\mathrm{TMSCF}_{3}(1 \mathrm{mmol})$ was slowly added via a syringe under argon while the reaction mixture was stirred at the indicated temperature. When the reaction was complete, 1,3-bis(trifluoromethyl)benzene (BTB, $0.5 \mathrm{mmol}$ ) was added. After mixing well the components, the stirring was stopped and the reaction was left undisturbed until all solids settled on the bottom of the flask. An aliquot $(0.7 \mathrm{~mL})$ of the supernatant was transferred under argon to a NMR tube for quantitative ${ }^{19} \mathrm{~F}$ NMR analysis. 
Supporting Information

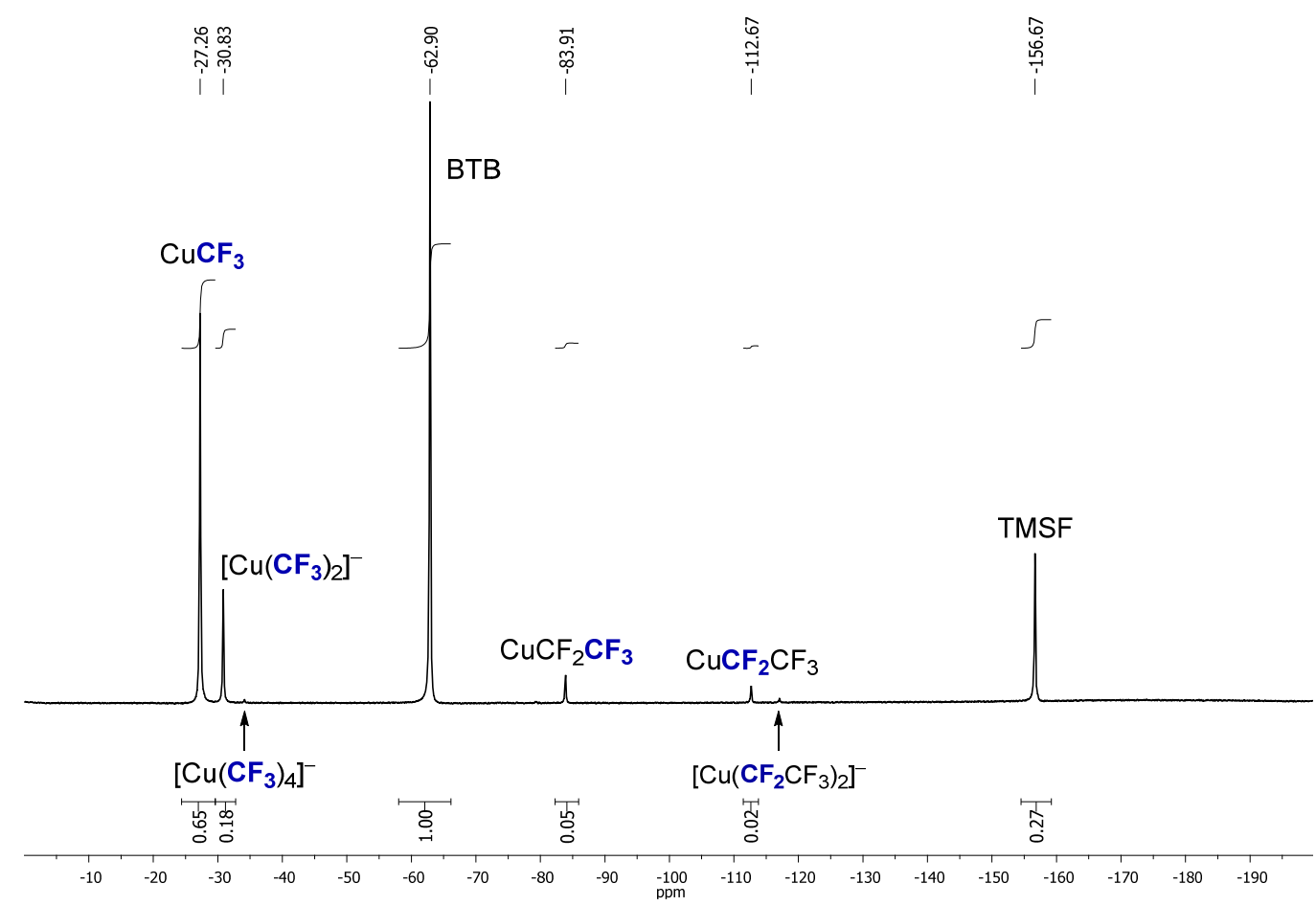

Figure S1. Representative ${ }^{19} \mathrm{~F}$ NMR spectra of $\mathrm{CuCF}_{3}$ from the $\mathrm{TMSCF}_{3} / \mathrm{KF} / \mathrm{CuX}$ system (unoptimized conditions). $\mathrm{BTB}=1,3$-bis(trifluoromethyl)benzene, TMS $=$ trimethylsilyl

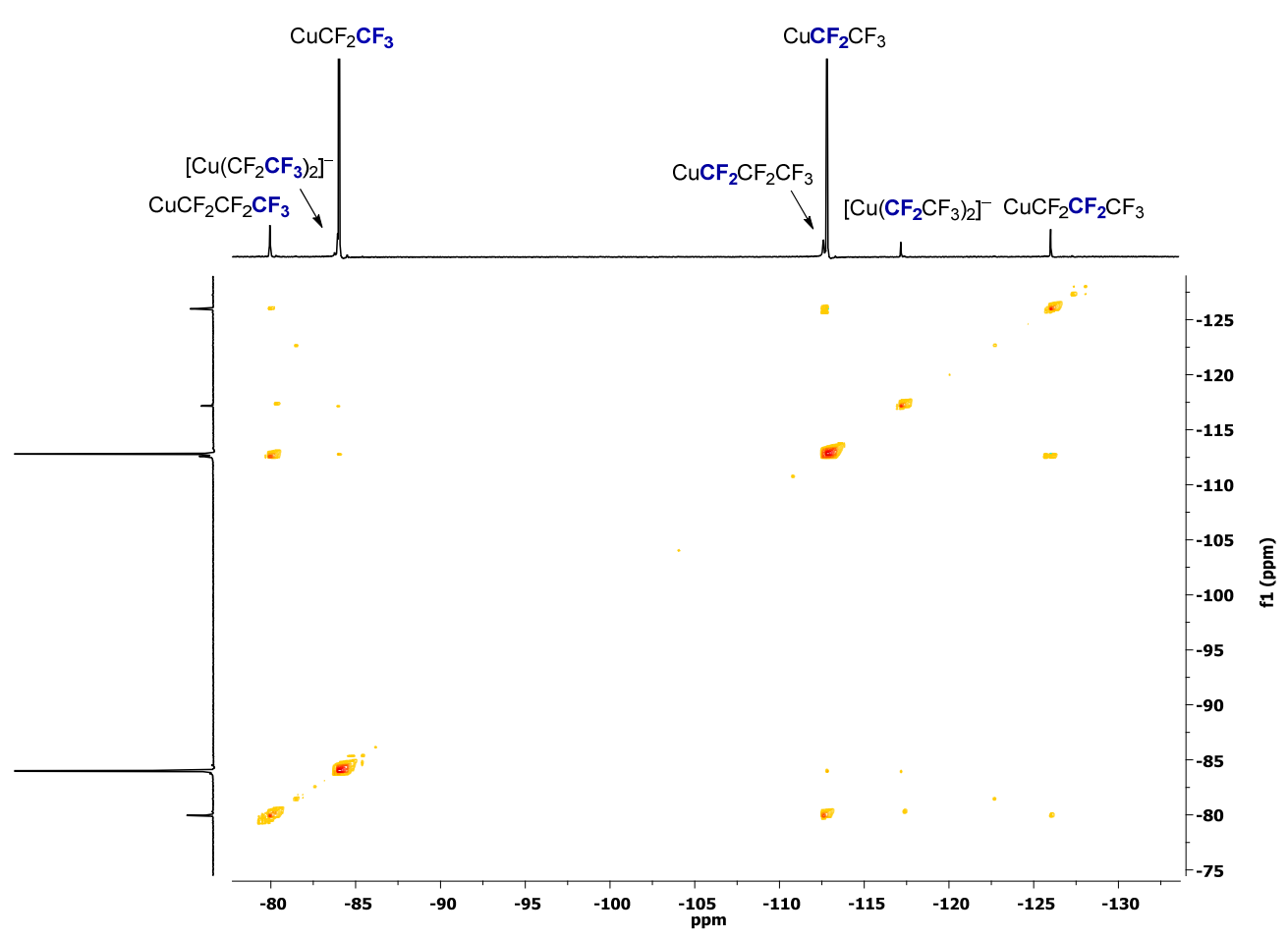

Figure S2. Full ${ }^{19} \mathrm{~F}$ COSY of $\mathrm{CuC}_{2} \mathrm{~F}_{5}$ from $\mathrm{TMSCF}_{3}$-derived $\mathrm{CuCF}_{3}$ 


\section{Stability of $\mathrm{TMSCF}_{3}$-derived $\mathrm{CuCF}_{3}$}

The stability of the $\mathrm{TMSCF}_{3}$-derived $\mathrm{CuCF}_{3}$ prepared as follows was monitored both at -30 ${ }^{\circ} \mathrm{C}$ and at room temperature. $\mathrm{KF}(175 \mathrm{mg}, 3 \mathrm{mmol})$ and $\mathrm{CuBr}(430 \mathrm{mg}, 3 \mathrm{mmol})$ were dried under vacuum overnight at $150{ }^{\circ} \mathrm{C}$ and $80{ }^{\circ} \mathrm{C}$, respectively. The solids and a magnetic stir bar were added into a two-neck round-bottom with PTFE stopcock and the system was evacuated under vacuum and refilled with argon three times. DMF $(1 \mathrm{~mL})$ and DMI $(1 \mathrm{~mL})$ were added under argon and the mixture vigorously stirred for $10 \mathrm{~min} . \mathrm{TMSCF}_{3}(443 \mu \mathrm{L}, 3 \mathrm{mmol})$ was slowly added via a syringe under argon at $0{ }^{\circ} \mathrm{C}$ and the reaction stirred at this temperature for $3 \mathrm{~h}$. When the reaction was complete, 1,3-bis(trifluoromethyl)benzene (BTB, $230 \mu \mathrm{L}, 1.5$ mmol) was added and after mixing well the components, the stirring was stopped and the reaction was left undisturbed until all solids settled on the bottom of the flask. An aliquot (0.7 $\mathrm{mL}$ ) of the supernatant was transferred under argon to a NMR tube for quantitative ${ }^{19} \mathrm{~F}$ NMR analysis.

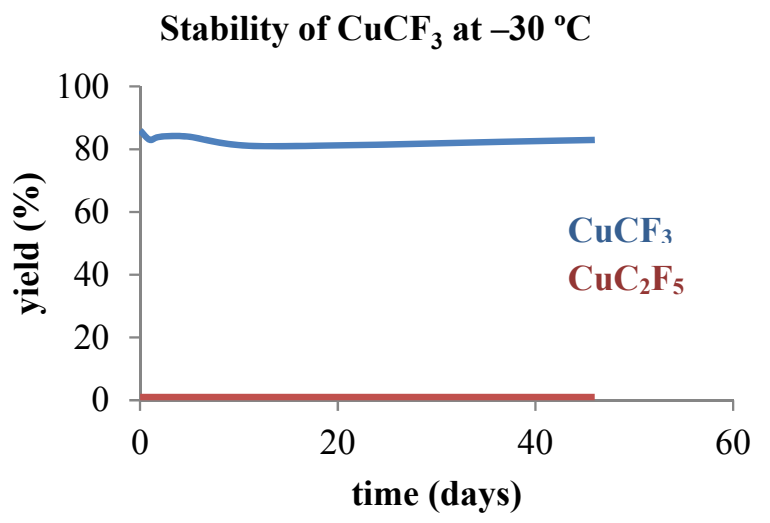

\begin{tabular}{ccc}
\hline $\begin{array}{c}\text { time } \\
\text { (days) }\end{array}$ & $\begin{array}{c}\text { yield } \\
\mathbf{C u C F}_{\mathbf{3}}(\mathbf{\%})\end{array}$ & $\begin{array}{c}\text { yield } \\
\mathbf{C u}_{\mathbf{C}} \mathbf{F}_{\mathbf{5}} \mathbf{( \% )}\end{array}$ \\
\hline 0 & 86 & 1 \\
1 & 83 & 1 \\
2 & 84 & 1 \\
5 & 84 & 1 \\
12 & 81 & 1 \\
46 & 83 & 1
\end{tabular}

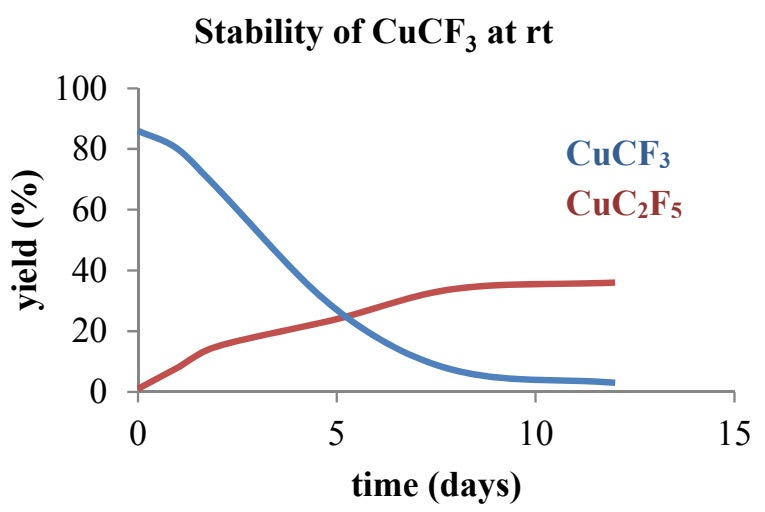

\begin{tabular}{ccc}
\hline $\begin{array}{c}\text { time } \\
\text { (days) }\end{array}$ & $\begin{array}{c}\text { yield } \\
\mathbf{C u C F}_{\mathbf{3}}(\mathbf{\%})\end{array}$ & $\begin{array}{c}\text { yield } \\
\mathbf{C u C}_{\mathbf{2}} \mathbf{F}_{\mathbf{5}} \mathbf{( \% )}\end{array}$ \\
\hline 0 & 86 & 1 \\
1 & 80 & 8 \\
2 & 67 & 15 \\
5 & 27 & 24 \\
8 & 7 & 34 \\
12 & 3 & 36
\end{tabular}

Figure S3. Stability studies of $\mathrm{TMSCF}_{3}$-derived $\mathrm{CuCF}_{3}$ 
Stability studies demonstrate that $\mathrm{CuCF}_{3}$ reagent solution can be stored in the freezer at -30 ${ }^{\circ} \mathrm{C}$ without significant decomposition for at least 1.5 months. In contrast, decomposition at room temperature occurred very fast and $c a$. $70 \%$ decomposition was reached after 5 days, which was almost complete after 12 days. The amount of $\mathrm{CuC}_{2} \mathrm{~F}_{5}$ increased moderately within this period and $\mathrm{CuC}_{2} \mathrm{~F}_{5}$ was produced in $40 \%$ yield (ca. 1/4 initial concentration of $\mathrm{CuCF}_{3}$ ). The yield of $\mathrm{CuC}_{2} \mathrm{~F}_{5}$ was calculated attending that two molecules of $\mathrm{CuCF}_{3}$ react to produce one molecule of $\mathrm{CuC}_{2} \mathrm{~F}_{5}$ (Scheme $\left.\mathrm{S} 1\right)$.

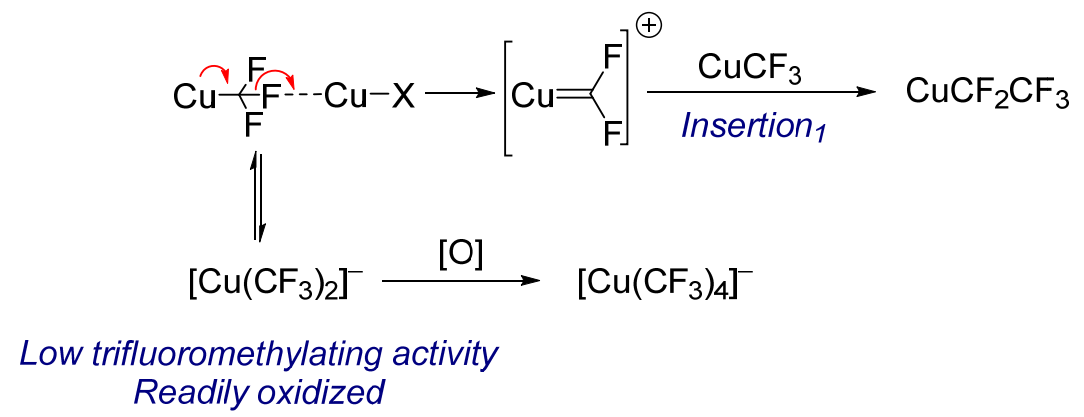

Scheme S1. Degradation of $\mathrm{CuCF}_{3}$ and plausible mechanism for the formation of $\mathrm{CuC}_{2} \mathrm{~F}_{5}{ }^{1-6}$

IMPORTANT NOTE: similarly, $\mathrm{TMSCF}_{3}$-derived $\mathrm{CuC}_{2} \mathrm{~F}_{5}$ proved sufficiently stable at room temperature to allow handling without special precautions during the set-up of reactions. Moreover, a reaction of $\mathbf{1 a}$ with an old batch of $\mathrm{CuC}_{2} \mathrm{~F}_{5}$ kept at $-30{ }^{\circ} \mathrm{C}$ for $>1$ year afforded expected product $\mathbf{2 a}$ in a very robust and reproducible way. No signs of degradation or the formation of side-reactions was detected using this batch.

\section{Composition of $\mathrm{TMSCF}_{3}$-derived $\mathrm{CuCF}_{3}$ and $\mathrm{CuC}_{2} \mathrm{~F}_{5}$ in solution}

The representation of the perfluoroalkyl species in solution is usually oversimplified denoting the entities involved just as "CuRf". As early as 1986, Burton already testified this

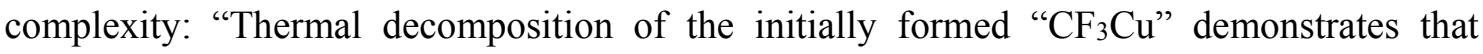
" $\mathrm{CF}_{3} \mathrm{Cu}$ " solutions are much more complex than previously appreciated". ${ }^{1}$ The species involved in the composition of $\mathrm{CuCF}_{3}$ and $\mathrm{CuC}_{2} \mathrm{~F}_{5}$ have been barely proposed, however, some authors postulated various organocopper units present in solution based on distinct signals presenting slightly different chemical shifts in ${ }^{19} \mathrm{~F}$ NMR. The $\delta$ (in ppm) reported for representative, proposed $\mathrm{CuR}_{f}$ species, including those of the present study are summarized in Table S1. 
Table S1. $\mathrm{CuR}_{f}$ species proposed under different preparation conditions

\begin{tabular}{|c|c|c|c|c|}
\hline Entry & $\mathrm{CuX}$ & {$\left[\mathrm{CuR}_{f}\right]^{a}$} & $\begin{array}{l}{ }^{19} \text { F NMR } \\
(\delta \text { in ppm })^{b}\end{array}$ & Reference \\
\hline 1 & $\mathrm{CuI}$ & {$\left[\mathrm{CuCF}_{3} \mathrm{I}\right]^{-}$} & NR & 7 \\
\hline 2 & $\mathrm{CuBr}$ & $\begin{array}{l}\mathrm{KBr} \cdot \mathrm{CuCF}_{3} \\
{\left[\mathrm{Cu}\left(\mathrm{CF}_{3}\right)_{2}\right]^{-}}\end{array}$ & $\begin{array}{l}-28.8 \\
-32.3\end{array}$ & 1,8 \\
\hline 3 & $\mathrm{CuTc}$ & $\begin{array}{l}{\left[\mathrm{Cu}\left(\mathrm{CF}_{3}\right)_{2}\right]^{-}} \\
\mathrm{L}_{\mathrm{n}} \mathrm{Cu}\left(\mathrm{CF}_{3}\right)\end{array}$ & $\begin{array}{l}-31.9 \\
-27.3 \\
\end{array}$ & 9 \\
\hline 4 & $\mathrm{CuI}$ & $\begin{array}{l}{\left[\mathrm{Cu}\left(\mathrm{CF}_{3}\right) \mathrm{I}\right]^{-}} \\
{\left[\mathrm{Cu}\left(\mathrm{CF}_{3}\right)_{2}\right]^{-}} \\
\mathrm{L}_{\mathrm{n}} \mathrm{CuCF}_{3}\end{array}$ & $\begin{array}{l}-28.7 \\
-31.9 \\
-26.9\end{array}$ & 10,11 \\
\hline 5 & $\mathrm{CuI}$ & $\begin{array}{l}{\left[\mathrm{Cu}\left(\mathrm{CF}_{3}\right) \mathrm{I}\right]^{-}} \\
{\left[\mathrm{Cu}\left(\mathrm{CF}_{3}\right)_{2}\right]^{-}}\end{array}$ & $\begin{array}{l}-29.1 \\
-31.9\end{array}$ & 9 \\
\hline 6 & $\mathrm{CuI}$ & $\begin{array}{l}{\left[\mathrm{Cu}\left(\mathrm{CF}_{3}\right) \mathrm{I}\right]^{-}} \\
{\left[\mathrm{Cu}\left(\mathrm{CF}_{3}\right)_{2}\right]^{-}}\end{array}$ & $\begin{array}{l}-28.7 \\
-31.4 \\
\end{array}$ & This work \\
\hline $7^{c}$ & $\mathrm{CuBr}$ & $\begin{array}{l}\mathrm{CuCF}_{3} \\
{\left[\mathrm{Cu}\left(\mathrm{CF}_{3}\right)_{2}\right]^{-}}\end{array}$ & $\begin{array}{l}-27.2 \\
-30.8\end{array}$ & This work \\
\hline $8^{c}$ & $\mathrm{CuCl}$ & $\begin{array}{l}\mathrm{CuCF}_{3} \\
{\left[\mathrm{Cu}\left(\mathrm{CF}_{3}\right)_{2}\right]^{-}}\end{array}$ & $\begin{array}{l}-27.3 \\
-30.8\end{array}$ & This work \\
\hline $9^{c}$ & {$[\mathrm{~K}(\mathrm{DMF})]\left[(\mathrm{tBuO})_{2} \mathrm{Cu}\right]$} & $\mathrm{L}_{\mathrm{n}} \mathrm{CuC}_{2} \mathrm{~F}_{5}$ & -111.8 & 12 \\
\hline 10 & {$[\mathrm{~K}(\mathrm{DMF})]\left[(\mathrm{tBuO})_{2} \mathrm{Cu}\right]$} & $\mathrm{CuC}_{2} \mathrm{~F}_{5}$ & -111.7 & 11 \\
\hline 11 & $\mathrm{CuI}$ & $\begin{array}{l}{\left[\mathrm{Cu}\left(\mathrm{C}_{2} \mathrm{~F}_{5}\right) \mathrm{I}\right]^{-}} \\
{\left[\mathrm{Cu}\left(\mathrm{C}_{2} \mathrm{~F}_{5}\right)_{2}\right]^{-}}\end{array}$ & $\begin{array}{l}-114.15 \\
-118.10 \\
\end{array}$ & 9,11 \\
\hline $12^{c}$ & $\mathrm{CuBr}$ & $\begin{array}{l}\mathrm{CuC}_{2} \mathrm{~F}_{5} \\
{\left[\mathrm{Cu}\left(\mathrm{C}_{2} \mathrm{~F}_{5}\right)_{2}\right]^{-}}\end{array}$ & $\begin{array}{l}-112.8 \\
-117.2\end{array}$ & This work \\
\hline
\end{tabular}

Data from Table S1 above indicates that the nature of different species formed in solution depends on the $\mathrm{CuX}$ salt employed as the copper source. Thus, when $\mathrm{CuI}$ is used, $\left[\mathrm{Cu}\left(\mathrm{CF}_{3}\right) \mathrm{I}\right]^{-}$ (ca. $-29 \mathrm{ppm})$ is preferentially observed owing to the high affinity of I towards $\mathrm{Cu}^{\mathrm{I}}$ (Table $\mathrm{S} 1$, entries 1, 4-6). On the other hand, neutral $\mathrm{CuCF}_{3}$ (Ia) (ca. -27 ppm) is preferentially produced from other $\mathrm{CuX}$ salts (Table $\mathrm{S} 1$, entries 3, 7, and 8). However slightly different is the chemical shift for $\mathrm{CuCF}_{3}$ (Table S1, entry 2), probably as the consequence of formation of a $\mathrm{KBr}$ adduct. A similar trend is observed with $\mathrm{CuC}_{2} \mathrm{~F}_{5}$ (Table S1, entries 9-12) with $\left[\mathrm{Cu}\left(\mathrm{C}_{2} \mathrm{~F}_{5}\right) \mathrm{X}\right]^{-}$displaying the $\mathrm{CF}_{2}$ around $2 \mathrm{ppm}$ high field in ${ }^{19} \mathrm{~F}$ NMR when $\mathrm{X}=\mathrm{I}$ compared to neutral $\mathrm{CuC}_{2} \mathrm{~F}_{5}$. Thus, we propose that equilibrium between the organocopper and cuprate species in the present system might resemble to that depicted in Scheme S2b. 


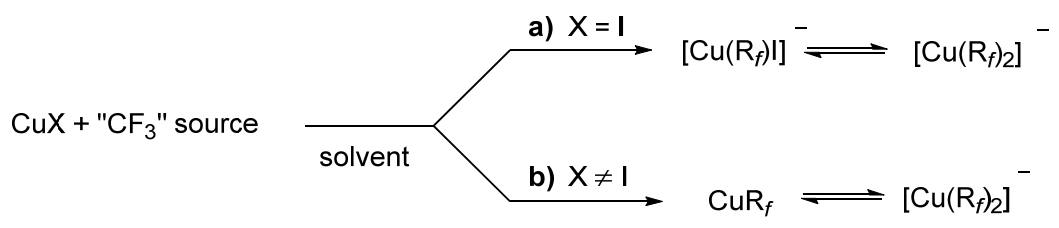

Scheme S2. Equilibration of $\mathrm{CuR}_{f}$ species depending on the halide

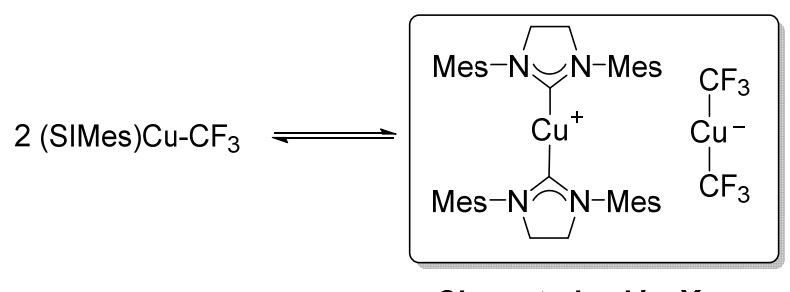

Characterized by X-ray

Scheme S3. Proposed equilibrium of $\mathrm{CuCF}_{3}$ species by Vicic and coworkers ${ }^{13}$

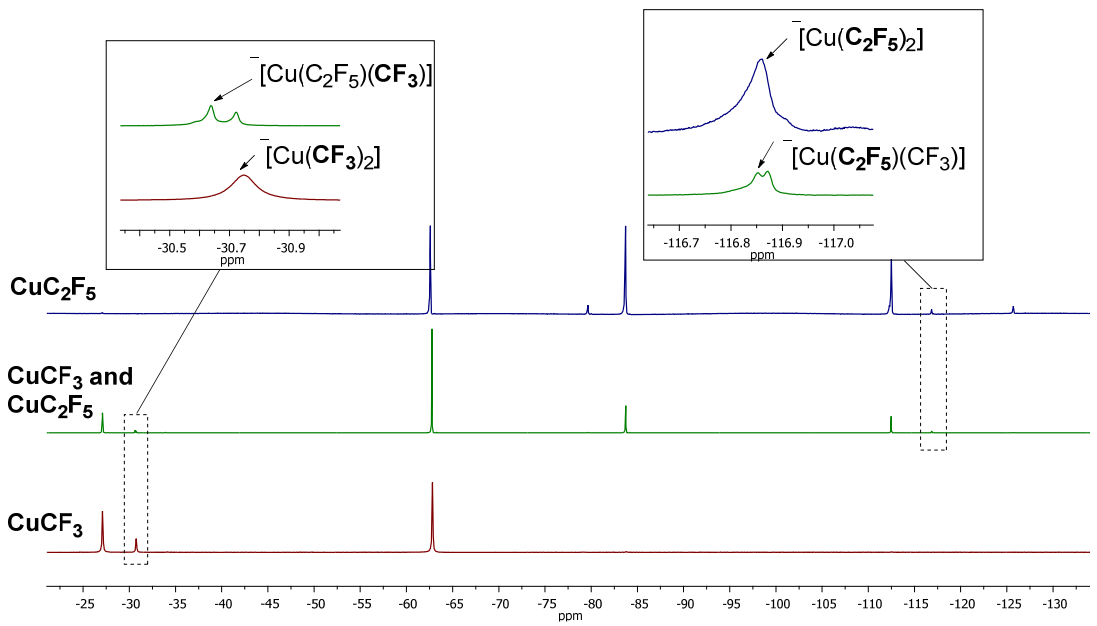

Figure S4. Signals of mixed species III shown in the ${ }^{19}$ F NMR spectra

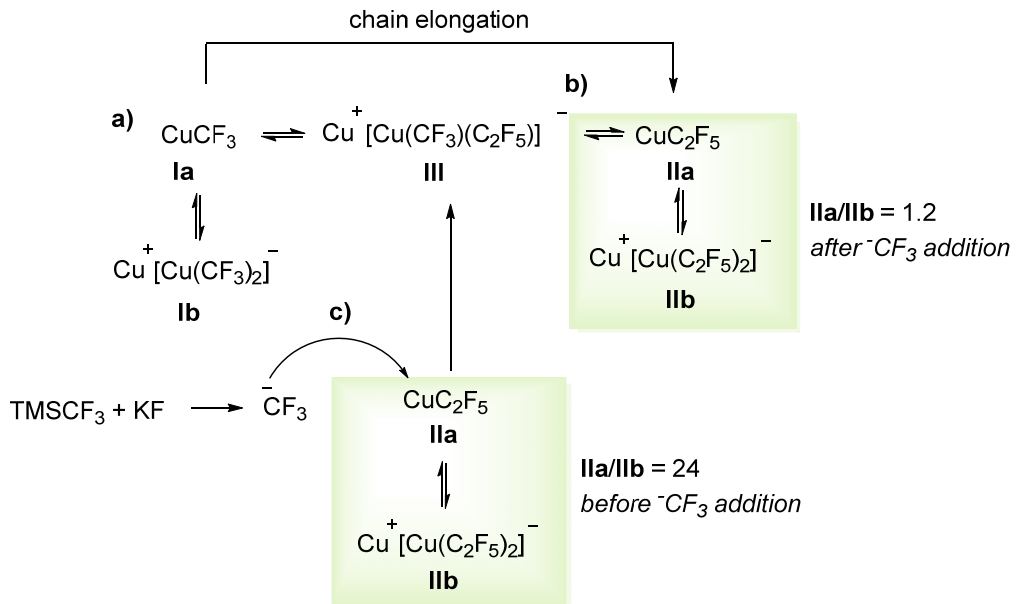

Scheme S4. Equilibrium between perfluoroalkyl organocopper and organocuprates 


\section{4. ${ }^{19}$ F DOSY NMR experiments}

$600 \mu \mathrm{L}$ of $0.4 \mathrm{M} \mathrm{CuC}_{2} \mathrm{~F}_{5}$ in non-deuterated DMF was transferred to a $5 \mathrm{~mm}$ NMR tube. ${ }^{19} \mathrm{~F}$ NMR spectra were acquired, comprising a standard 1D spectrum. Additionally for ${ }^{19} \mathrm{~F}$ NMR diffusion measurement a diffusion-edited ledbpgppr2s pulse program including bipolar gradient pulses and a longitudinal eddy current delay (LED) was used.

${ }^{19} \mathrm{~F} 1 \mathrm{D}$ standard spectra: one dimensional ${ }^{19} \mathrm{~F}$ pulse experiments were carried out using non proton decouple sequence (RD-90 ACQ). Recycling delay was set to 4s and AQ time to 0.58 s. The spectral width was $240 \mathrm{ppm}$, and a total of 32-64 transients were collected into $64 \mathrm{k}$ data points for each ${ }^{19} \mathrm{~F}$ spectrum.

Diffusion-edited ${ }^{19} \mathrm{~F}$ spectra: ${ }^{19} \mathrm{~F}$ diffusion spectra were measured using a diffusion-edited pulse sequence with bipolar gradients and the longitudinal eddy-current delay (LED) scheme

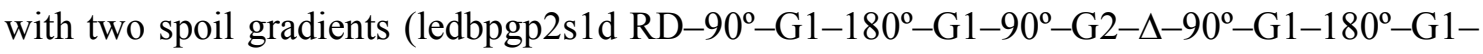
$90^{\circ}-\mathrm{G} 2-\tau-90^{\circ}$-acquire FID), using 64 scans, 8 dummy scans, spectrum width $240 \mathrm{ppm}, 64 \mathrm{k}$ time and frequency domain data points, line broadening $1 \mathrm{~Hz}, \mathrm{RD} 4 \mathrm{~s}$, maximum gradient strength (G1) of 54.0 Gauss per cm, and eddy current delay $(\tau) 50 \mathrm{~ms}$. A diffusion time $(\Delta)$ of 60-80 ms and bipolar sine shaped gradient pulses of length $2.4-3 \mathrm{~ms}(\delta)$ were applied to obtain 16-64 transients for the calculation of the diffusion coefficient $(D)$ and DOSY 2D spectrum. All the acquired NMR spectra were phased, baseline-corrected, referenced and processed to get 2D spectrum using Topspin v3.2 $\left(\right.$ Bruker $\left.^{\circledR}\right)$ software.

\section{Determination of diffusion constants $(D)$ :}

$\mathrm{CF}_{3} \mathrm{CH}_{2} \mathrm{OH}$

S1<smiles>FC(F)(F)c1cc(P(c2cc(C(F)(F)F)cc(C(F)(F)F)c2)c2cc(C(F)(F)F)cc(C(F)(F)F)c2)cc(C(F)(F)F)c1</smiles>

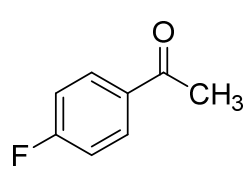

S2

$\mathrm{L}_{\mathrm{n}} \mathrm{CuC}_{2} \mathrm{~F}_{5}$

S5

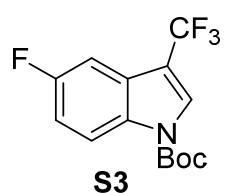

S3

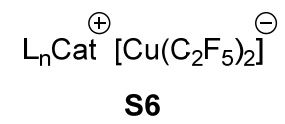

Figure S5. Compounds used for measuring the diffusion constant $(D)$ by ${ }^{19} \mathrm{~F}$ NMR 
Trifluoroethanol (S1)

$\begin{array}{lllllllll}\text { G/cm } & 2.30 & 8.23 & 14.15 & 20.08 & 26.00 & 31.9 & 37.85 & 43.78 \\ \text { Intensity (I, } & 100 & 83.30 & 56.69 & 31.49 & 14.53 & 5.46 & 1.47 & 0.40 \\ \text { normalized) } & 4.61 & 4.42 & 4.04 & 3.45 & 2.68 & 1.70 & 0.39 & -0.91 \\ \text { In(I) } & & & & & & & \end{array}$
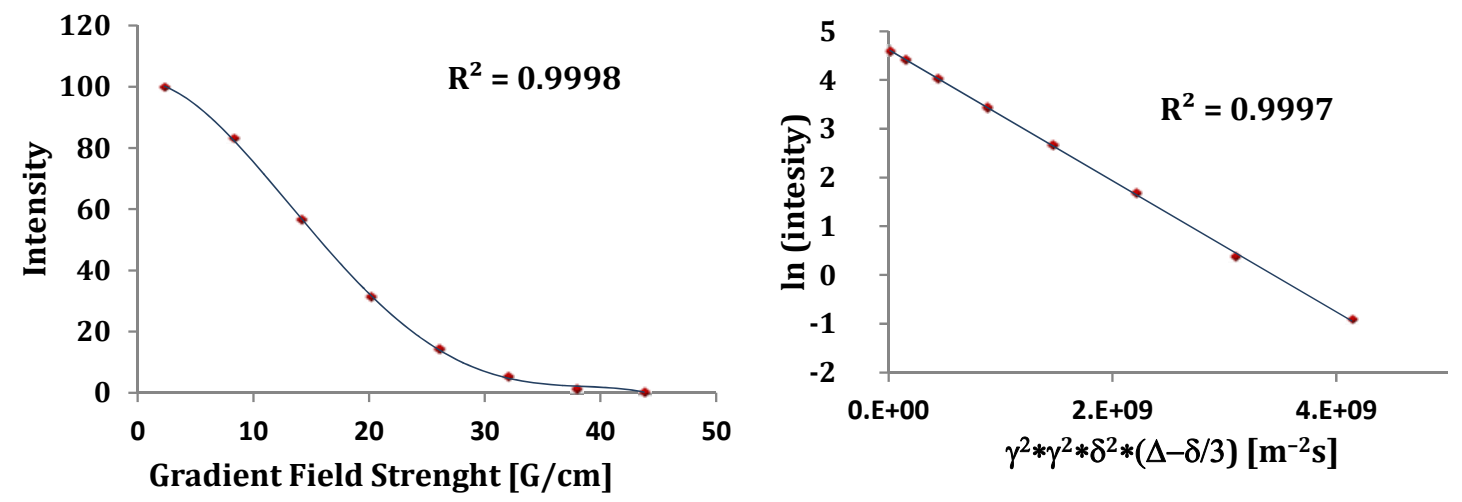

\section{4'-Fluoroacetophenone (S2)}

$\begin{array}{lllllllll}\text { G/cm } & 2.30 & 8.23 & 14.15 & 20.08 & 26.00 & 31.9 & 37.85 & 43.78 \\ \text { Intensity (I, } & 100 & 84.05 & 58.38 & 33.57 & 15.91 & 6.175 & 1.97 & 0.54 \\ \text { normalized) } & 4.61 & 4.43 & 4.07 & 3.51 & 2.77 & 1.82 & 0.68 & -0.63 \\ \text { In(I) } & & & & & & & \end{array}$
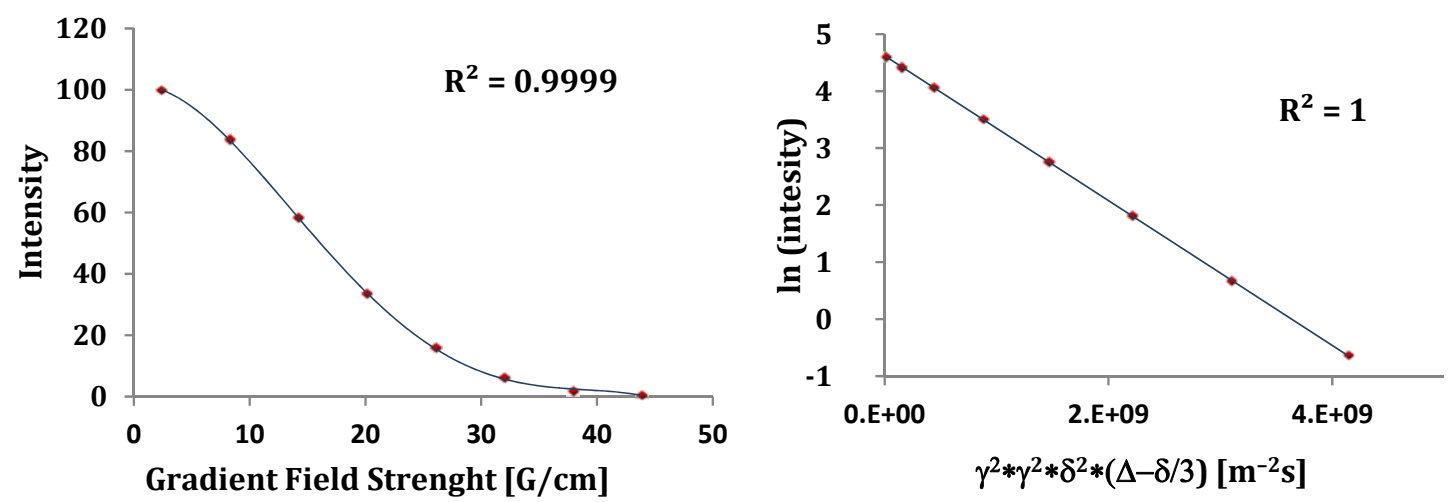

tert-Butyl-5-fluoro-3-(trifluoromethyl)-1H-indole-1-carboxylate (S3)

G/cm

Intensity (I, normalized) $\ln (\mathrm{I})$

$\begin{array}{llllllll}2.30 & 8.23 & 14.15 & 20.08 & 26.00 & 31.9 & 37.85 & 43.78 \\ 100 & 88.45 & 69.86 & 45.59 & 26.54 & 12.35 & 3.55 & 1.95 \\ 4.61 & 4.48 & 4.25 & 3.82 & 3.28 & 2.51 & 1.27 & 0.67\end{array}$



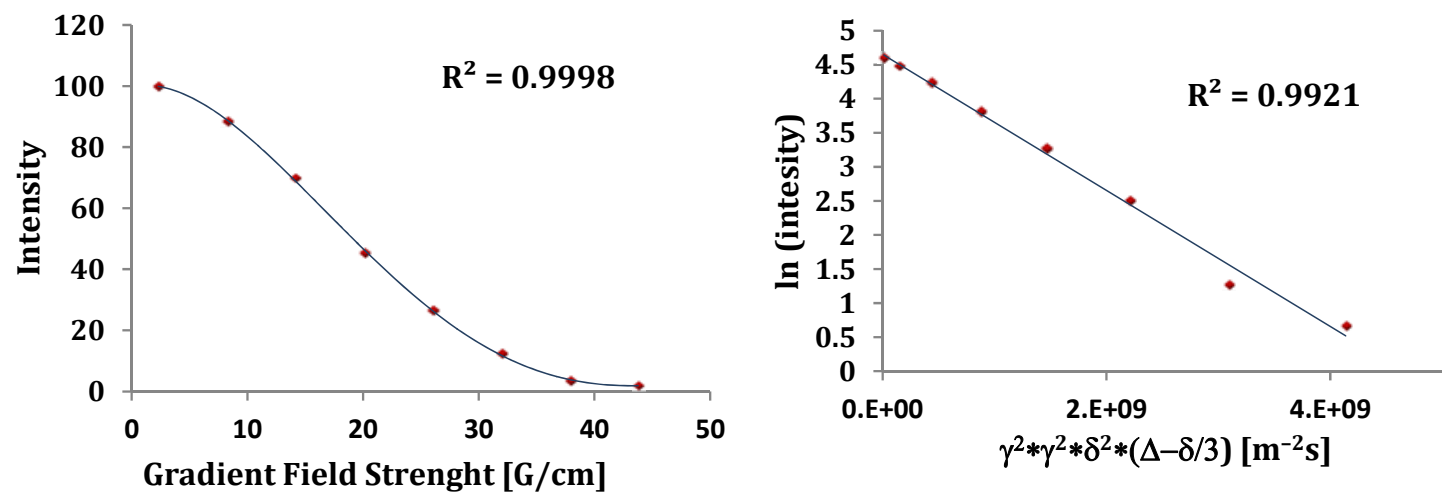

Tris[3,5-bis(trifluoromethyl)phenyl]phosphine (S4)

$\begin{array}{lllllllll}\text { G/cm } & 2.30 & 8.23 & 14.15 & 20.08 & 26.00 & 31.9 & 37.85 & 43.78 \\ \text { Intensity (I, } & 100 & 90.27 & 74.34 & 58.20 & 39.67 & 24.42 & 12.52 & 5.63 \\ \text { normalized) } & 4.61 & 4.50 & 4.31 & 4.06 & 3.68 & 3.20 & 2.53 & 1.73 \\ \text { In(I) } & & & & & & & & \end{array}$
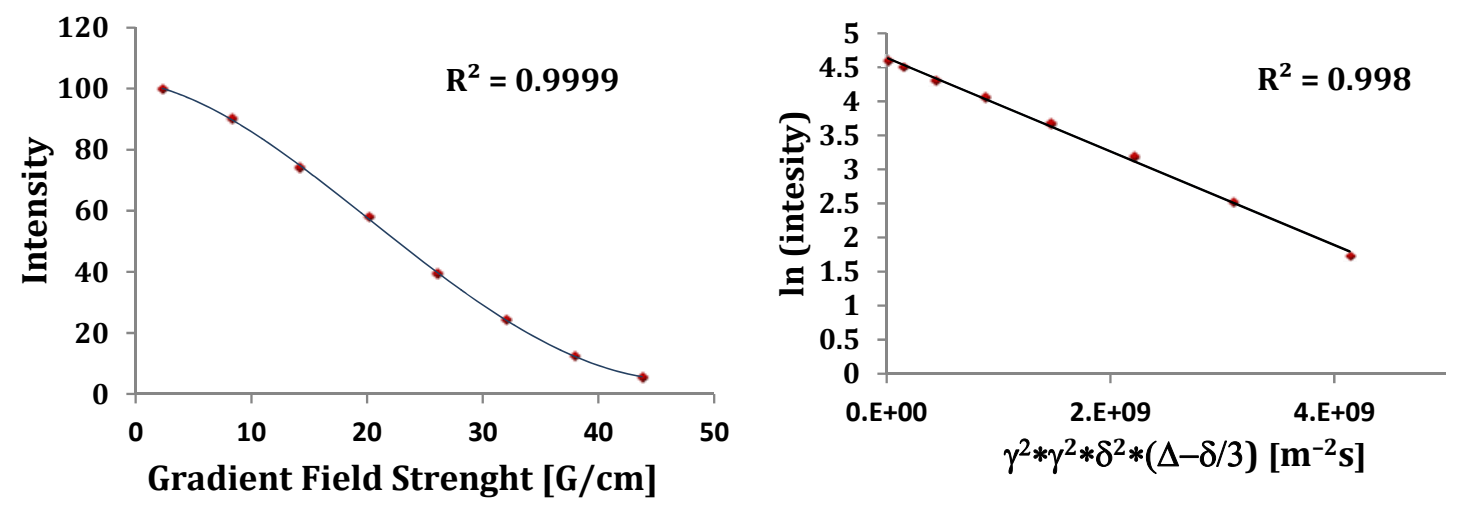

\section{$\mathrm{CuC}_{2} \mathrm{~F}_{5}$ (S5)}

G/cm

Intensity (I, normalized)

$\ln (\mathrm{I})$

$\begin{array}{llllllll}2.30 & 8.23 & 14.15 & 20.08 & 26.00 & 31.9 & 37.85 & 43.78 \\ 100 & 88.60 & 70.89 & 50.19 & 30.57 & 17.11 & 8.10 & 3.77 \\ 4.61 & 4.49 & 4.26 & 3.91 & 3.42 & 2.84 & 2.09 & 1.33\end{array}$



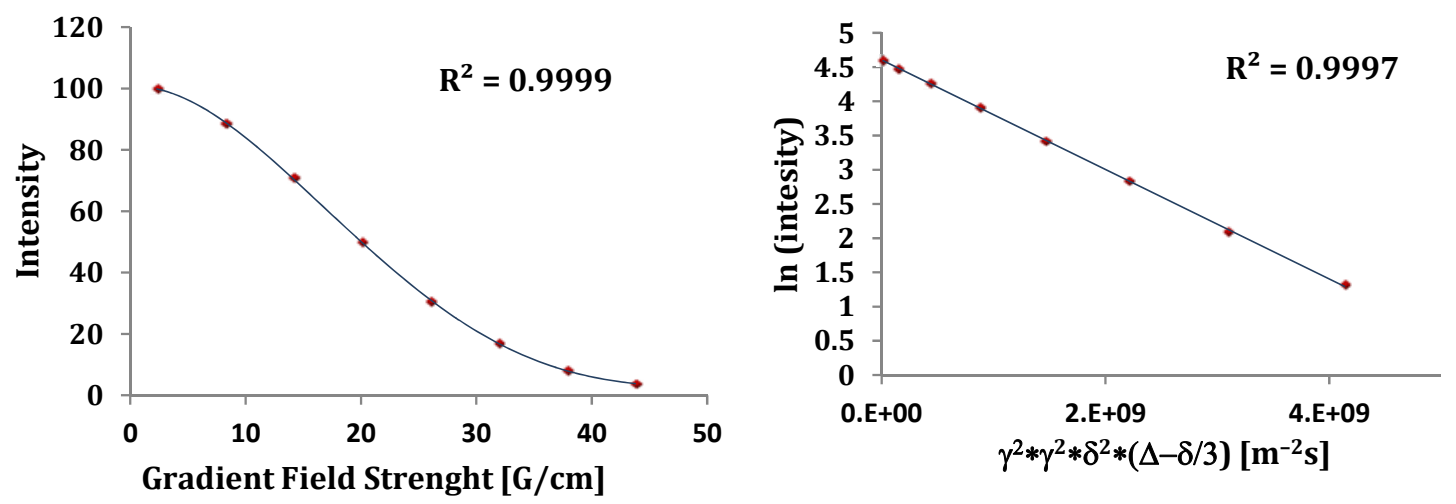

Anionic $\left[\mathrm{Cu}\left(\mathrm{C}_{2} \mathrm{~F}_{5}\right)_{2}\right]^{-}(\mathrm{S} 6)$

$\begin{array}{lllllllll}\text { G/cm } & 2.30 & 8.23 & 14.15 & 20.08 & 26.00 & 31.9 & 37.85 & 43.78 \\ \text { Intensity (I, } & 100 & 83.88 & 70.10 & 48.33 & 33.48 & 18.55 & 7.55 & 3.97 \\ \text { normalized) } & 4.61 & 4.43 & 4.25 & 3.89 & 3.51 & 2.92 & 2.02 & 1.38 \\ \text { In(I) } & & & & & & & \end{array}$
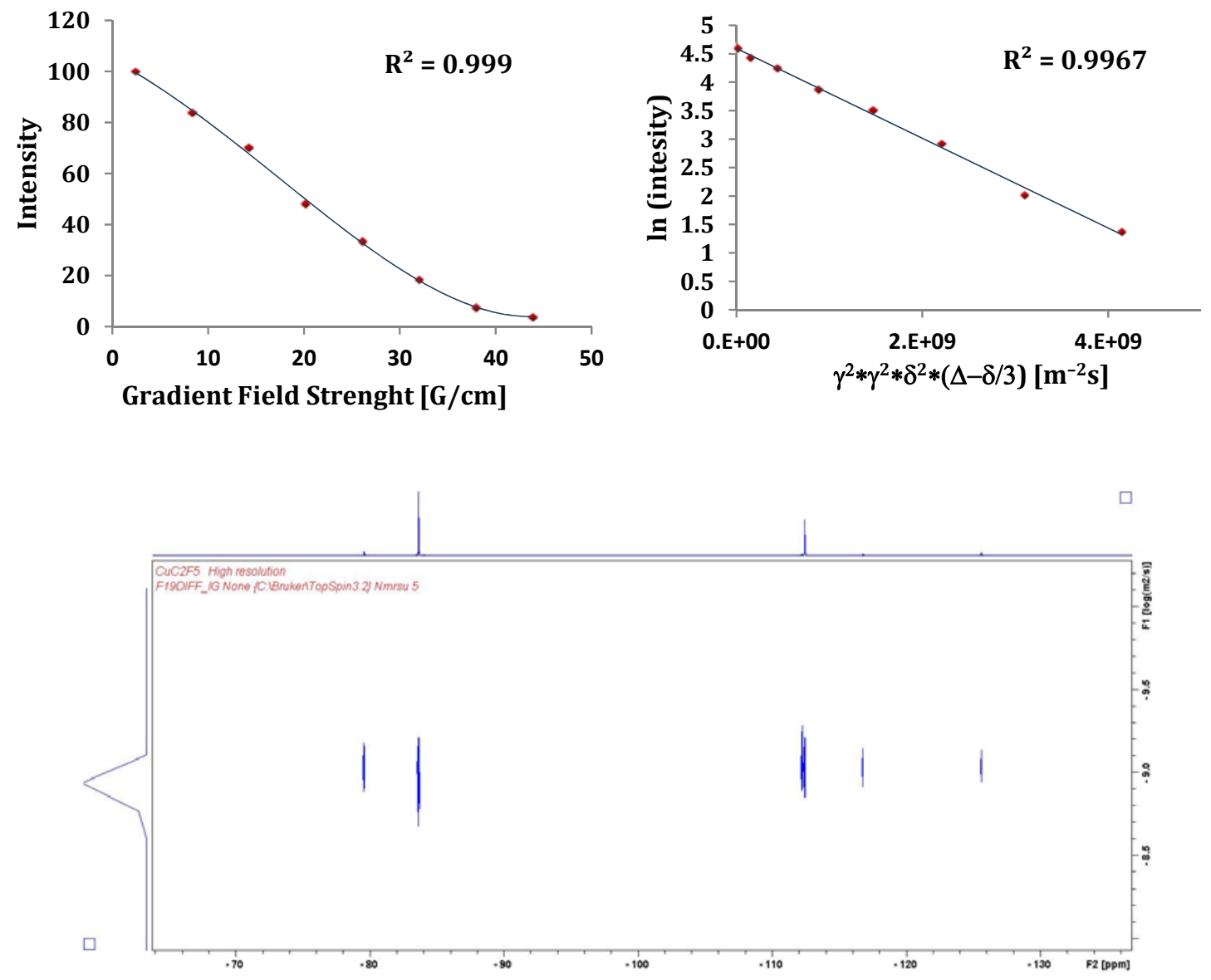

Figure S6. ${ }^{19} \mathrm{~F}$ DOSY $2 \mathrm{D}$ spectrum of $\mathrm{CuC}_{2} \mathrm{~F}_{5}$ from $\mathrm{TMSCF}_{3}$-derived $\mathrm{CuCF}_{3}$ 
Table S2. Molecular weight estimation

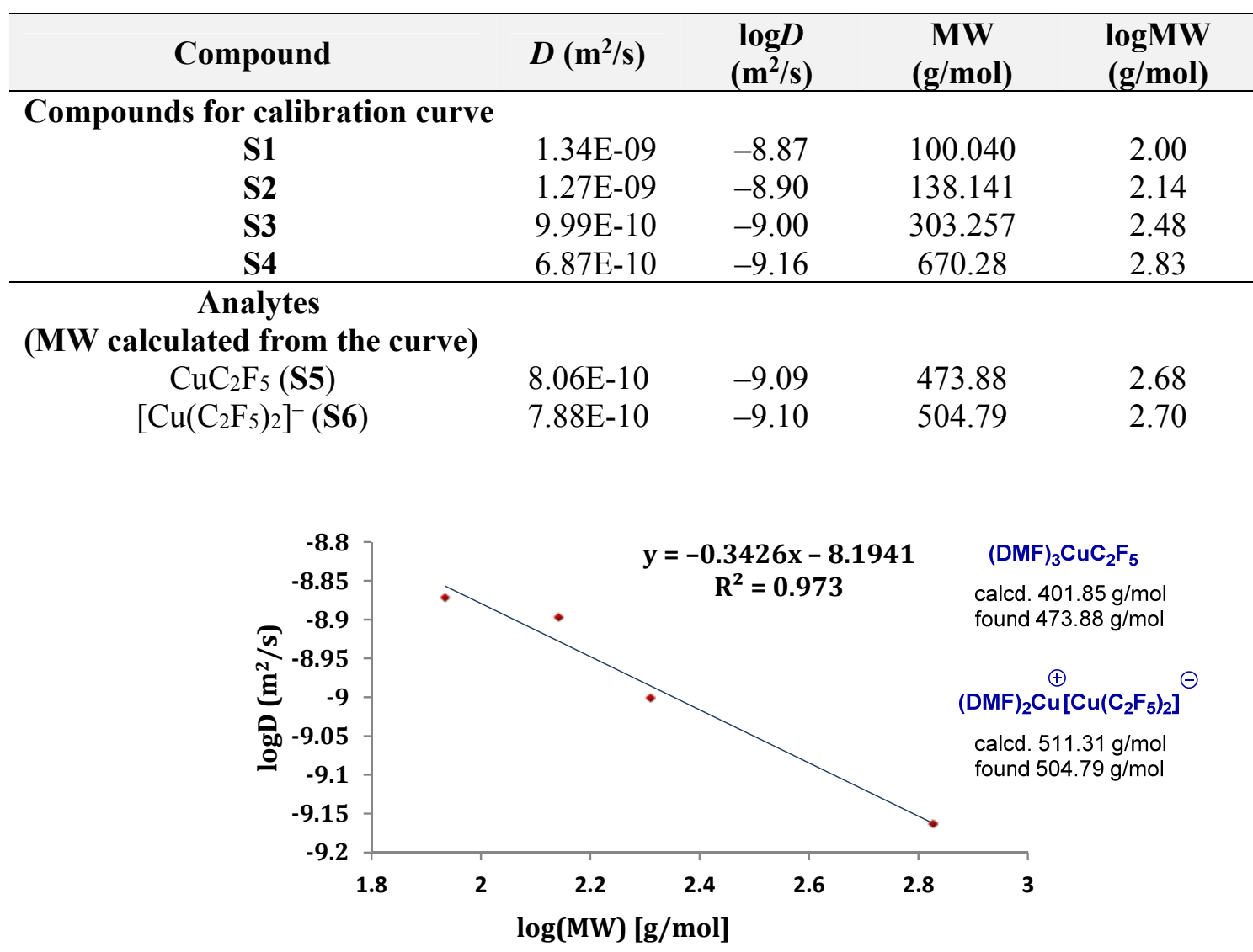

Figure S7. $\log D$ versus $\log \mathrm{MW}$

\section{ESI-MS experiments}

ESI-MS spectra were acquired both in positive and negative ionization by a flow injection analysis at a flow rate of $0.3 \mathrm{~mL} \mathrm{~min}^{-1}$ with $95: 5$ acetonitrile/water and $0.05 \%$ acetic acid. The mass spectra was acquired between $100-1200 \mathrm{~m} / \mathrm{z}$ at a rate of 2 spectra $\mathrm{s}^{-1}$. The MS parameters were set as indicated in Table S3.

Table S3. MS parameters

\begin{tabular}{|l|l|l|}
\hline Parameter & ESI $(+)$ & ESI(-) \\
\hline Gas Temp $\left({ }^{\circ} \mathrm{C}\right)$ & 200 & 200 \\
\hline Gas Flow $(\mathrm{L} / \mathrm{min})$ & 14 & 14 \\
\hline Nebulizer $(\mathrm{psig})$ & 35 & 35 \\
\hline SheathGasTemp $\left({ }^{\circ} \mathrm{C}\right)$ & 350 & 350 \\
\hline SheathGasFlow $(\mathrm{L} / \mathrm{min})$ & 11 & 11 \\
\hline Vcap $(\mathrm{V})$ & 3500 & 3500 \\
\hline Nozzle Voltage $(\mathrm{V})$ & 1000 & 1000 \\
\hline
\end{tabular}




\begin{tabular}{|l|l|l|} 
Fragmentor (V) & 380 & 380 \\
\hline Skimmer1 (V) & 65 & 65 \\
\hline OctopoleRFPeak & 750 & 750 \\
\hline
\end{tabular}

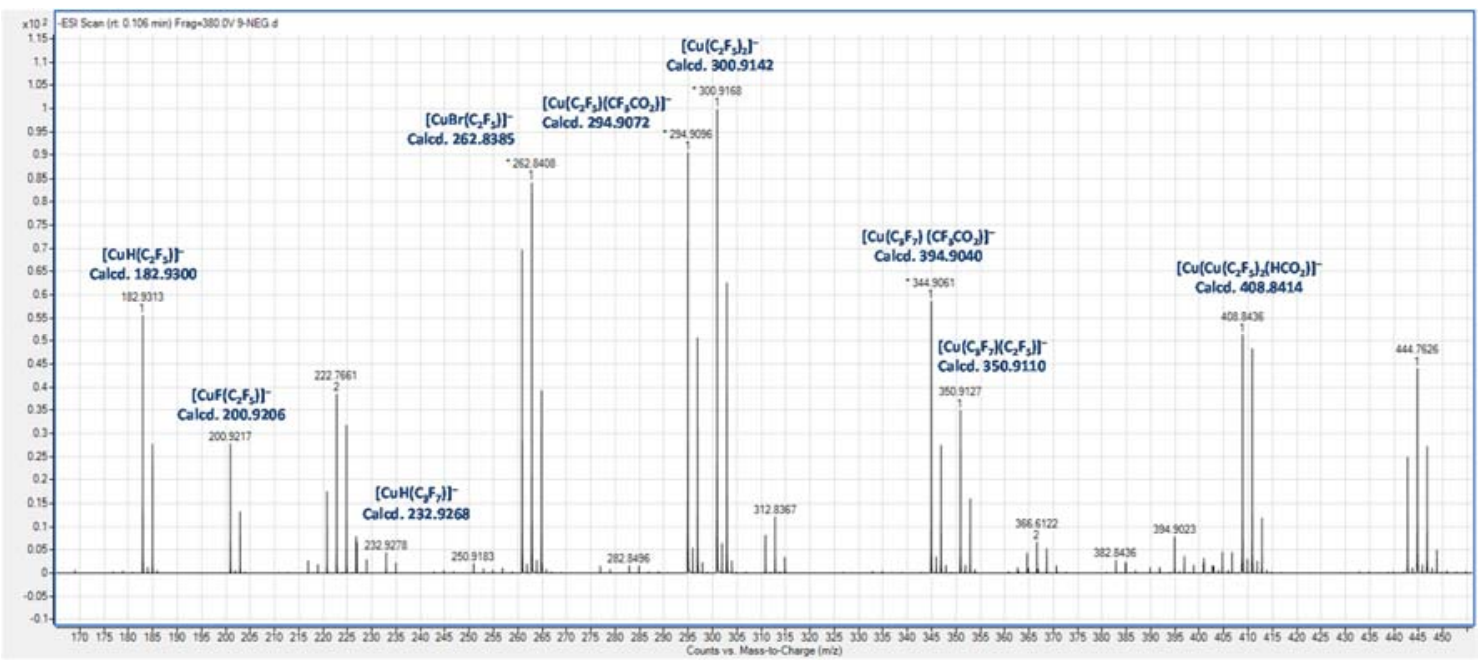

Figure S8. ESI-MS of $\mathrm{CuC}_{2} \mathrm{~F}_{5}$ in negative ion mode ESI(-). No ionizable $\mathrm{Cu}$-species were discernible in positive ion mode $\operatorname{ESI}(+)$

\section{Optimization of pentafluoroethylation of iodinated heterocycles}

Using "ligandless" $\mathbf{T M S C F}_{3}$-derived $\mathbf{C u C}_{2} \mathbf{F}_{5}$ : a Schlenk flask charged with 3,4,6-tri-Obenzyl-2-iodo-D-glucal 1a $(54 \mathrm{mg}, 0.1 \mathrm{mmol})$ was purged and backfilled with argon three times. $\mathrm{CuC}_{2} \mathrm{~F}_{5}(0.4 \mathrm{M}$ in DMF, $0.47 \mathrm{~mL}, 0.2 \mathrm{mmol})$ and 1,3-bis(trifluoromethyl)benzene (BTB, $7.8 \mu \mathrm{L}, 0.05 \mathrm{mmol}$ ) were sequentially added under argon and the Schlenk flask was capped with a rubber septum. The reaction mixture was heated in a silicon oil bath at the indicated temperature and monitored by ${ }^{19} \mathrm{~F}$ NMR for quantitative analysis.

\section{Addition of ligands into $\mathrm{TMSCF}_{3}$-derived $\mathrm{CuC}_{2} \mathrm{~F}_{5}$}

Solid ligands: a Schlenk flask charged with 3,4,6-tri-O-benzyl-2-iodo-D-glucal 1a (14.5 mg, $0.026 \mathrm{mmol})$ and the corresponding ligand $(0.04 \mathrm{mmol})$ was purged and backfilled with argon three times. DMF $(0.6 \mathrm{~mL}), \mathrm{CuC}_{2} \mathrm{~F}_{5}(0.4 \mathrm{M}$ in $\mathrm{DMF}, 0.1 \mathrm{~mL}, 0.04 \mathrm{mmol})$ and 1,3bis(trifluoromethyl)benzene (BTB, $4 \mu \mathrm{L}, 0.026 \mathrm{mmol}$ ) were sequentially added under argon and the Schlenk flask was capped with a rubber septum. The reaction mixture was heated in a silicon oil bath at the indicated temperature and monitored by ${ }^{19} \mathrm{~F}$ NMR for quantitative analysis.

Pyridine: a Schlenk flask charged with 3,4,6-tri-O-benzyl-2-iodo-D-glucal 1a (14.5 mg, 0.26 mmol) was purged and backfilled with argon three times. DMF $(0.5 \mathrm{~mL})$, pyridine $(0.1 \mathrm{~mL})$, 
$\mathrm{CuC}_{2} \mathrm{~F}_{5}(0.4 \mathrm{M}$ in DMF, $0.1 \mathrm{~mL}, 0.04 \mathrm{mmol})$ and 1,3-bis(trifluoromethyl)benzene (BTB, 4 $\mu \mathrm{L}, 0.026 \mathrm{mmol}$ ) were sequentially added under argon and the Schlenk flask was capped with a rubber septum. The reaction mixture was heated in a silicon oil bath at the indicated temperature and monitored by ${ }^{19} \mathrm{~F}$ NMR for quantitative analysis.

Using "ligandless" $\mathbf{C}_{2} \mathbf{F}_{5} \mathbf{H}$-derived $\mathbf{C u C}_{2} \mathbf{F}_{5}$ : a Schlenk flask charged with 3,4,6-tri-Obenzyl-2-iodo-D-glucal 1a ( $82 \mathrm{mg}, 0.15 \mathrm{mmol})$ was purged and backfilled with argon three times. $\mathrm{CuC}_{2} \mathrm{~F}_{5}(0.7 \mathrm{M}$ in DMF, $0.4 \mathrm{~mL}, 0.3 \mathrm{mmol})$ and 1,3-bis(trifluoromethyl)benzene (BTB, $11.6 \mu \mathrm{L}, 0.075 \mathrm{mmol}$ ) were sequentially added under argon and the Schlenk flask was capped with a rubber septum. The reaction mixture was heated in a silicon oil bath at the indicated temperature and monitored by ${ }^{19} \mathrm{~F}$ NMR for quantitative analysis. The pentafluoroethanederived reagent $\mathrm{CuC}_{2} \mathrm{~F}_{5}$ stabilized with $\mathrm{Et}_{3} \mathrm{~N} \cdot 3 \mathrm{HF}$ (TREAT-HF) was prepared following a reported procedure. ${ }^{12}$ At the moment of use, the concentration of the stabilized reagent (referred to as $\mathrm{CuC}_{2} \mathrm{~F}_{5}$ ) was $0.7 \mathrm{M}$ in DMF.

$\mathrm{CuC}_{2} \mathrm{~F}_{5}$ reagents with "extra" TREAT-HF were prepared as follows: to two flame-dried Schlenk flasks charged with $1 \mathrm{~mL}$ of the $\mathrm{CuC}_{2} \mathrm{~F}_{5}$ solution different volumes of TREAT-HF (purity 99\%) were added. TREAT-HF (13 $\mu \mathrm{L}, 0.08 \mathrm{mmol}$ ) was added to obtain $\mathrm{CuC}_{2} \mathrm{~F}_{5}-$ $0.3 \mathrm{HF}$ and TREAT-HF (26 $\mu \mathrm{L}, 0.16 \mathrm{mmol})$ to obtain $\mathrm{CuC}_{2} \mathrm{~F}_{5}-0.6 \mathrm{HF}$. The resultant solutions were stirred at room temperature for $5 \mathrm{~min}$ and left unperturbed for $1 \mathrm{~h}$ (precipitation of KF). The supernatants were used immediately.

\section{In situ reaction monitoring of the pentafluoroethylation of $1 \mathrm{~d}$}

To illustrate the robustness of our $\mathrm{TMSCF}_{3}$-derived "ligadless" complex, pentafluoroethylation of $\mathbf{1 d}$ was performed in deuterated DMF and the progress monitored by ${ }^{1} \mathrm{H}$ NMR. We also noticed that reaction took place faster than using conventional DMF and 2a was produced quantitatively after only $24 \mathrm{~h}$ at $50{ }^{\circ} \mathrm{C}$ (Figure S9). As it can be observed directly from the reaction crude (no extractions/filtrations) only the desired product is detected by ${ }^{1} \mathrm{H}$ NMR apart from TMSF, water, and residual DMF.

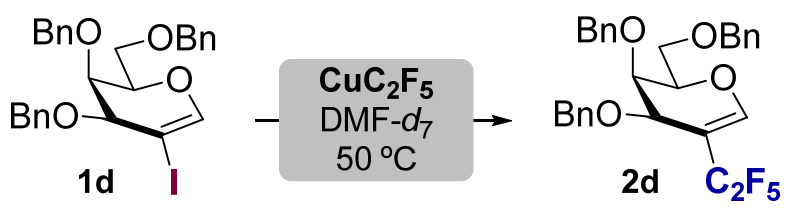




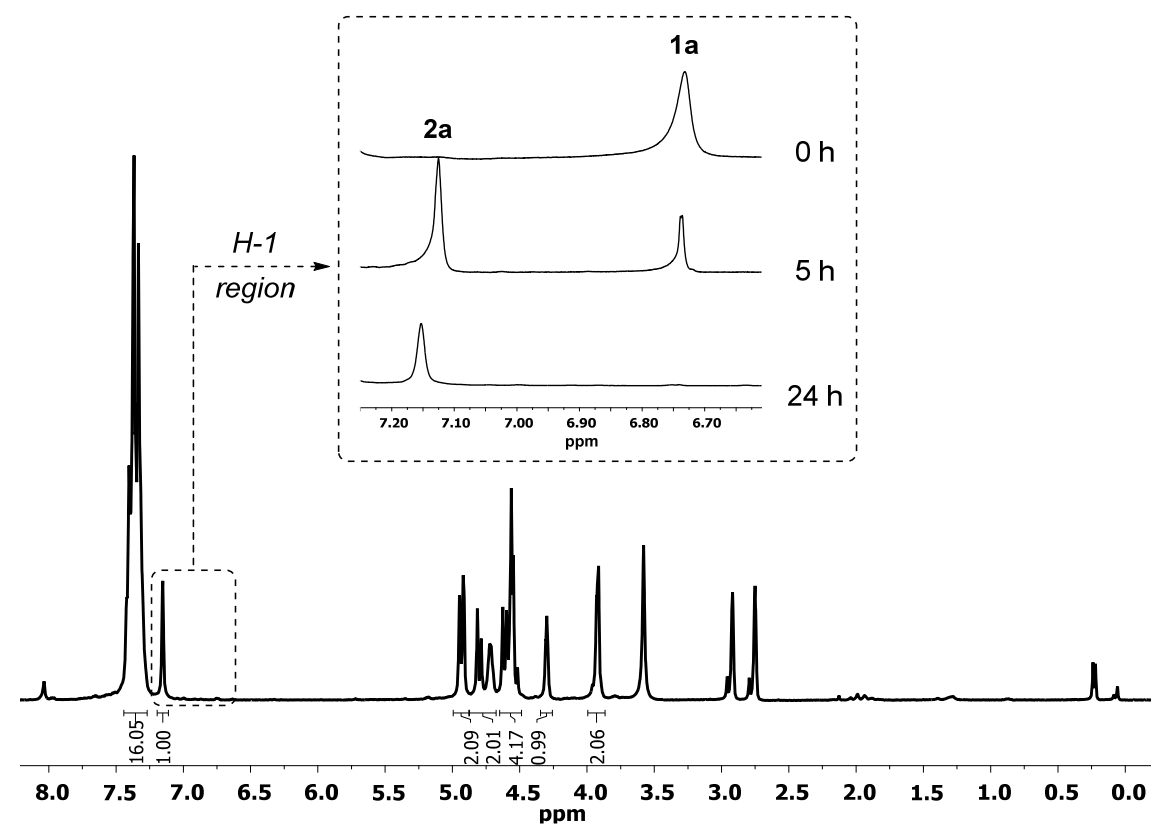

Figure S9. In situ reaction monitoring by ${ }^{1} \mathrm{H}$ NMR (DMF-d $7,400 \mathrm{MHz}$ )

\section{Conformational analysis of 2 a}

The incorporation of $\mathrm{C}_{2} \mathrm{~F}_{5}$ had an impact on the conformation as noticed by the low $J_{3,4}$ and $J_{4,5}$ values $(<2 \mathrm{~Hz})$. In fact, both coupling constant values decrease while steric hindrance of $\mathrm{C}-2$ substituent increases, probably indicating a progressive ring flattering $>$ flipping due to 1,2-allylic $\left(\mathrm{A}^{1,2}\right)$ strain (Figure S10). ${ }^{14}$

$\begin{array}{llll}\mathbf{X} & \boldsymbol{J}_{\mathbf{3}, \mathbf{4}}(\mathbf{H z}) & \boldsymbol{J}_{\mathbf{4}, \mathbf{5}}(\mathrm{Hz}) & {[\mathrm{Ref}]} \\ \mathbf{H} & 6.2 & 8.2 & 14 \\ \mathbf{I} & 5.0 & 6.6 & 16 \\ \mathbf{C F}_{\mathbf{3}} & 3.2 & 3.2 & 15 \\ \mathbf{C}_{\mathbf{2}} \mathbf{F}_{\mathbf{5}} & <2 & <2 & \text { This work }\end{array}$

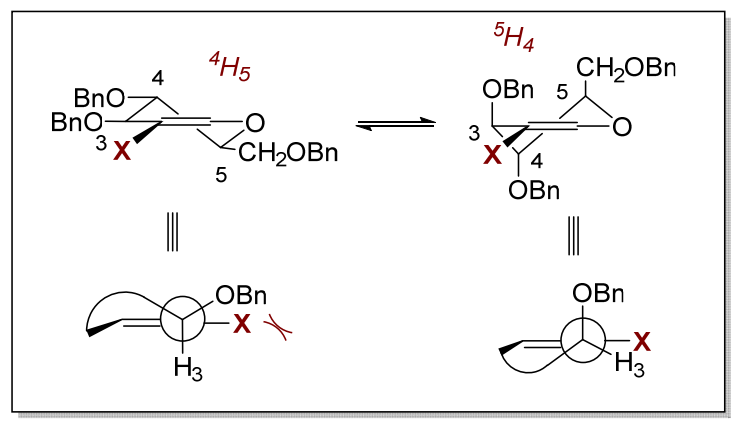

Figure S10. Conformational analysis of 2-substituted-3,4,6-tri-O-benzyl-D-glucals ${ }^{14-16}$

\section{Optimization of the pentafluoroethylation of halogenated (hetero)arenes}

Solid compounds: an NMR tube charged with the corresponding (hetero)aryl halide $(0.171$ mmol) was purged and backfilled with argon three times. $\mathrm{CuC}_{2} \mathrm{~F}_{5}(0.4 \mathrm{M}$ in DMF, $0.4 \mathrm{~mL}$, $0.26 \mathrm{mmol}$ ) and 1,3-bis(trifluoromethyl)benzene (BTB, $13 \mu \mathrm{L}, 0.084 \mathrm{mmol}$ ) were 
sequentially added under argon and the NMR tube was capped with a rubber septum. The reaction mixture was heated in a silicon oil bath at the indicated temperature and monitored by ${ }^{19} \mathrm{~F}$ NMR for quantitative analysis.

Liquid compounds: an NMR tube was purged and backfilled with argon three times. $\mathrm{CuC}_{2} \mathrm{~F}_{5}(0.4 \mathrm{M}$ in $\mathrm{DMF}, 0.4 \mathrm{~mL}, 0.26 \mathrm{mmol})$, (hetero)aryl halide $(0.171 \mathrm{mmol})$, and 1,3bis(trifluoromethyl)benzene (BTB, $13 \mu \mathrm{L}, 0.084 \mathrm{mmol})$ were sequentially added under argon and the NMR tube was capped with a rubber septum. The reaction mixture was heated in a silicon oil bath at the indicated temperature and monitored by ${ }^{19} \mathrm{~F}$ NMR for quantitative analysis.

Table S4. Reaction scope with aryl and heteroaryl halides

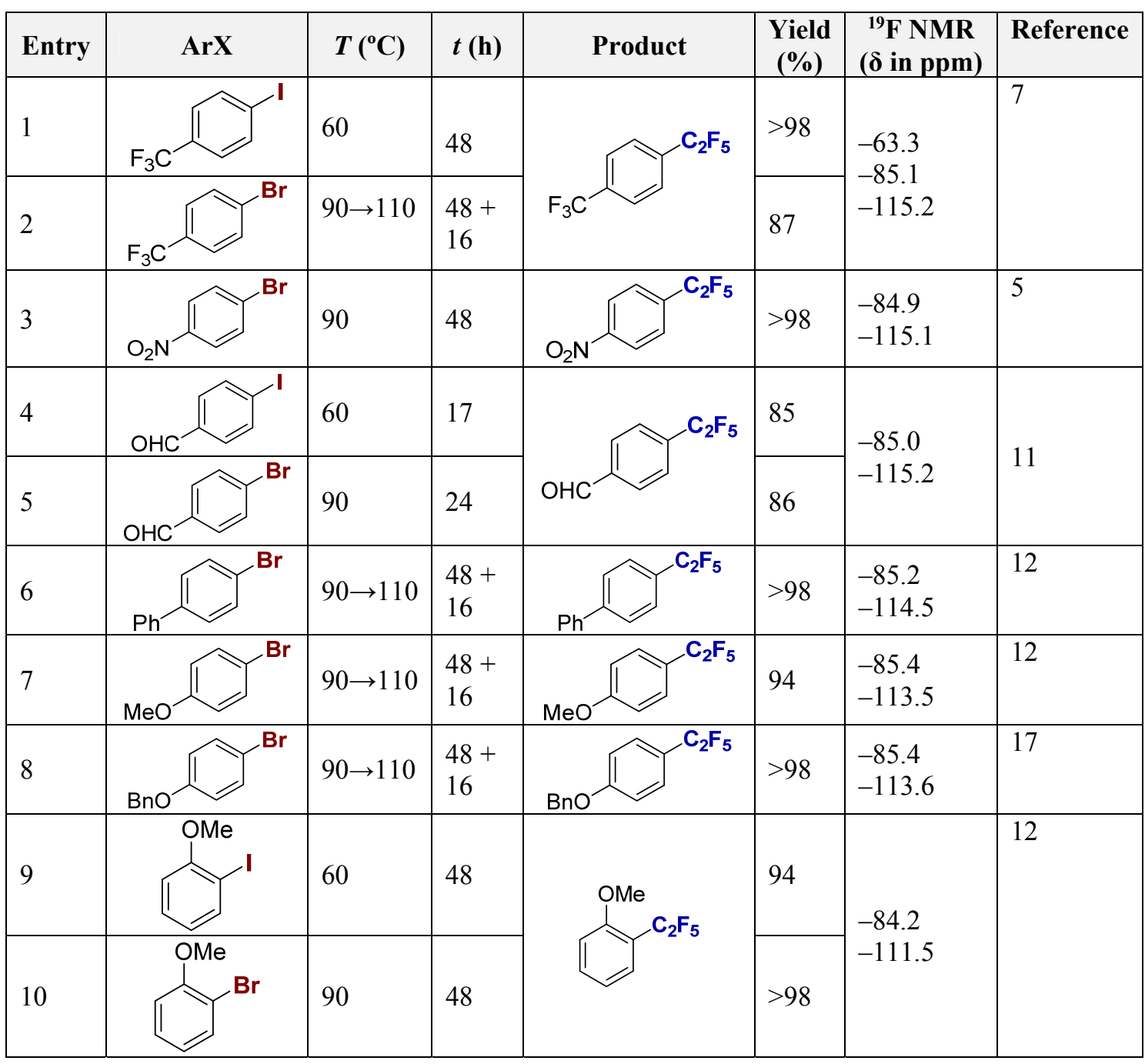


Supporting Information

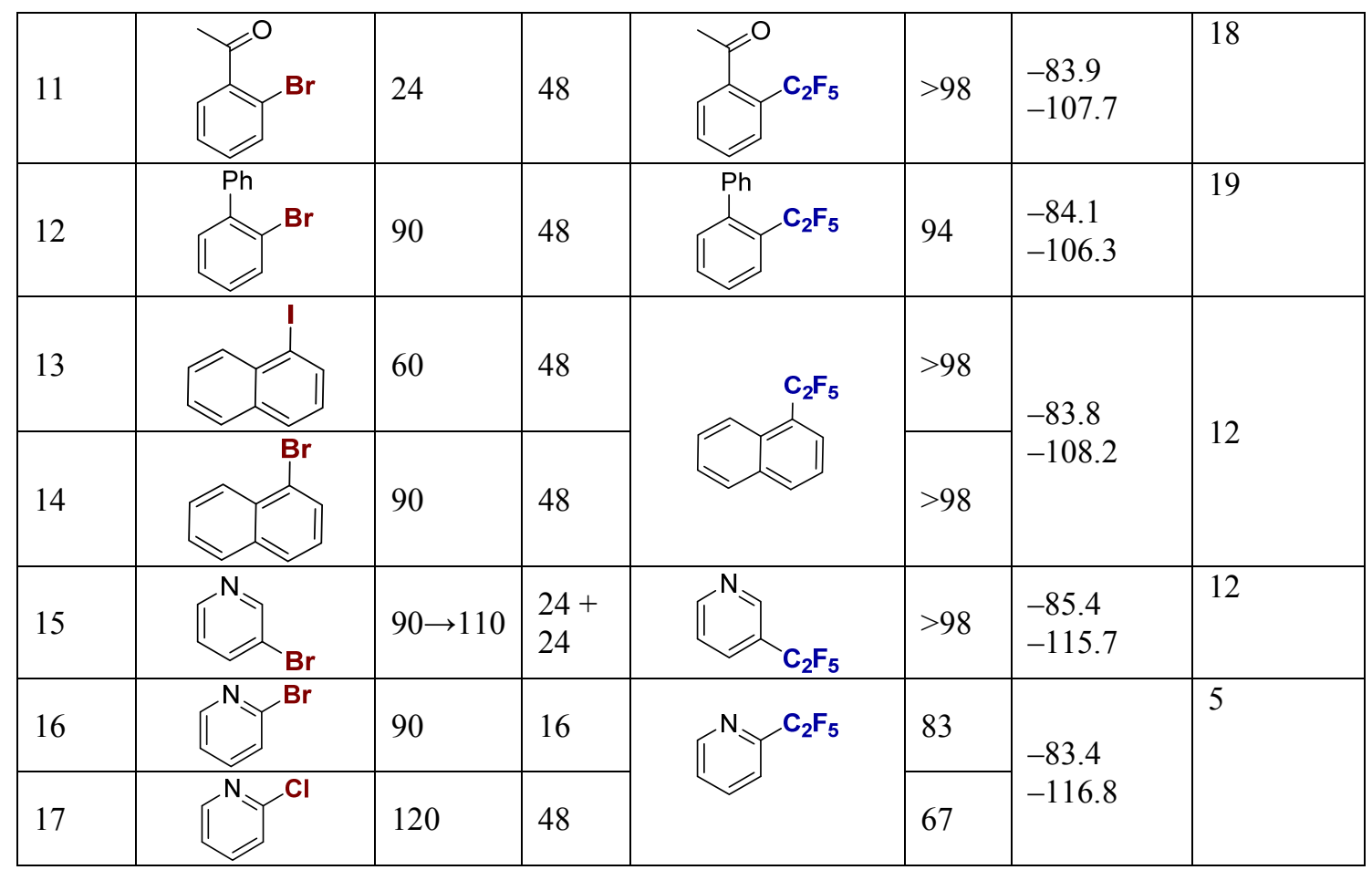


Supporting Information

\section{NMR Spectra}

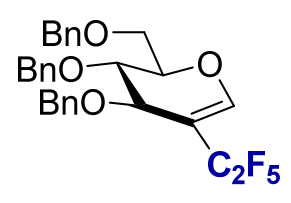

mํำ
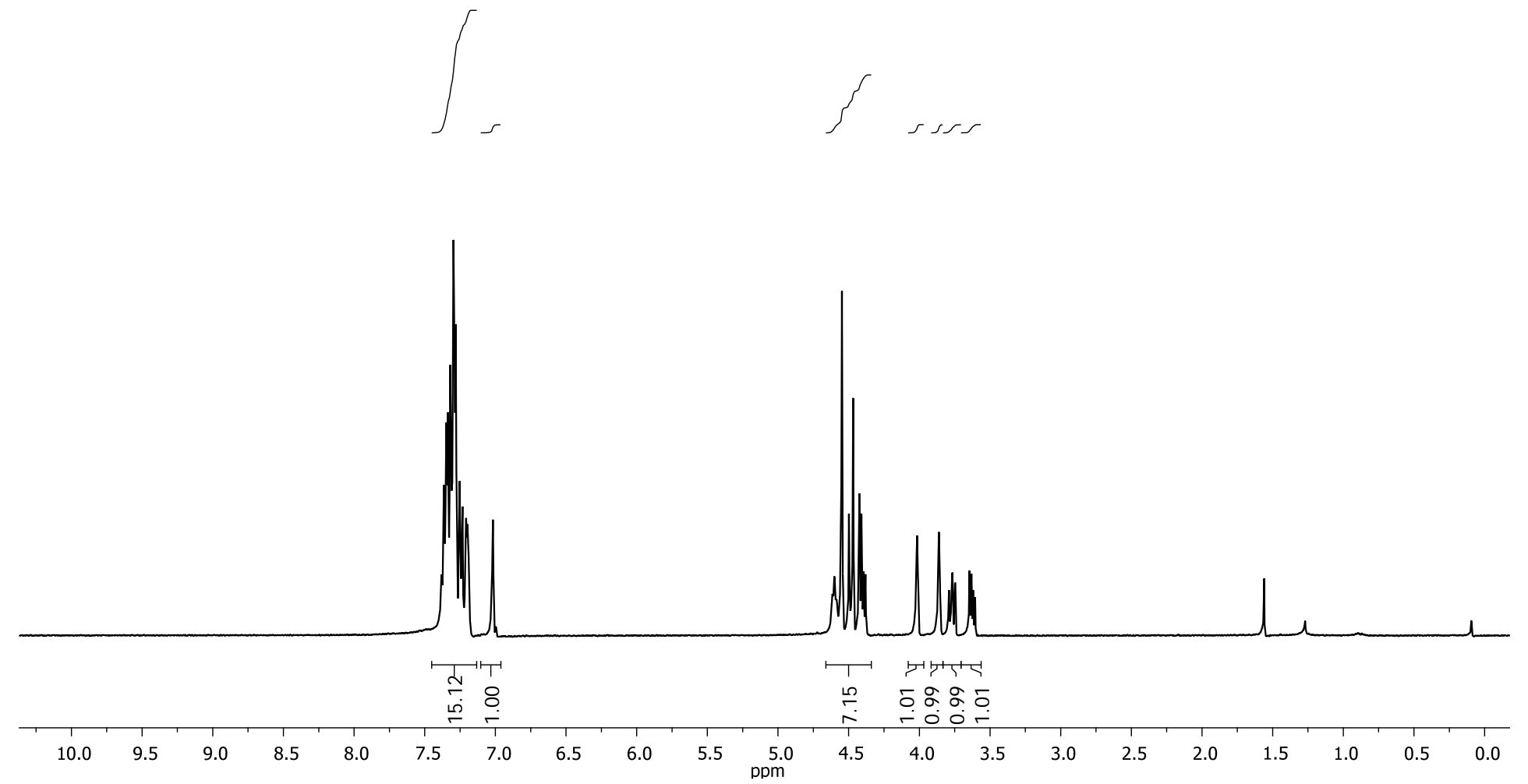

Figure S11. ${ }^{1} \mathrm{H}$ NMR $\left(\mathrm{CDCl}_{3}, 400 \mathrm{MHz}\right)$ of $\mathbf{2 a}$ 
Supporting Information

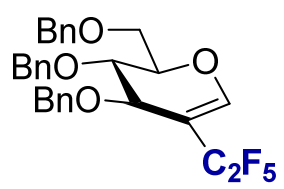

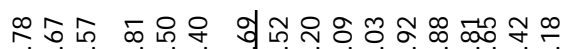

守守守 $\hat{m} \hat{m}$ o

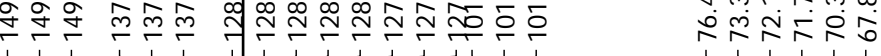

$\mathrm{C}_{2} \mathrm{~F}_{5}$

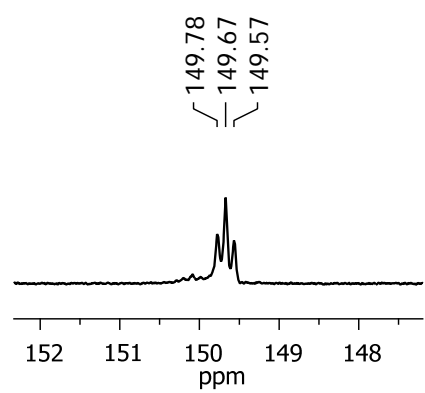

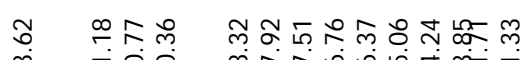

I

กำ ₹ $\stackrel{\infty}{?}$

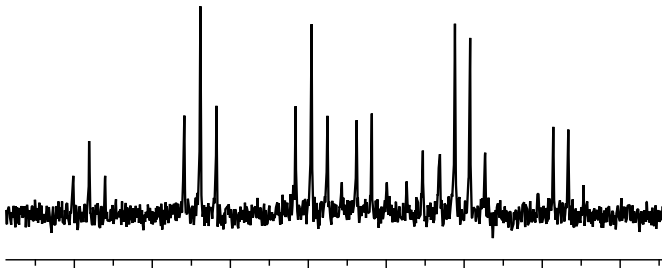

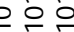
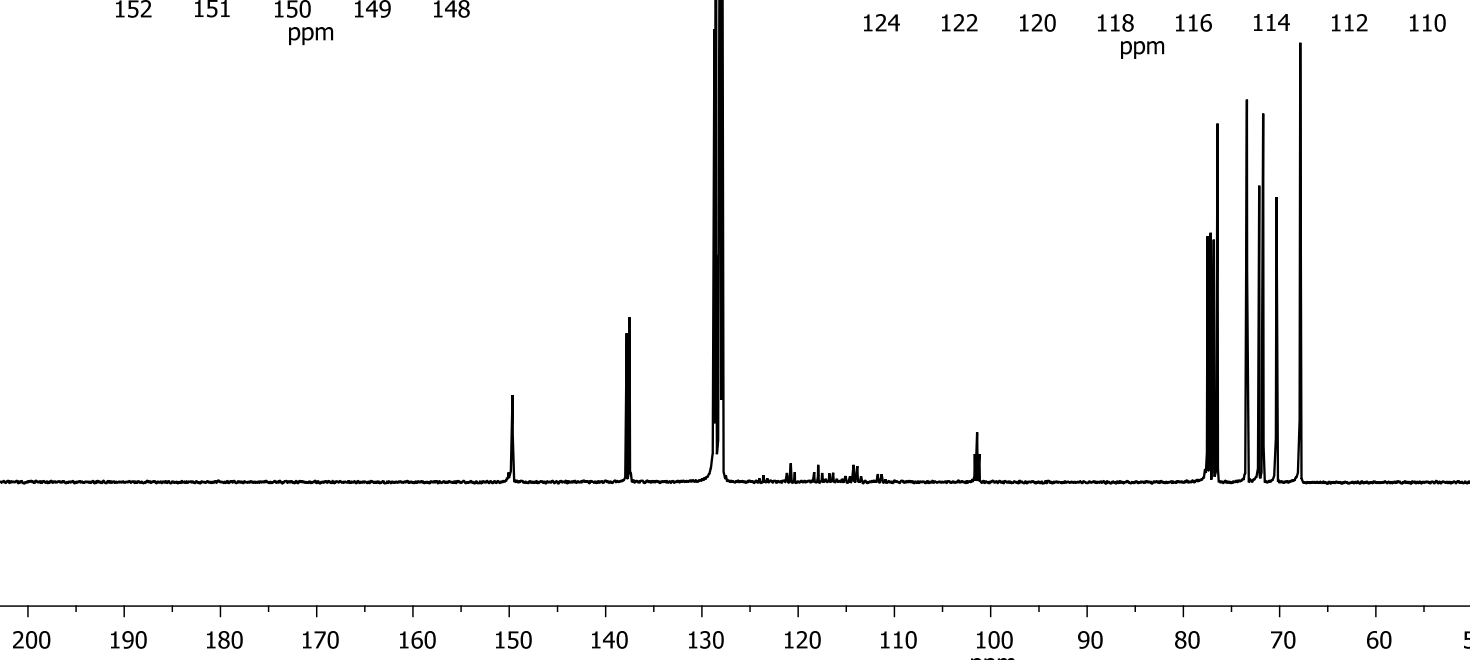

$\begin{array}{lllll}140 & 130 & 120 & 110 & \begin{array}{r}100 \\ \mathrm{ppm}\end{array}\end{array}$

$90 \quad 80$

70

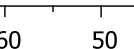

$40 \quad 30$

$20 \quad 10 \quad 0$

Figure S12. ${ }^{13} \mathrm{C}\left\{{ }^{1} \mathrm{H}\right\} \mathrm{NMR}\left(\mathrm{CDCl}_{3}, 100.6 \mathrm{MHz}\right)$ of $\mathbf{2 a}$ 
Supporting Information

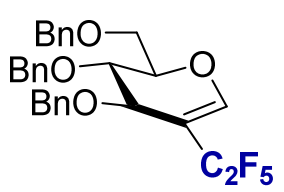

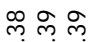

路要

$\mathrm{C}_{2} \mathrm{~F}_{5}$

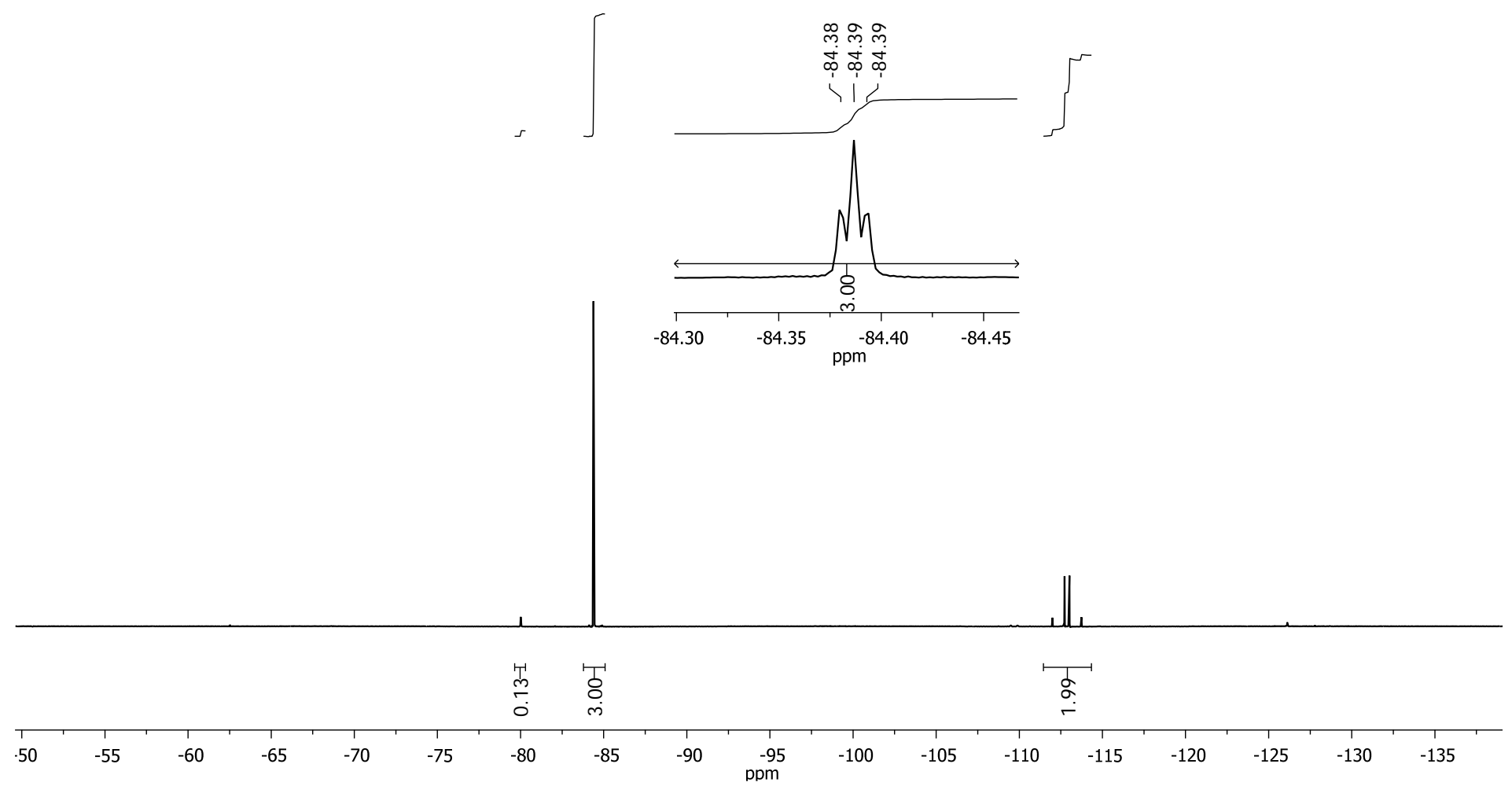

Figure S13. ${ }^{19} \mathrm{~F}$ NMR $\left(\mathrm{CDCl}_{3}, 376.5 \mathrm{MHz}\right)$ of $\mathbf{2 a}$ 
Supporting Information

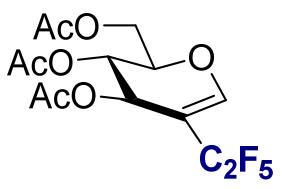

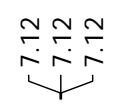

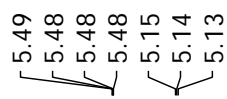

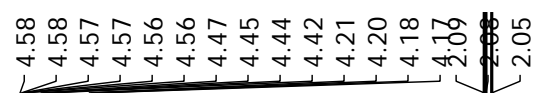

$\int$

$\iiint \iint$

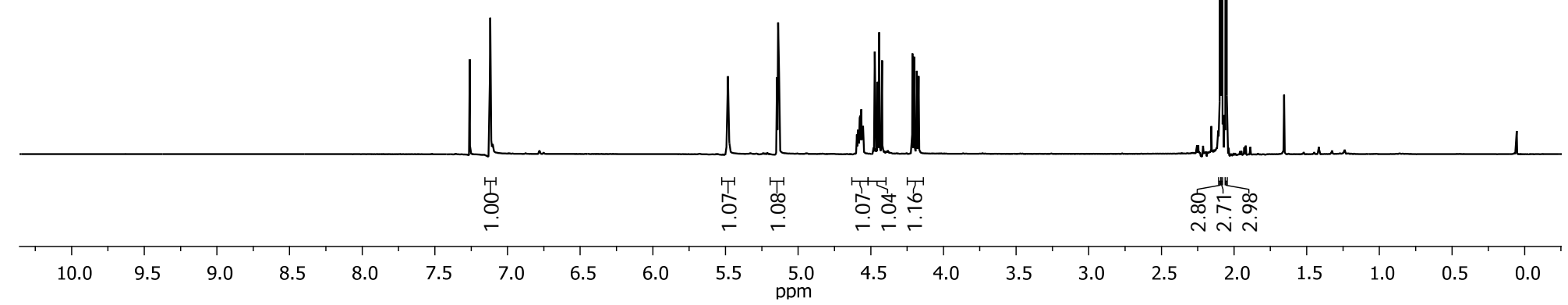

Figure S14. ${ }^{1} \mathrm{H} \mathrm{NMR}\left(\mathrm{CDCl}_{3}, 400 \mathrm{MHz}\right)$ of $\mathbf{2 b}$

S21 
Supporting Information
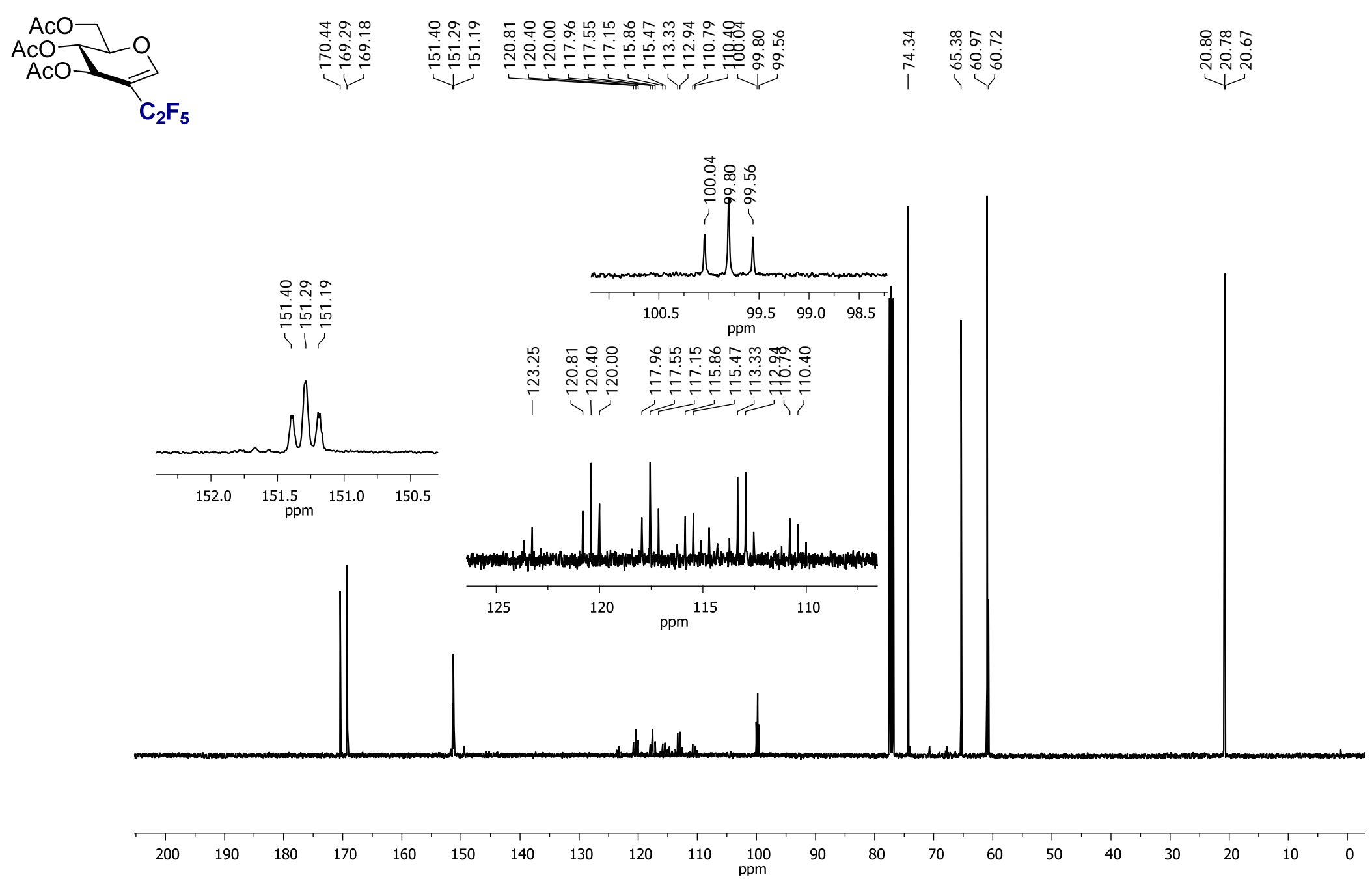

Figure S15. ${ }^{13} \mathrm{C}\left\{{ }^{1} \mathrm{H}\right\} \mathrm{NMR}\left(\mathrm{CDCl}_{3}, 100.6 \mathrm{MHz}\right)$ of $\mathbf{2 b}$ 
Supporting Information

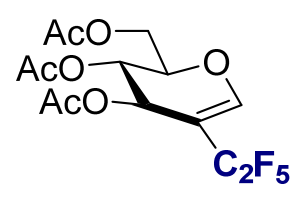

$\underbrace{\substack{n \\ 0}}$

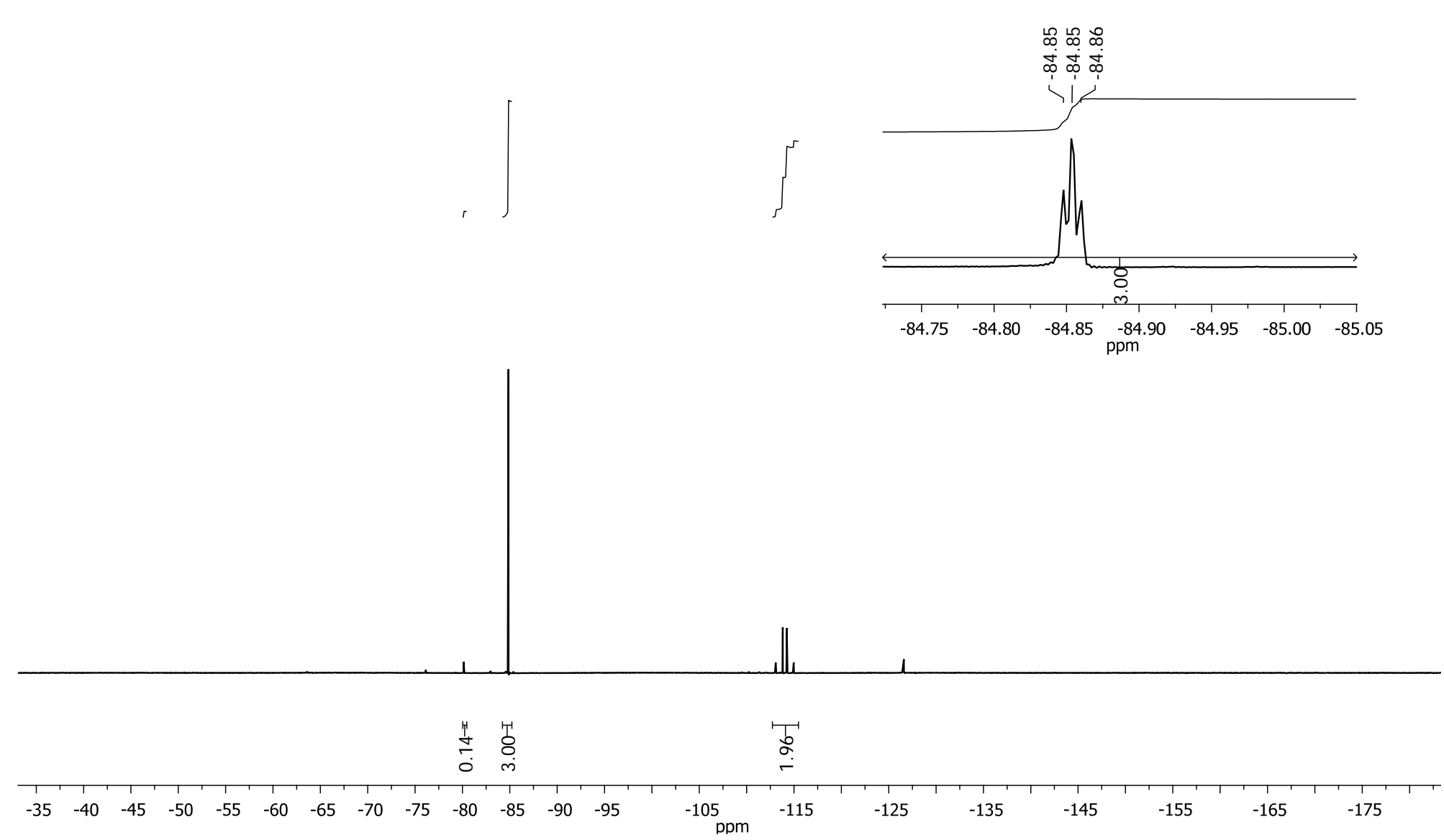

Figure S16. ${ }^{19} \mathrm{~F}$ NMR $\left(\mathrm{CDCl}_{3}, 376.5 \mathrm{MHz}\right)$ of $\mathbf{2 b}$ 
Supporting Information

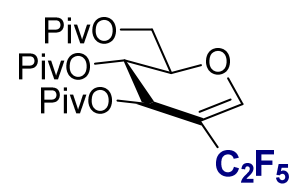

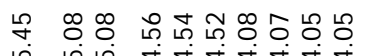

மी ம்

$\mathrm{C}_{2} \mathrm{~F}_{5}$
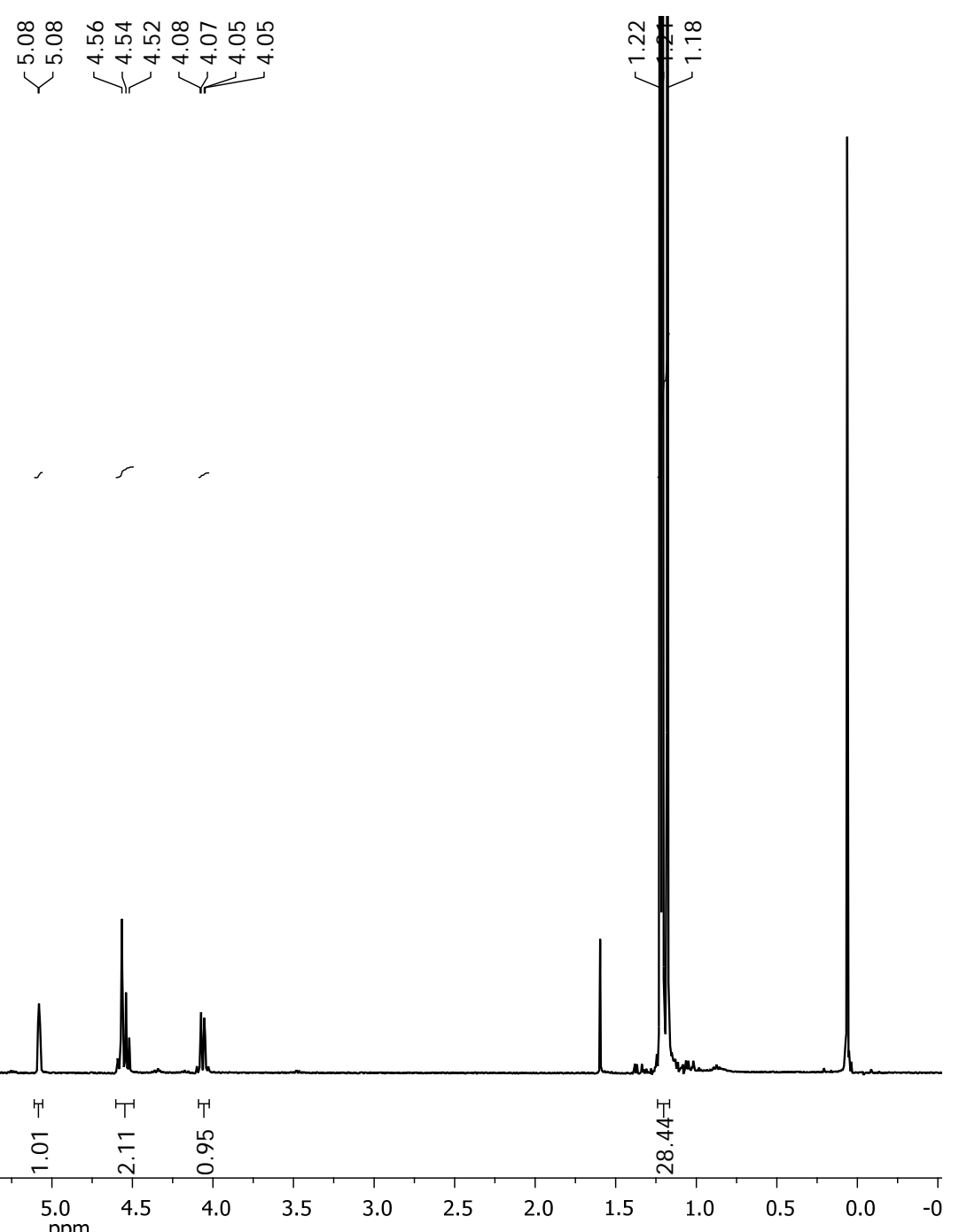

Figure S17. ${ }^{1} \mathrm{H}$ NMR $\left(\mathrm{CDCl}_{3}, 400 \mathrm{MHz}\right)$ of $2 \mathrm{c}$ 
Supporting Information
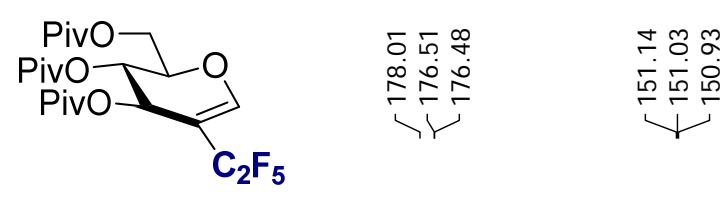

㲾|

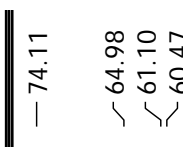
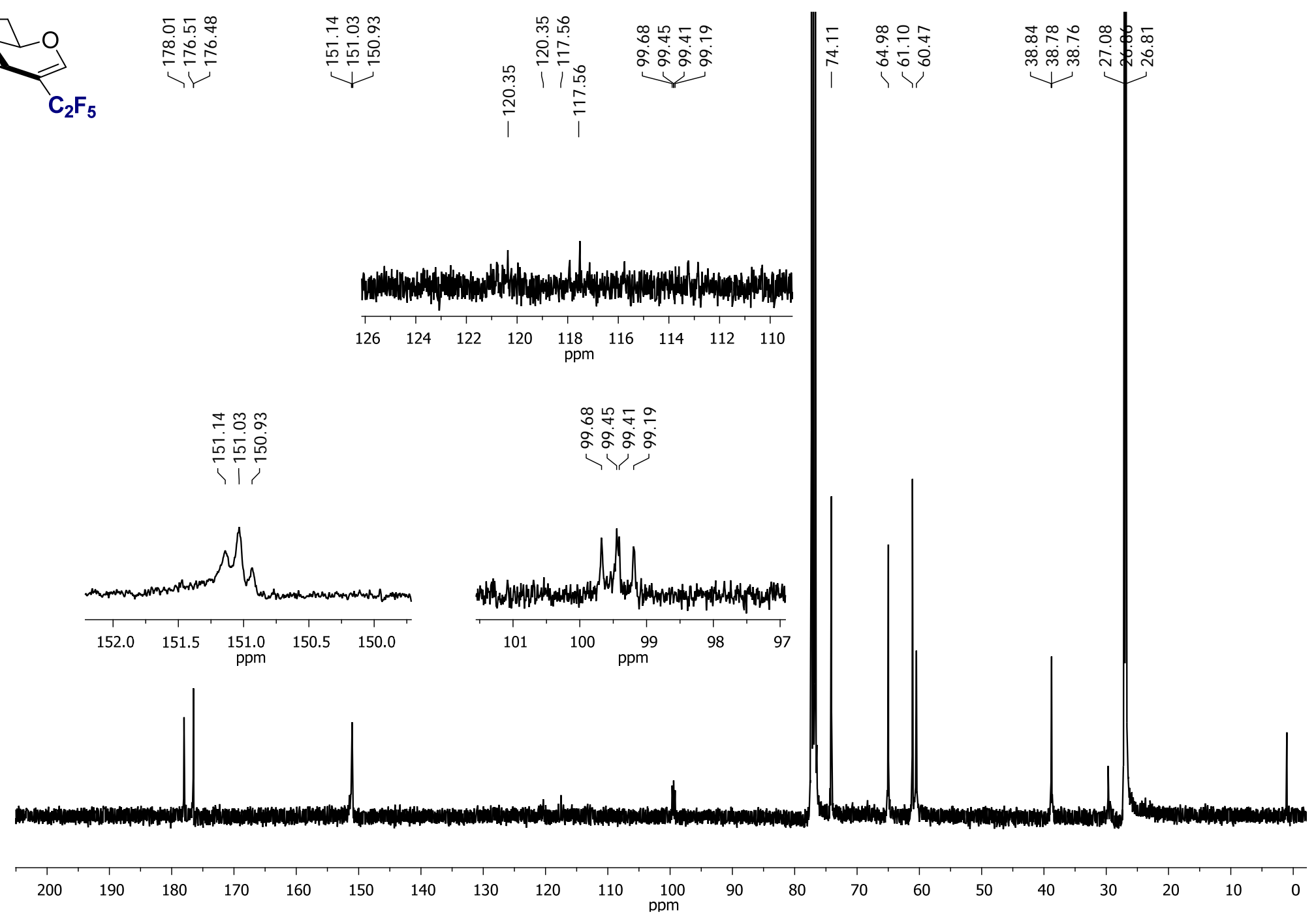

Figure S18. ${ }^{13} \mathrm{C}\left\{{ }^{1} \mathrm{H}\right\} \mathrm{NMR}\left(\mathrm{CDCl}_{3}, 100.6 \mathrm{MHz}\right)$ of $\mathbf{2 c}$ 
Supporting Information

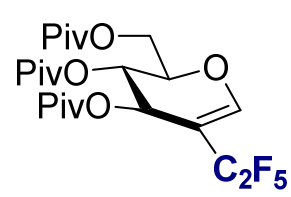

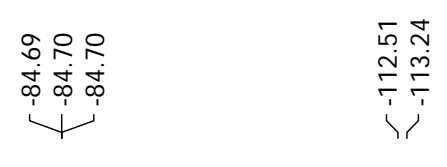

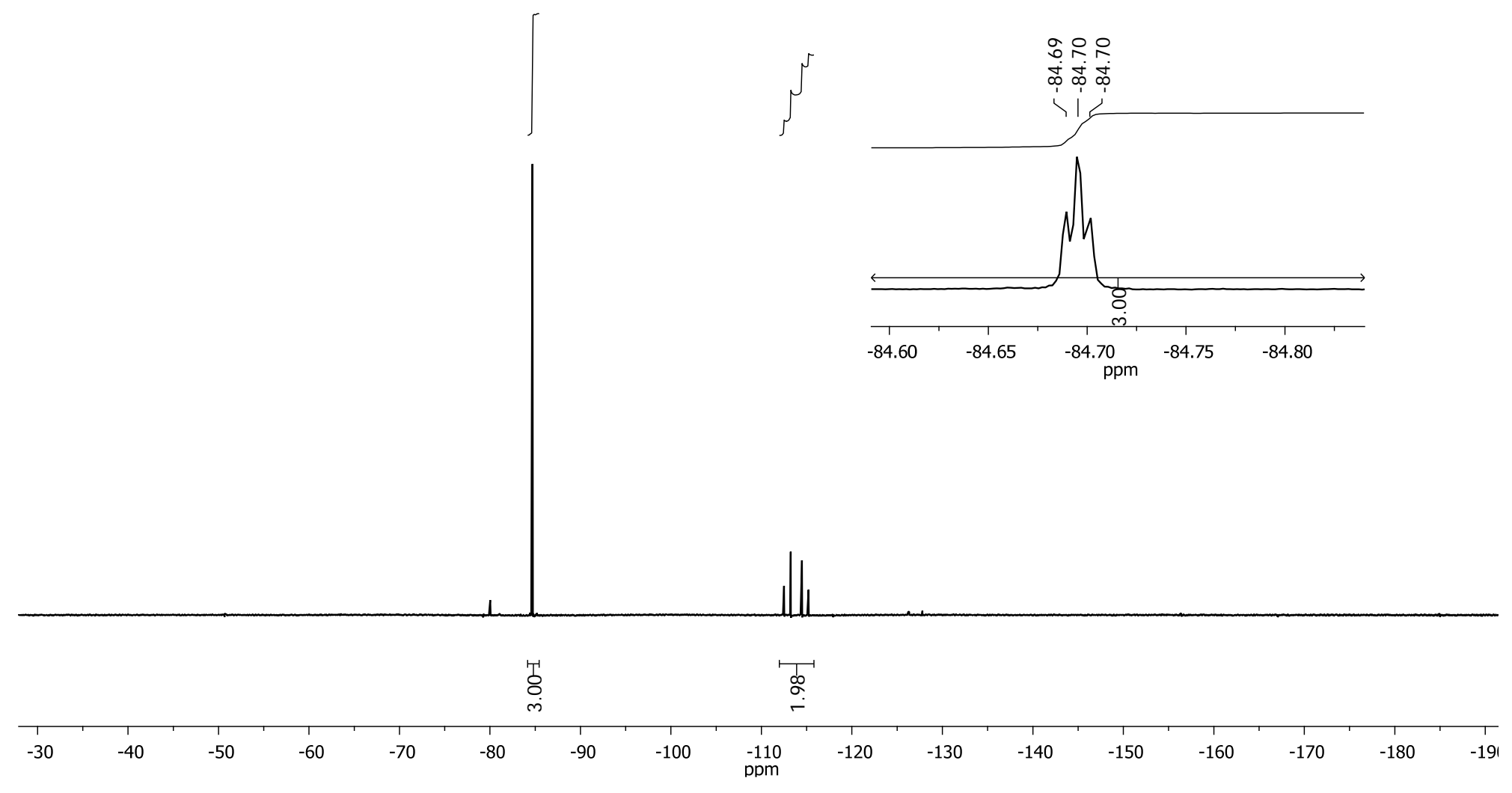

Figure $\mathbf{S 1 9}{ }^{19} \mathrm{~F}$ NMR $\left(\mathrm{CDCl}_{3}, 376.5 \mathrm{MHz}\right)$ of $\mathbf{2 c}$ 
Supporting Information
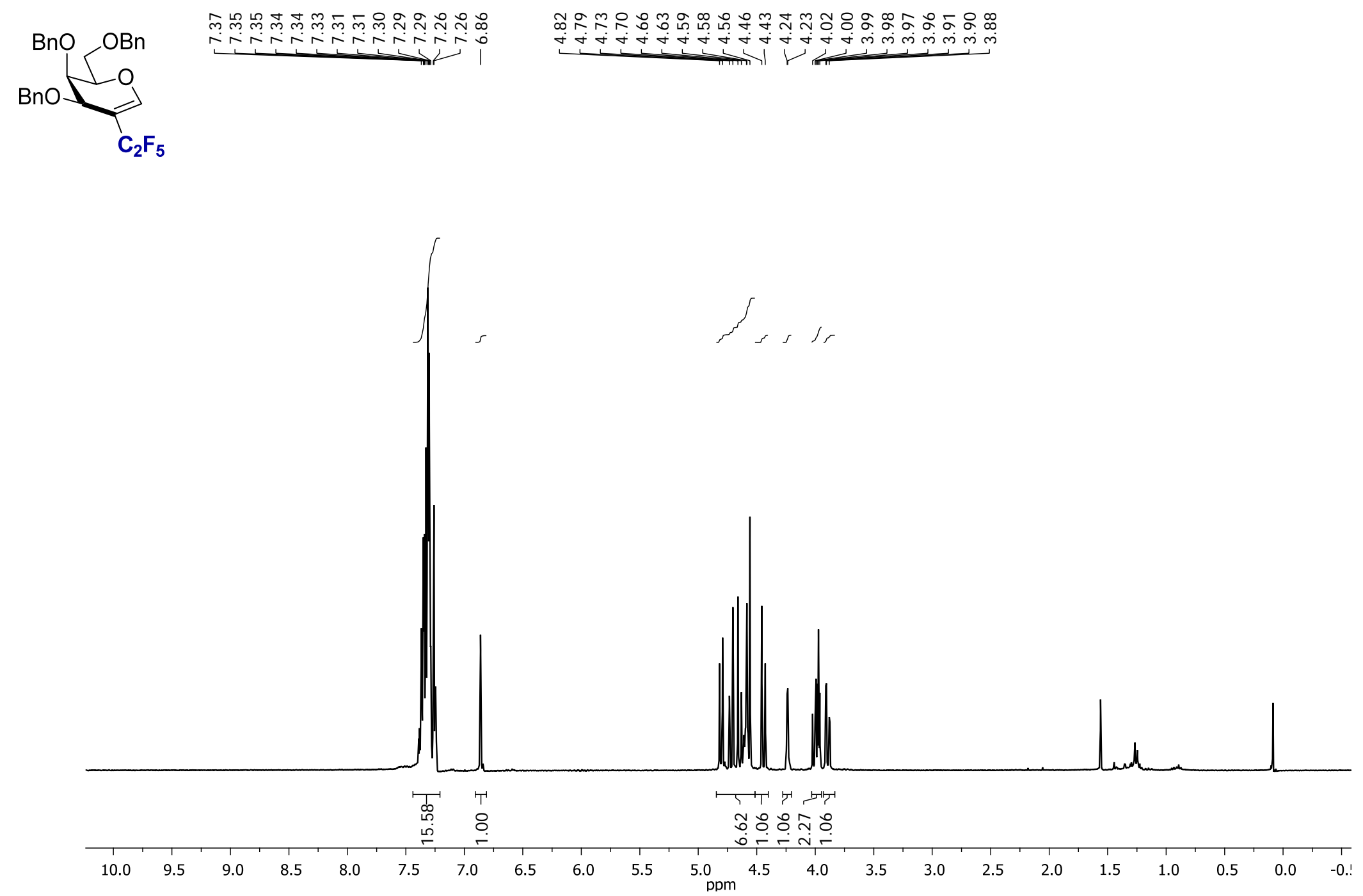

Figure S20. ${ }^{1} \mathrm{H} \mathrm{NMR}\left(\mathrm{CDCl}_{3}, 400 \mathrm{MHz}\right)$ of $\mathbf{2 d}$ 
Supporting Information

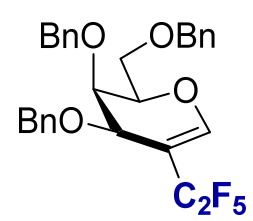

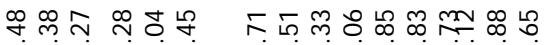

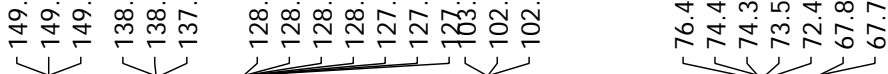

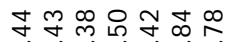

$\mathrm{C}_{2} \mathrm{~F}_{5}$
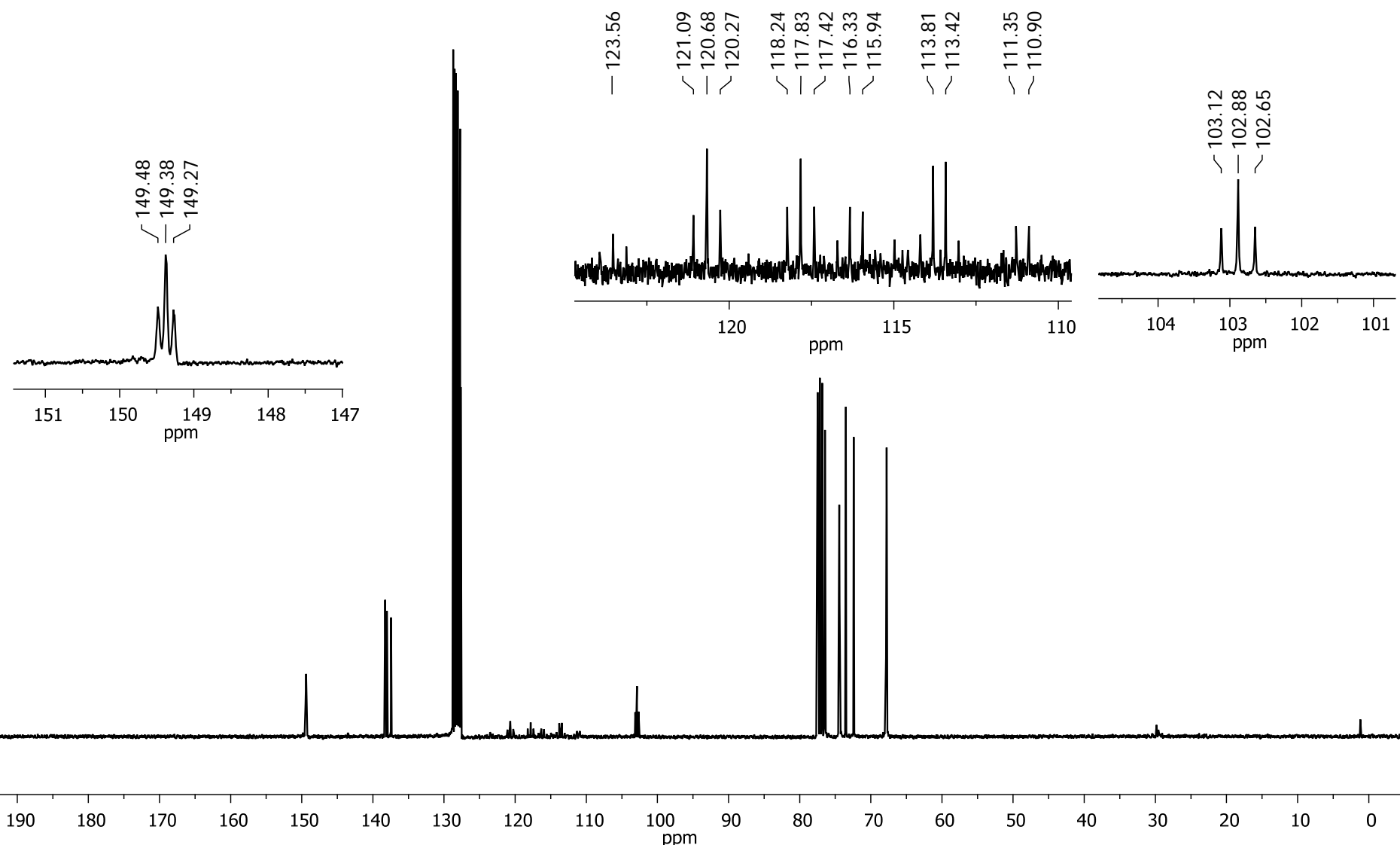

Figure S21. ${ }^{13} \mathrm{C}\left\{{ }^{1} \mathrm{H}\right\} \mathrm{NMR}\left(\mathrm{CDCl}_{3}, 100.6 \mathrm{MHz}\right)$ of $\mathbf{2 d}$ 
Supporting Information
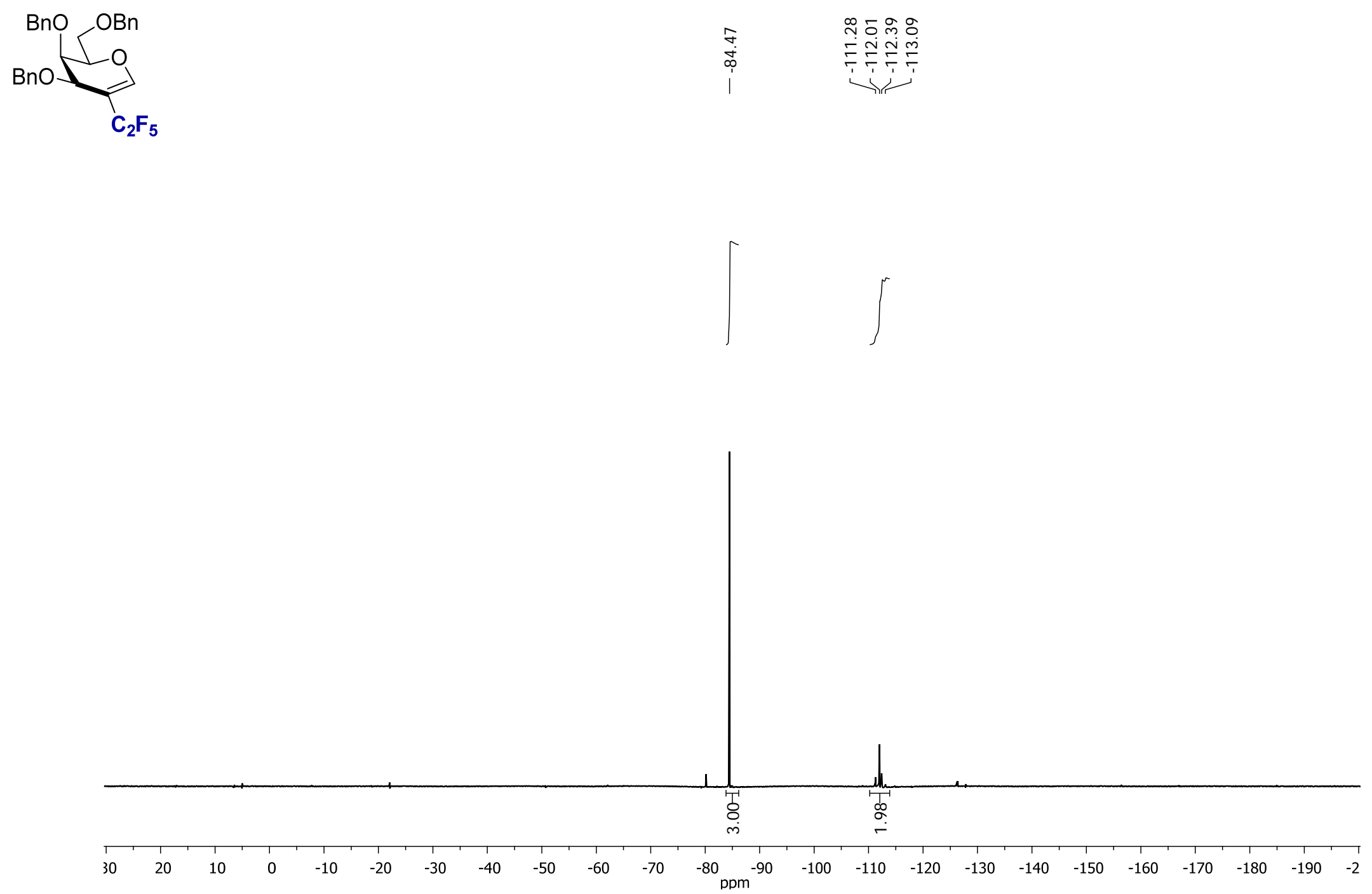

Figure S22. ${ }^{19} \mathrm{~F}$ NMR $\left(\mathrm{CDCl}_{3}, 376.5 \mathrm{MHz}\right)$ of $\mathbf{2 d}$ 
Supporting Information

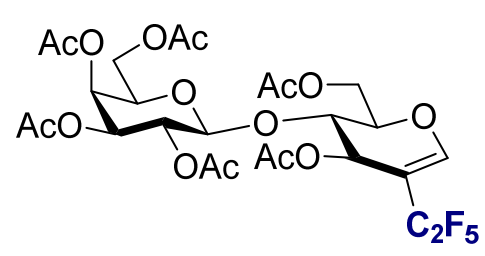

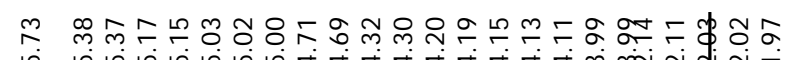

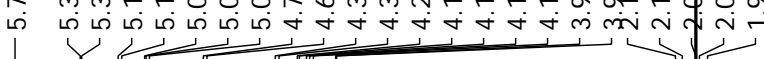

厂

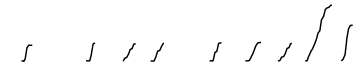

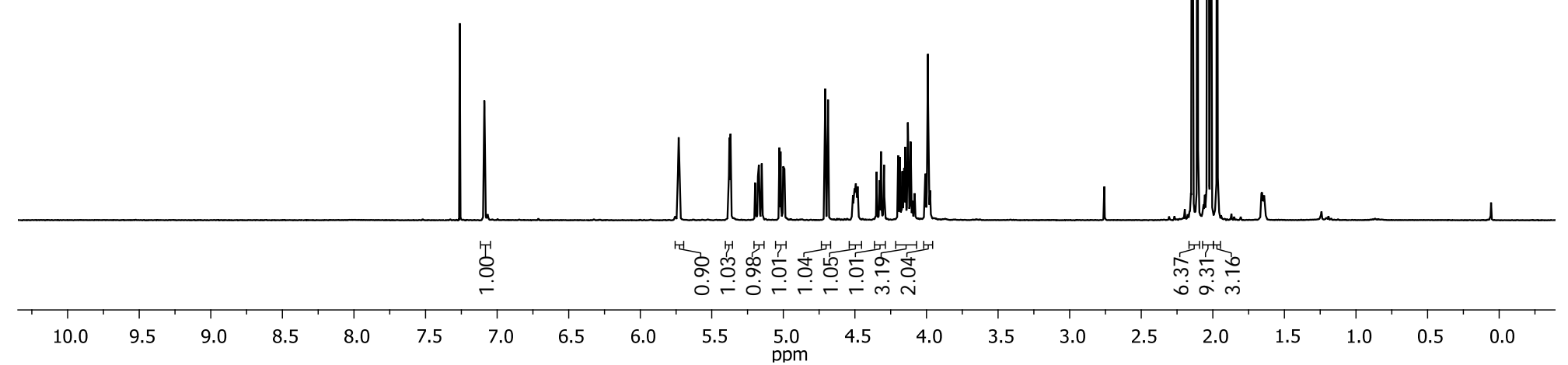

Figure S23. ${ }^{1} \mathrm{H} \mathrm{NMR}\left(\mathrm{CDCl}_{3}, 400 \mathrm{MHz}\right)$ of $2 \mathbf{e}$ 
Supporting Information

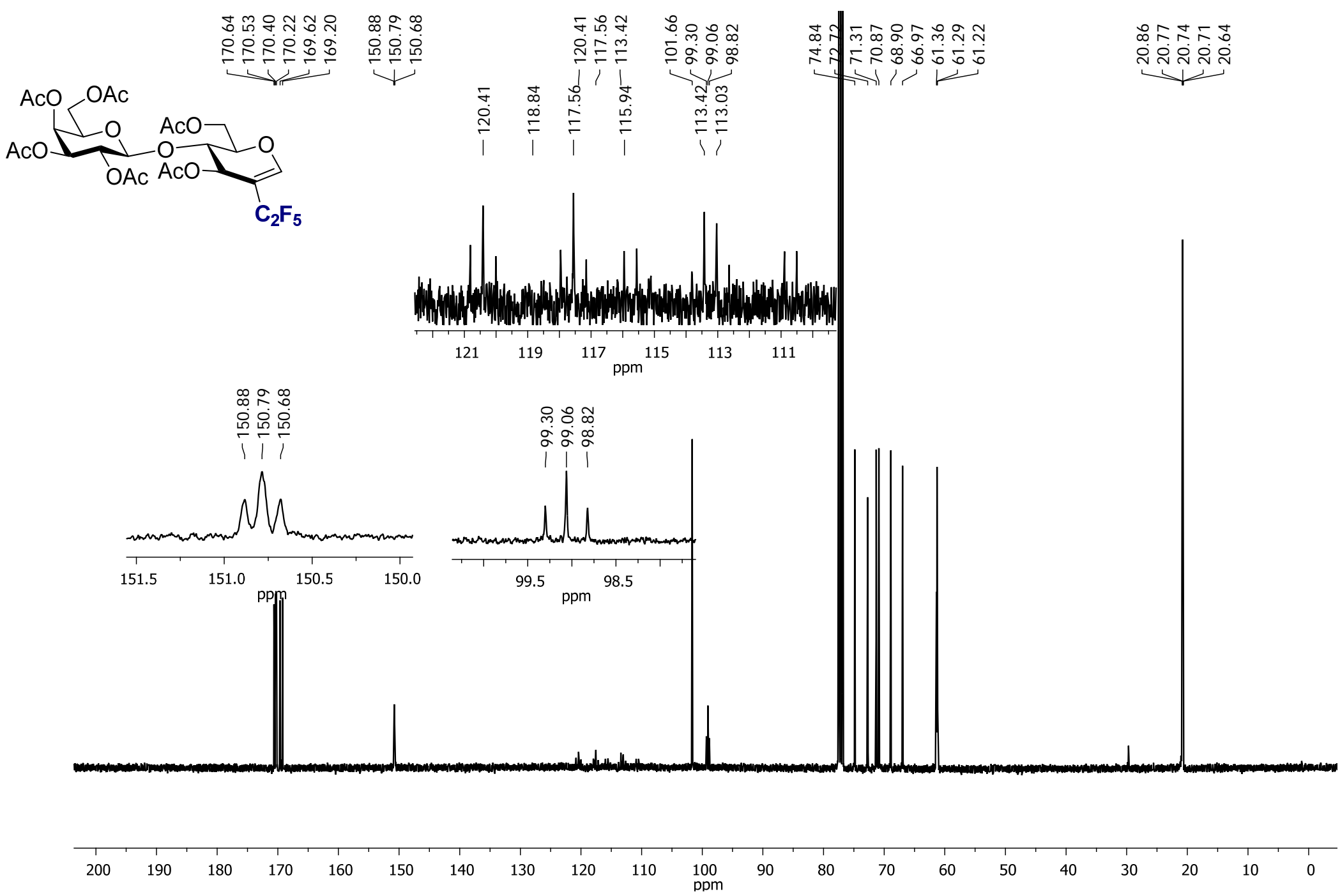

Figure S24. ${ }^{13} \mathrm{C}\left\{{ }^{1} \mathrm{H}\right\} \mathrm{NMR}\left(\mathrm{CDCl}_{3}, 100.6 \mathrm{MHz}\right)$ of $\mathbf{2 e}$ 
Supporting Information

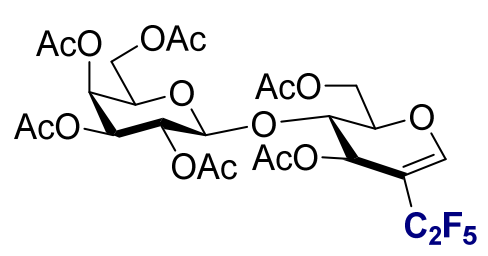

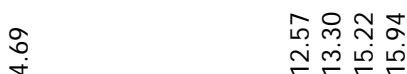

官

पi ir
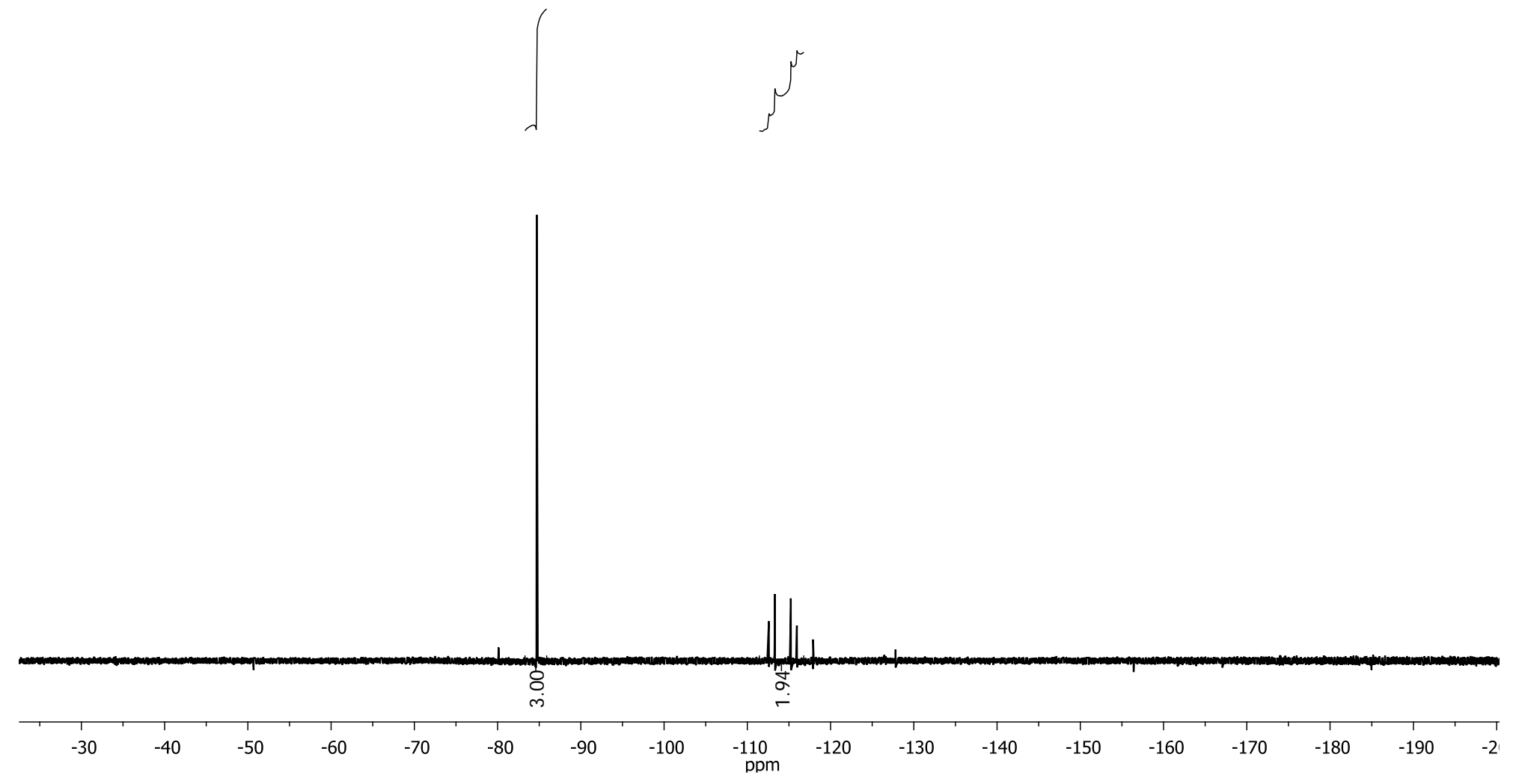

Figure S25. ${ }^{19} \mathrm{~F}$ NMR $\left(\mathrm{CDCl}_{3}, 376.5 \mathrm{MHz}\right)$ of $2 \mathbf{e}$ 
Supporting Information

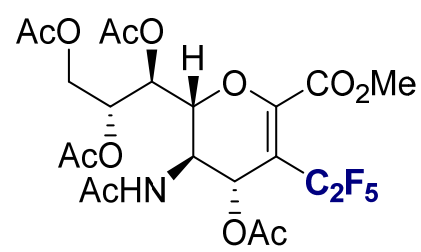

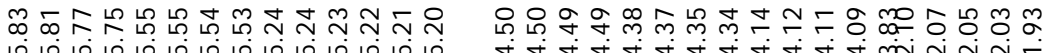

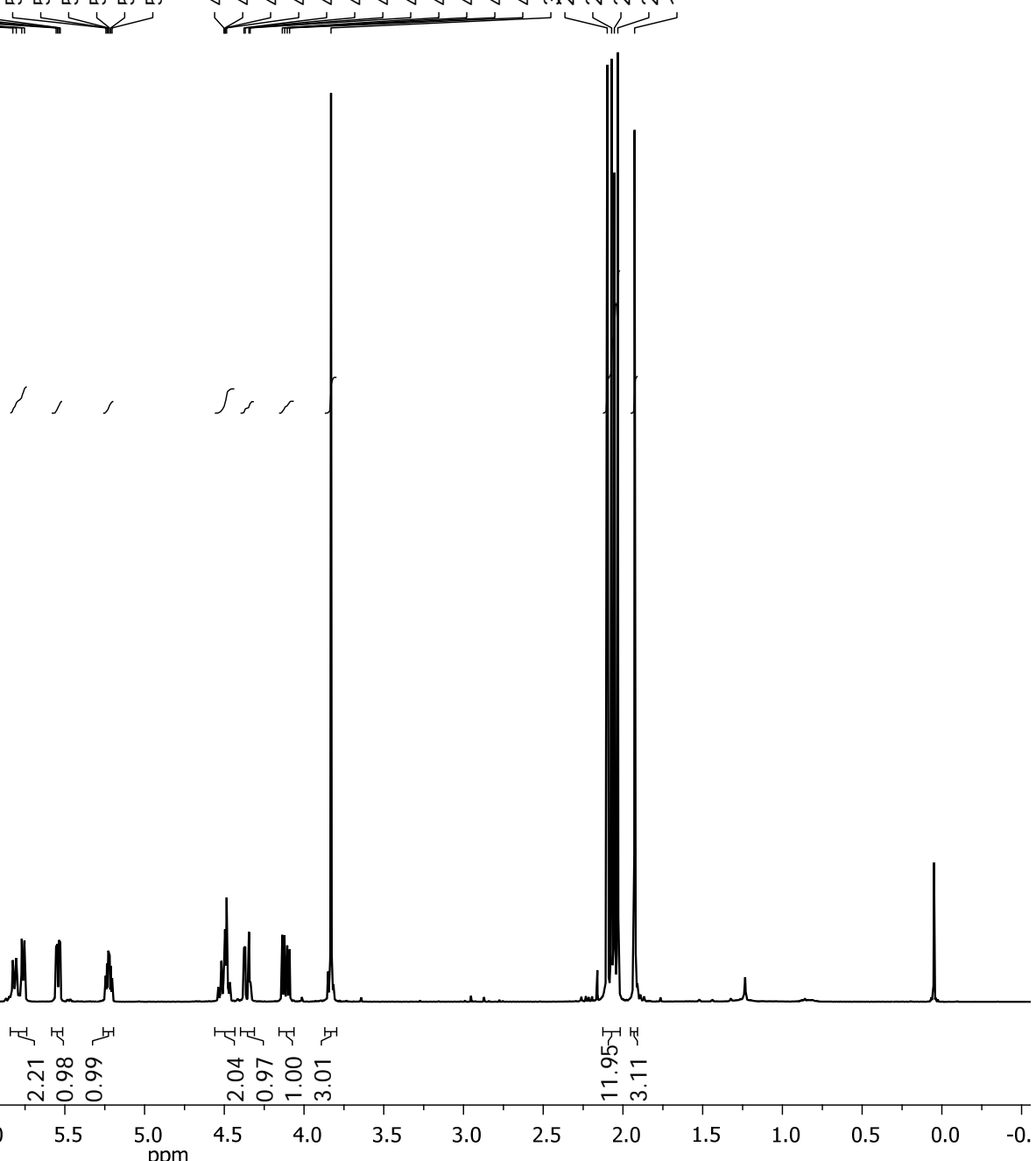

Figure S26. ${ }^{1} \mathrm{H} \mathrm{NMR}\left(\mathrm{CDCl}_{3}, 400 \mathrm{MHz}\right)$ of $\mathbf{2 f}$ 
Supporting Information

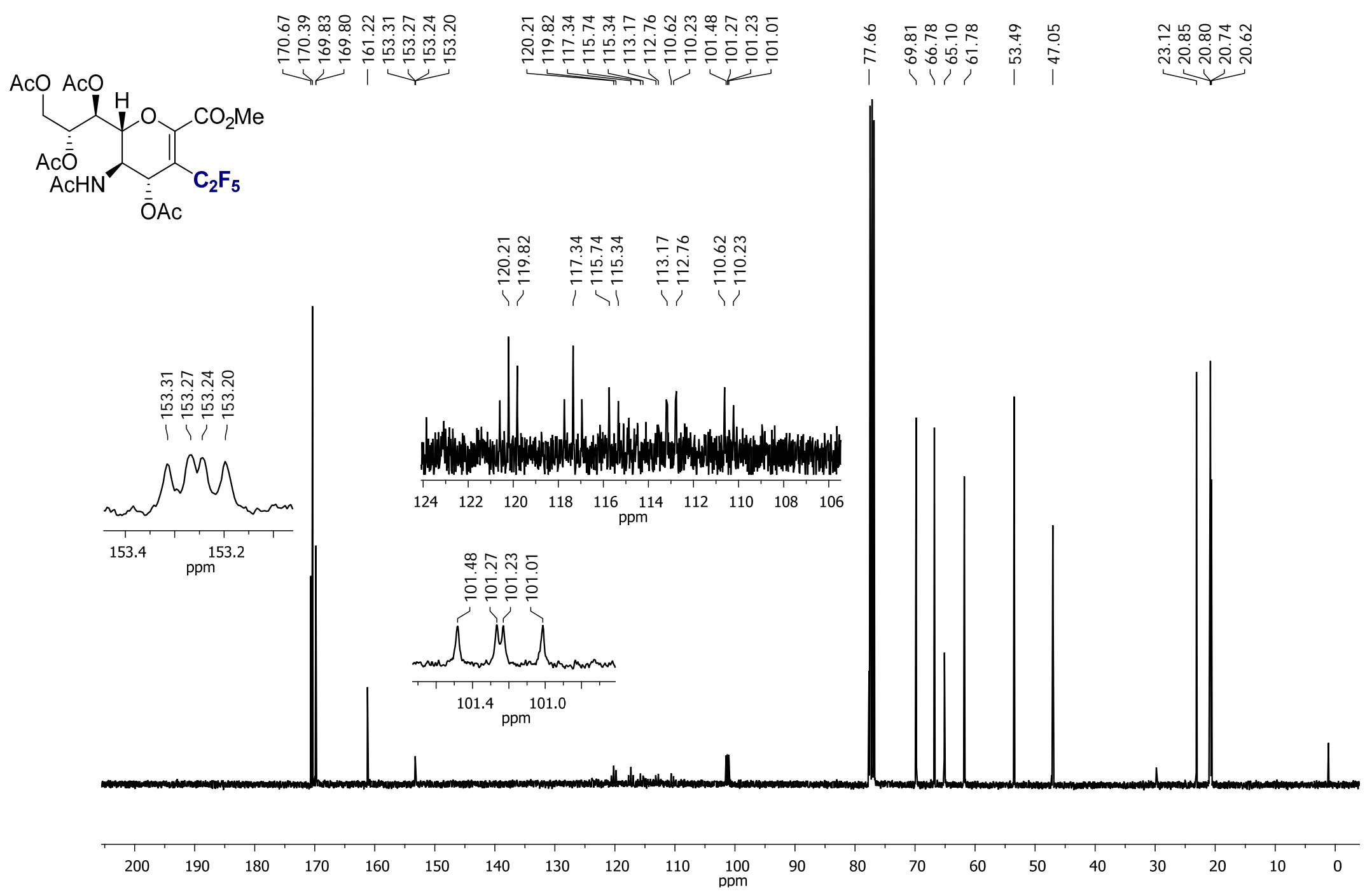

Figure S27. ${ }^{13} \mathrm{C}\left\{{ }^{1} \mathrm{H}\right\} \mathrm{NMR}\left(\mathrm{CDCl}_{3}, 100.6 \mathrm{MHz}\right)$ of $\mathbf{2 f}$ 
Supporting Information
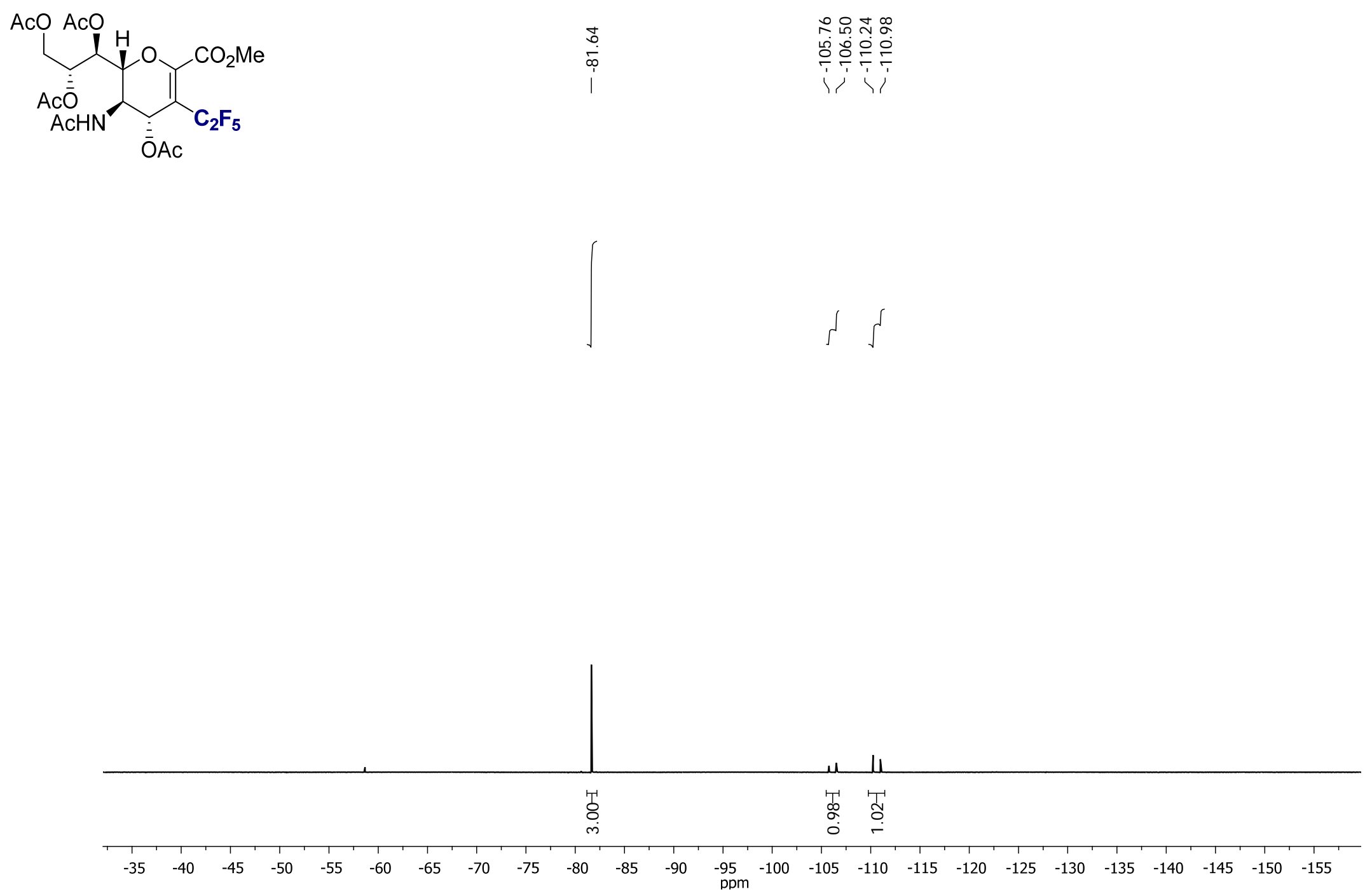

Figure S28. ${ }^{19} \mathrm{~F}$ NMR $\left(\mathrm{CDCl}_{3}, 376.5 \mathrm{MHz}\right)$ of $\mathbf{2 f}$ 
Supporting Information

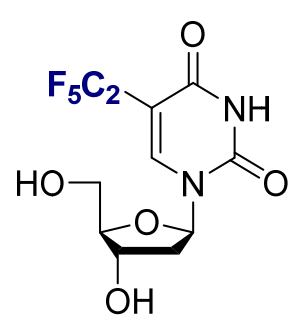

$\infty$
$\infty$
$\infty$
$\infty$

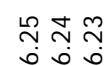

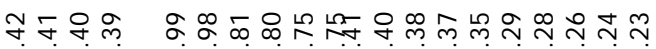

ن

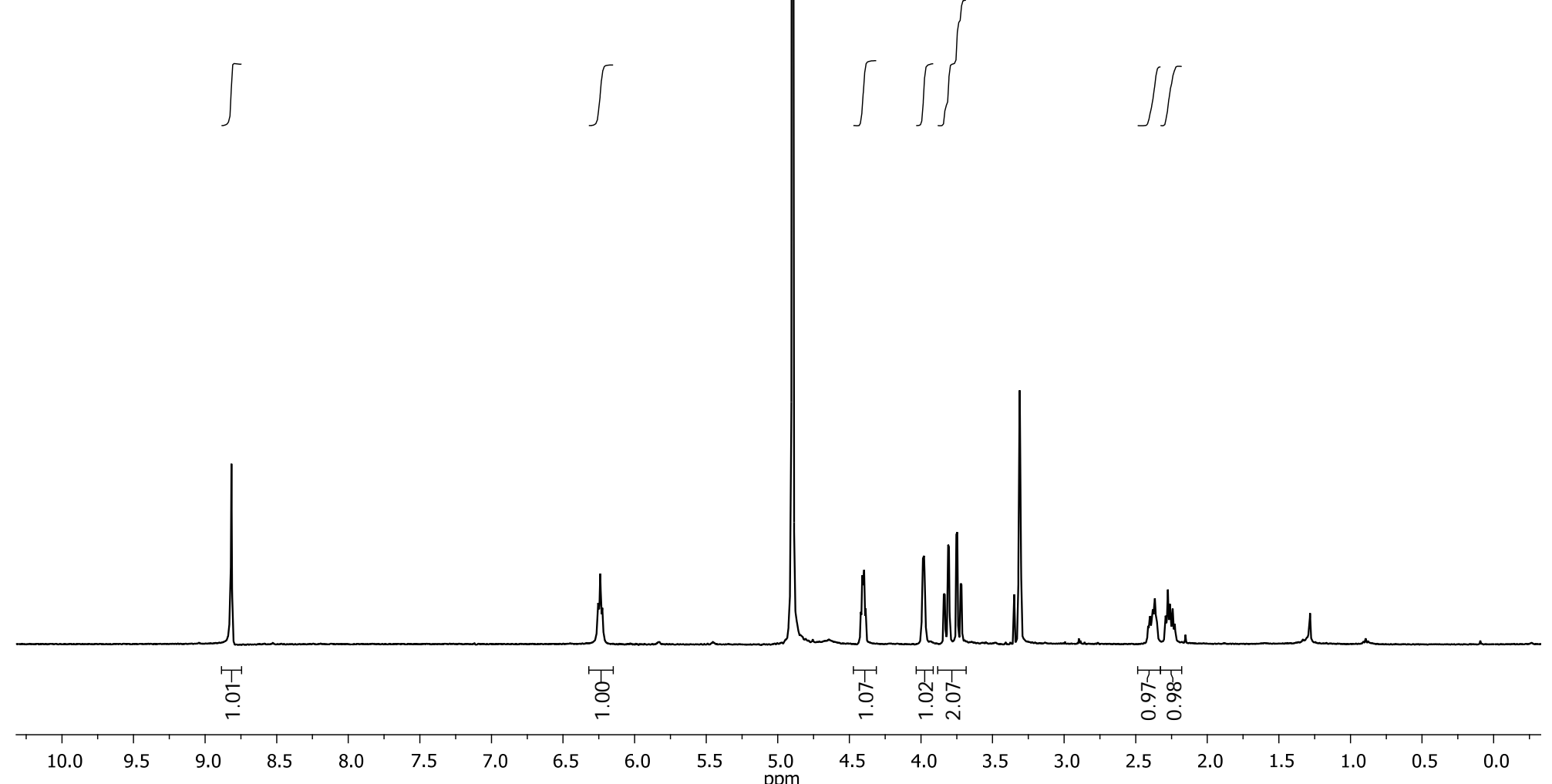

Figure S29. ${ }^{1} \mathrm{H}$ NMR $\left(\mathrm{CD}_{3} \mathrm{OD}, 400 \mathrm{MHz}\right)$ of $\mathbf{2 g}$ 
Supporting Information

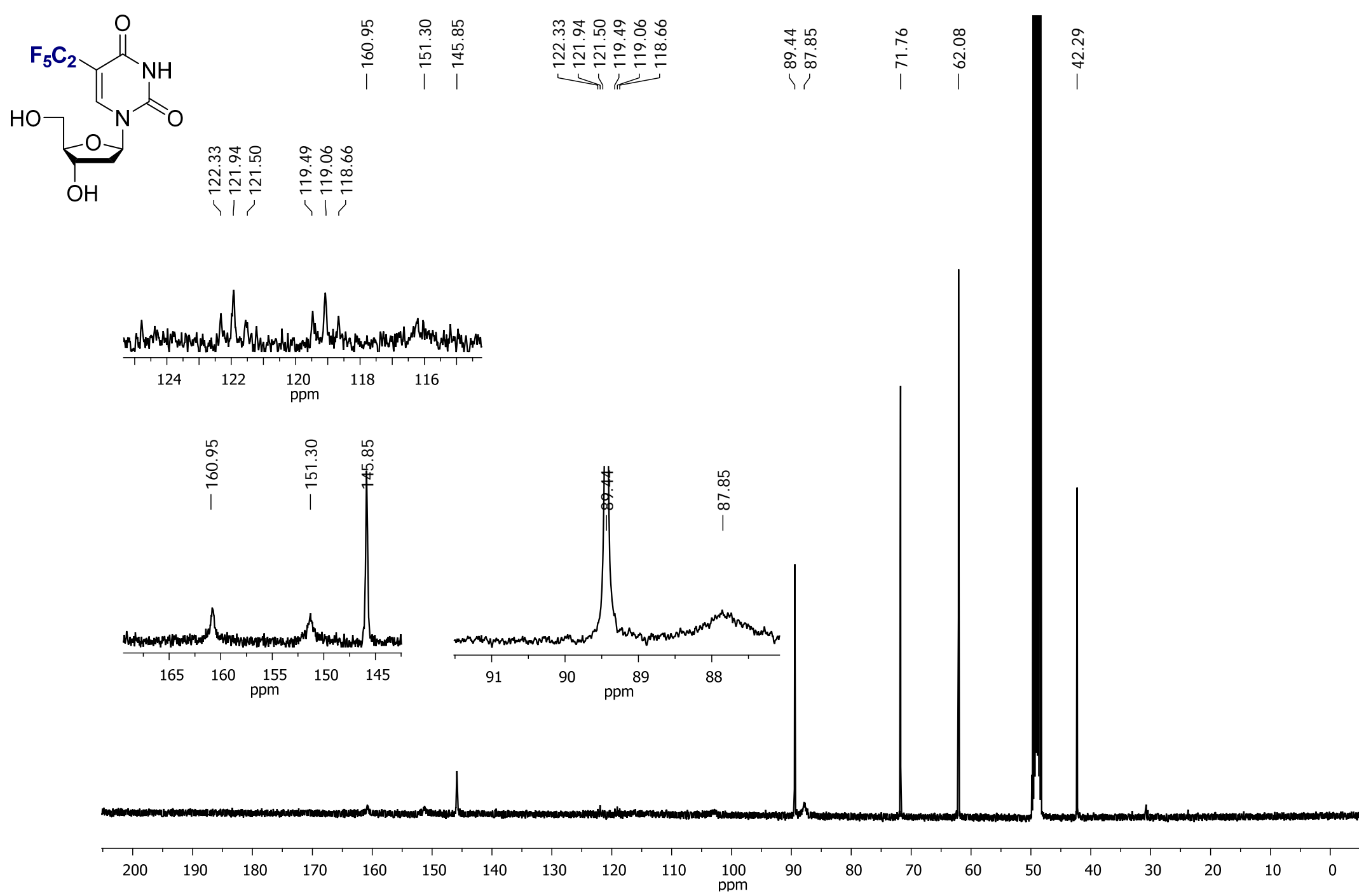

Figure S30. ${ }^{13} \mathrm{C}\left\{{ }^{1} \mathrm{H}\right\}$ NMR $\left(\mathrm{CD}_{3} \mathrm{OD}, 100.6 \mathrm{MHz}\right)$ of $\mathbf{2 g}$ 
Supporting Information
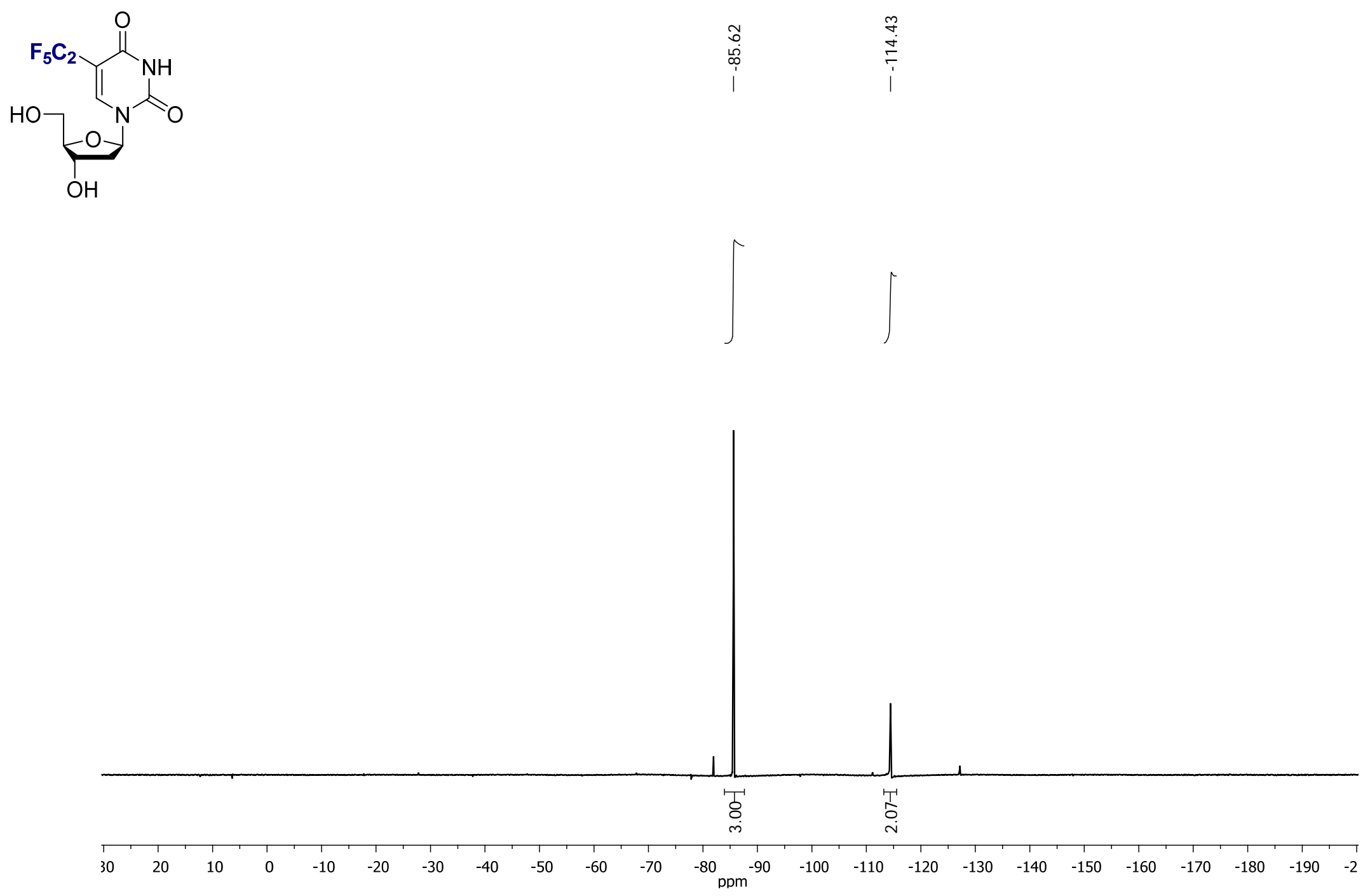

Figure S31. ${ }^{19} \mathrm{~F}$ NMR $\left(\mathrm{CD}_{3} \mathrm{OD}, 376.5 \mathrm{MHz}\right)$ of $\mathbf{2 g}$ 
Supporting Information
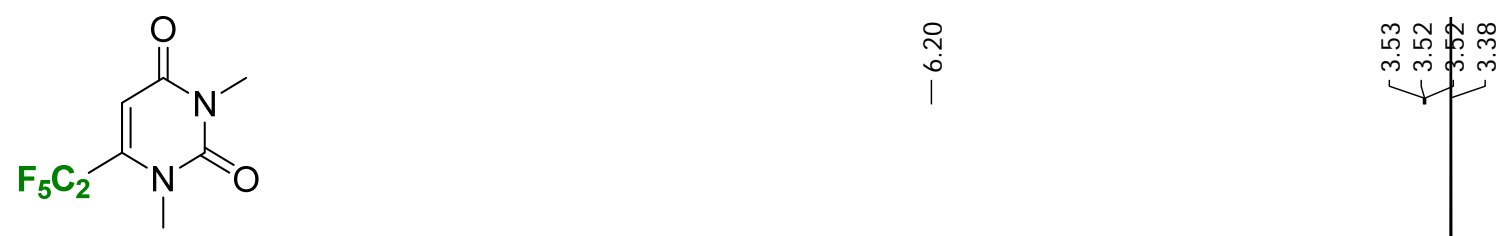

1
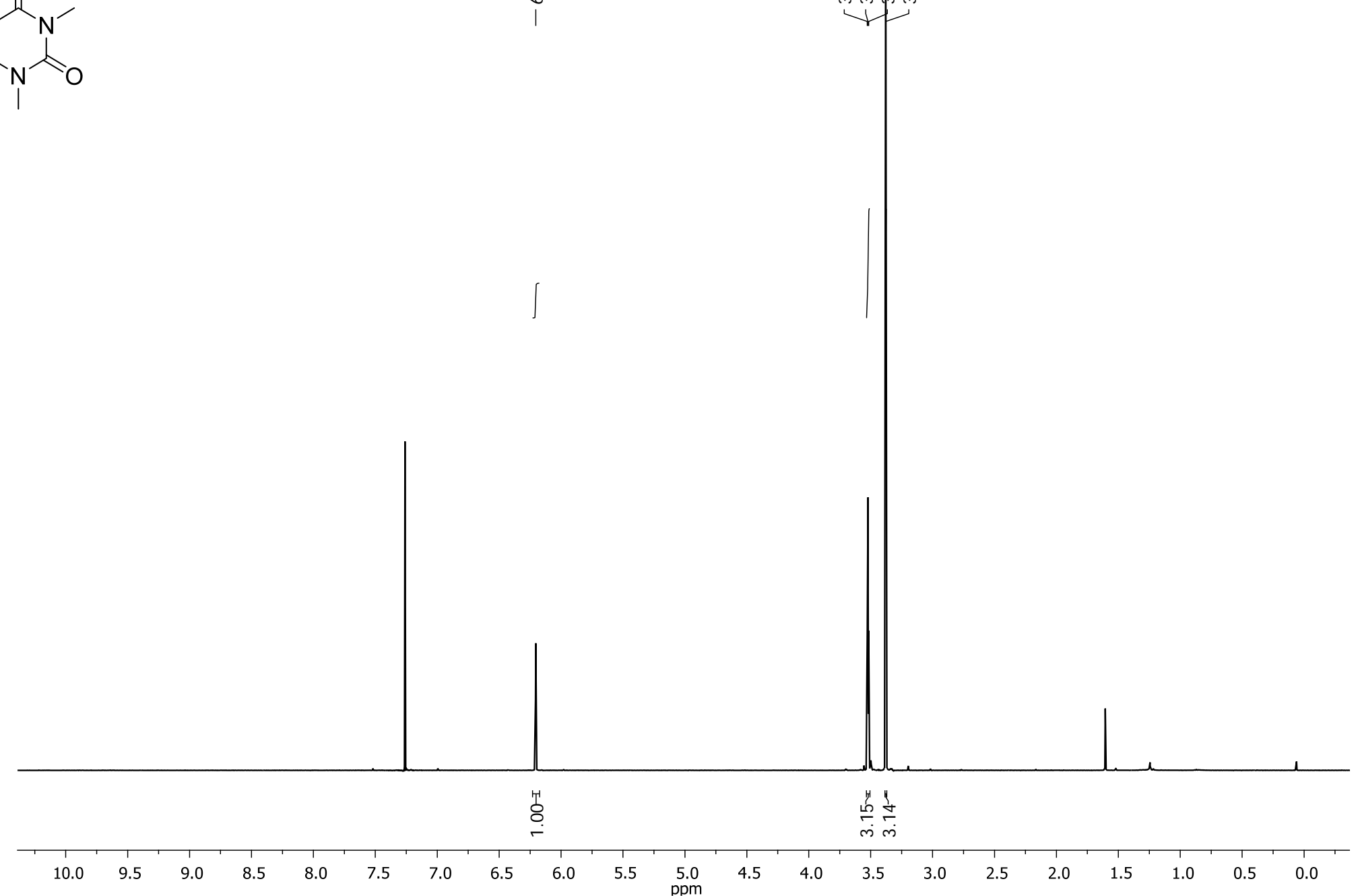

Figure S32. ${ }^{1} \mathrm{H} \mathrm{NMR}\left(\mathrm{CDCl}_{3}, 400 \mathrm{MHz}\right)$ of $\mathbf{2 h}$ 
Supporting Information

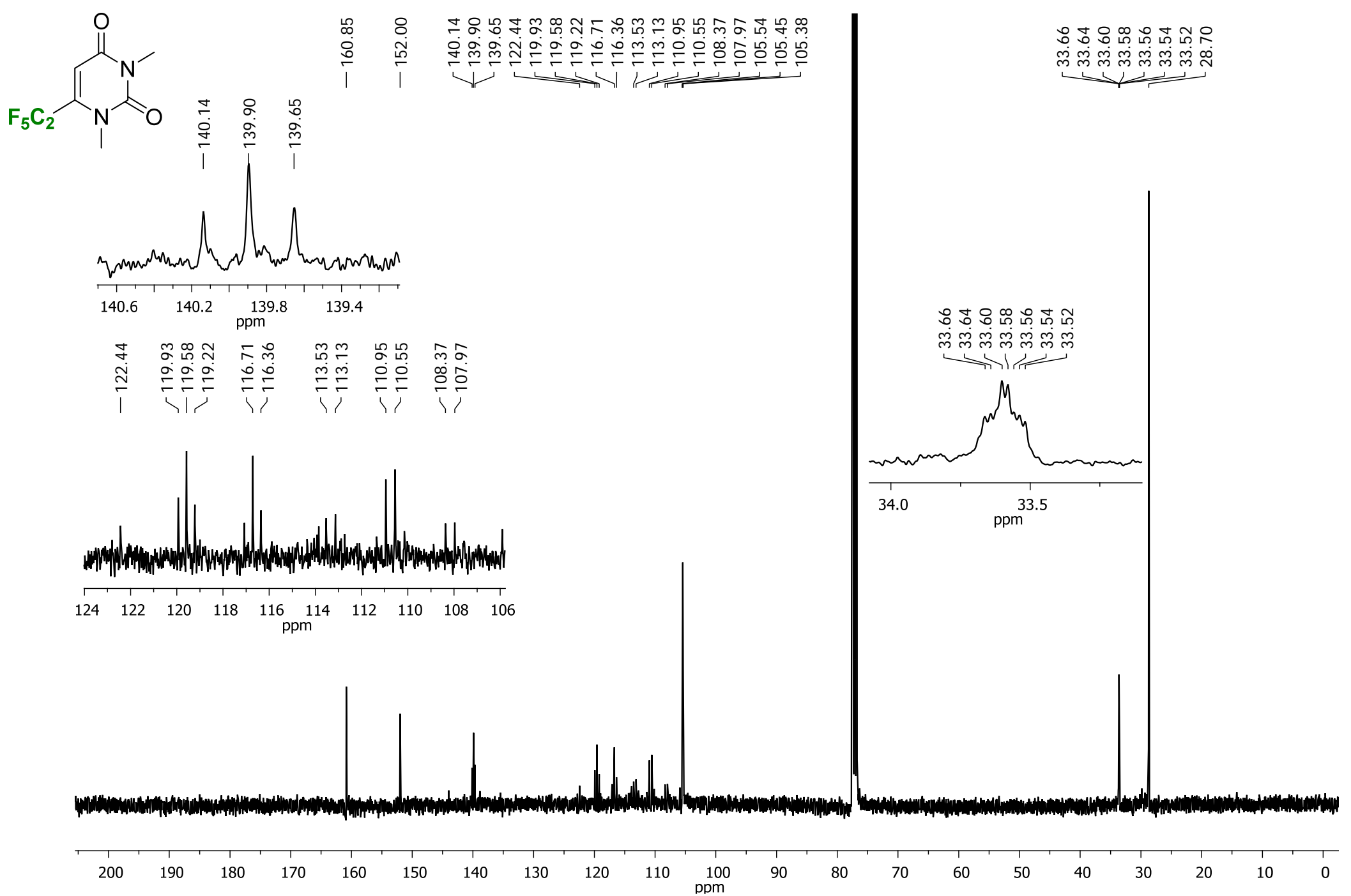

Figure S33. ${ }^{13} \mathrm{C}\left\{{ }^{1} \mathrm{H}\right\} \mathrm{NMR}\left(\mathrm{CDCl}_{3}, 100.6 \mathrm{MHz}\right)$ of $\mathbf{2 h}$ 
Supporting Information
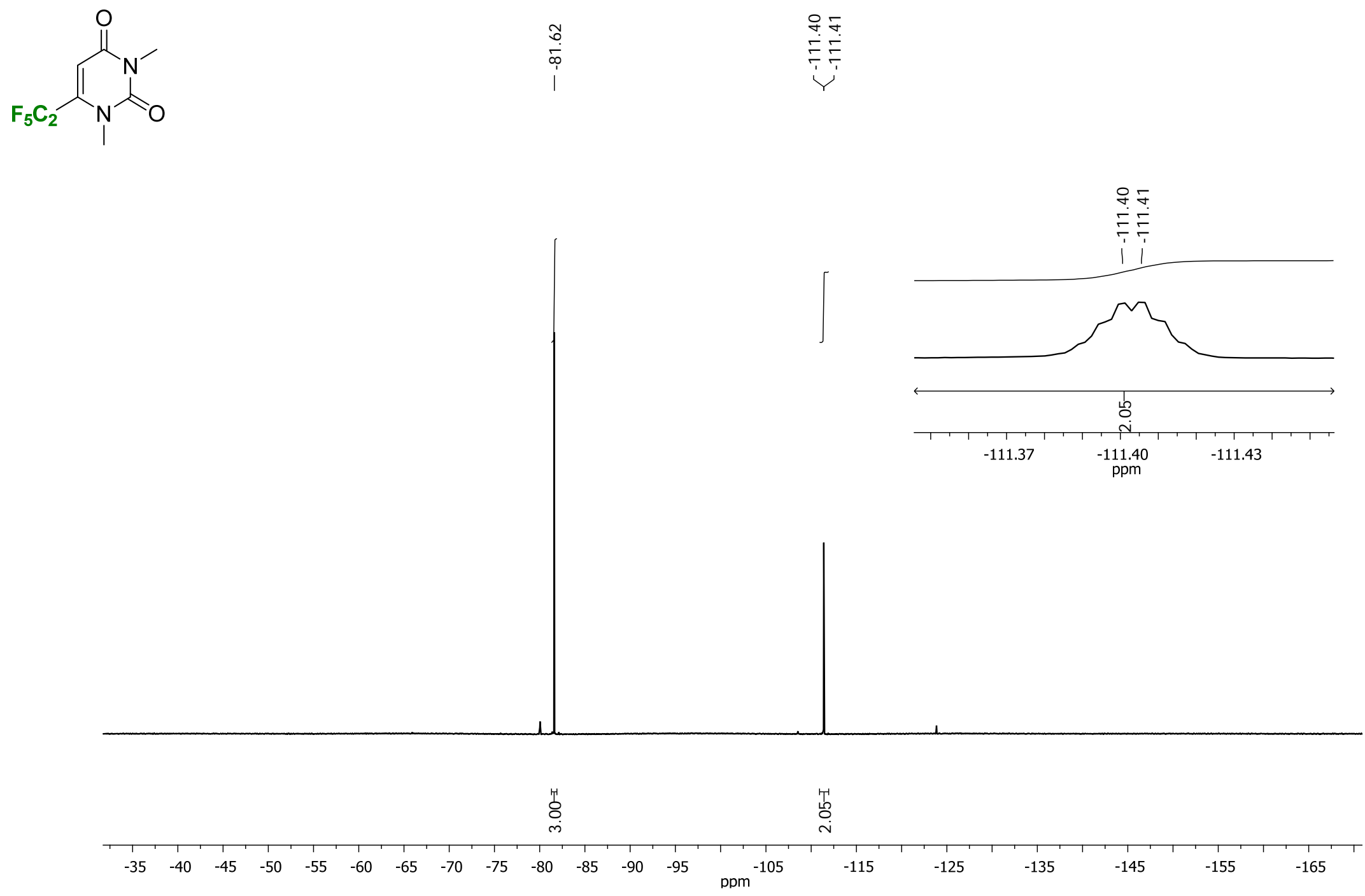

Figure S34. ${ }^{19} \mathrm{~F}$ NMR $\left(\mathrm{CDCl}_{3}, 376.5 \mathrm{MHz}\right)$ of $\mathbf{2 h}$ 


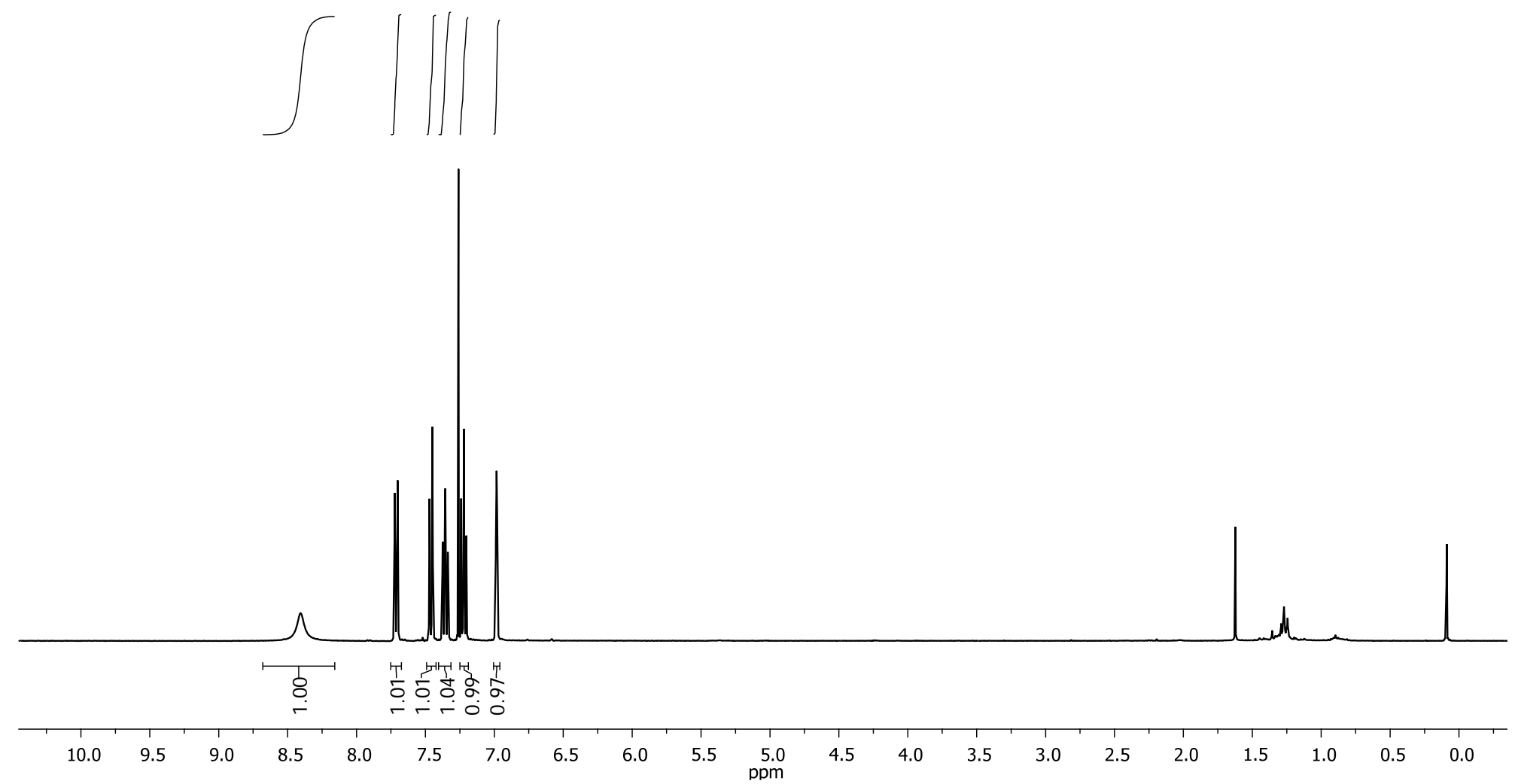

Figure S35. ${ }^{1} \mathrm{H} \mathrm{NMR}\left(\mathrm{CDCl}_{3}, 400 \mathrm{MHz}\right)$ of $\mathbf{2 i}$ 


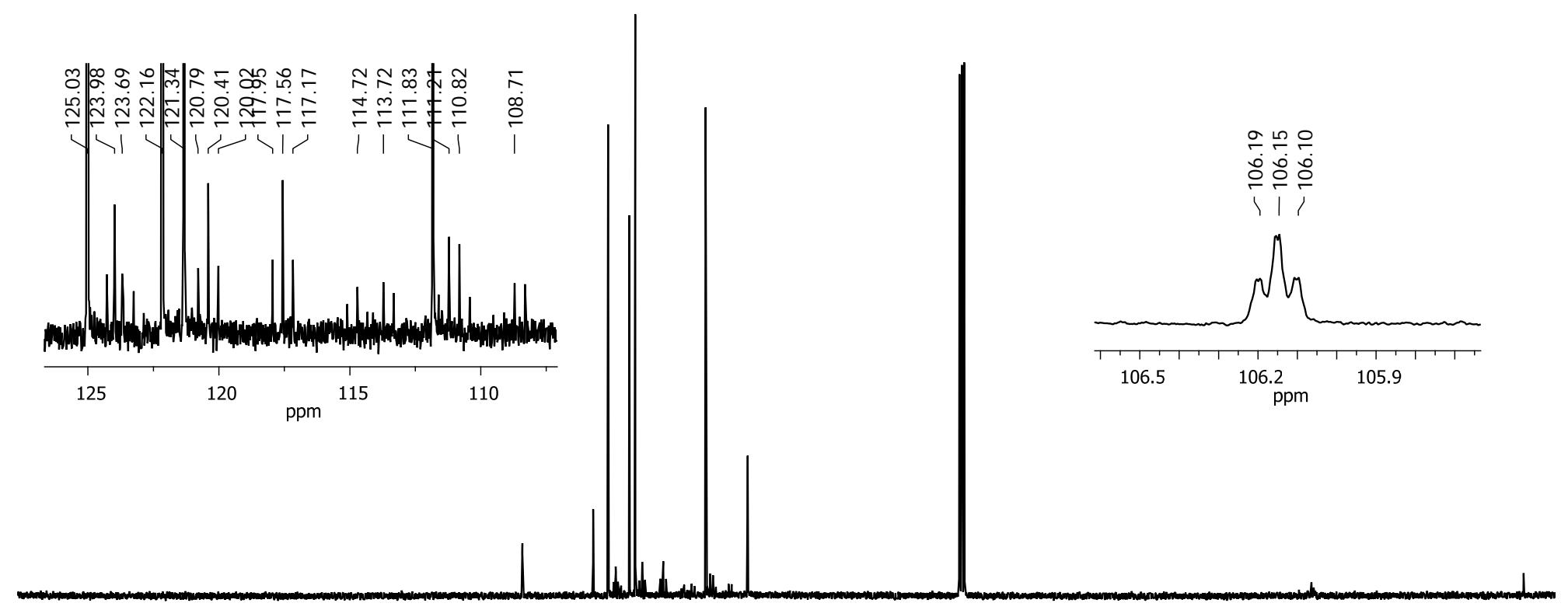

$200 \quad 190 \quad 180 \quad 170 \quad 160$
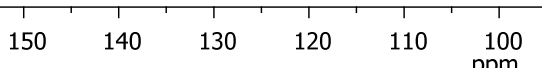

100
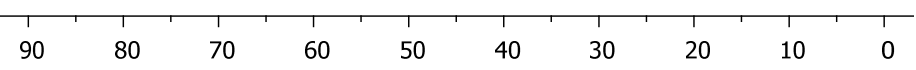

Figure S36. ${ }^{13} \mathrm{C}\left\{{ }^{1} \mathrm{H}\right\} \mathrm{NMR}\left(\mathrm{CDCl}_{3}, 100.6 \mathrm{MHz}\right)$ of $\mathbf{2 i}$ 
Supporting Information

$\mathrm{C}_{2} \mathrm{~F}_{5}$

$$
\text { 许 }
$$

œ

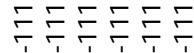

调
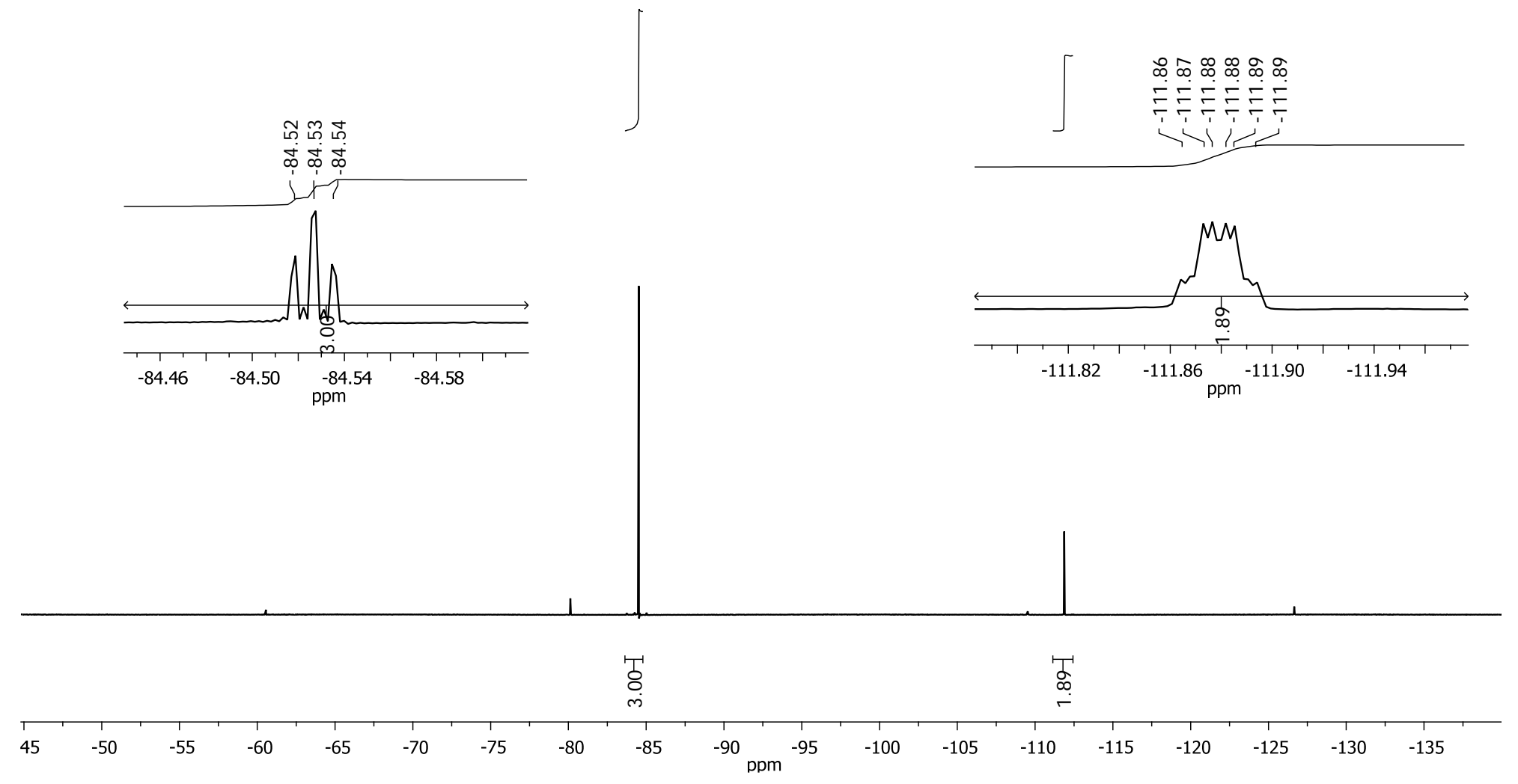

Figure S37. ${ }^{19} \mathrm{~F}$ NMR $\left(\mathrm{CDCl}_{3}, 376.5 \mathrm{MHz}\right)$ of $\mathbf{2 i}$ 
Supporting Information

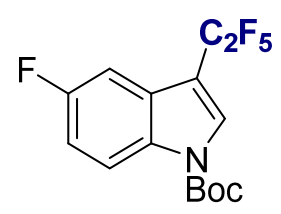

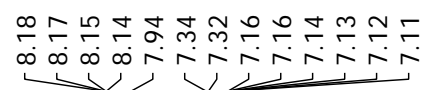

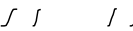

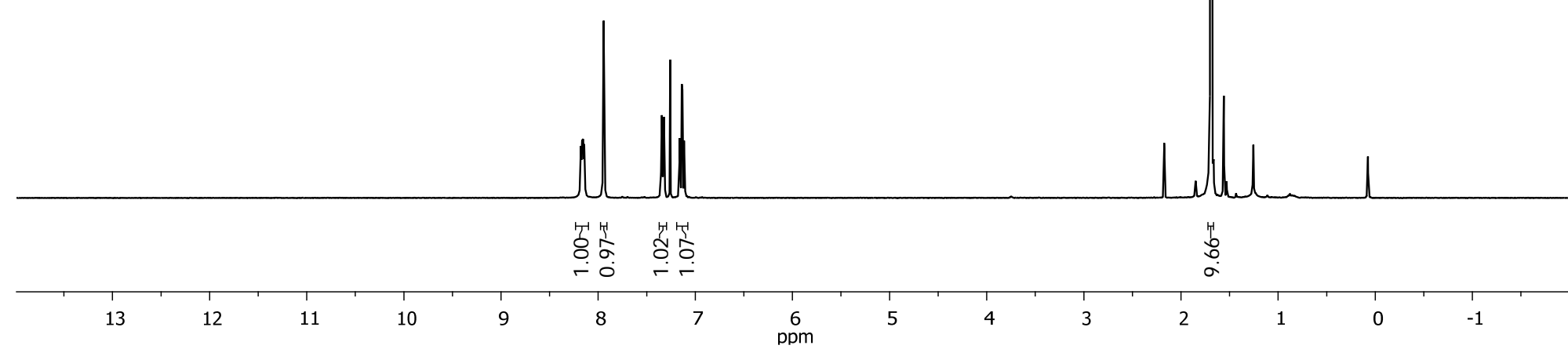

Figure S38. ${ }^{1} \mathrm{H} \mathrm{NMR}\left(\mathrm{CDCl}_{3}, 400 \mathrm{MHz}\right)$ of $\mathbf{2} \mathbf{j}$ 
Supporting Information
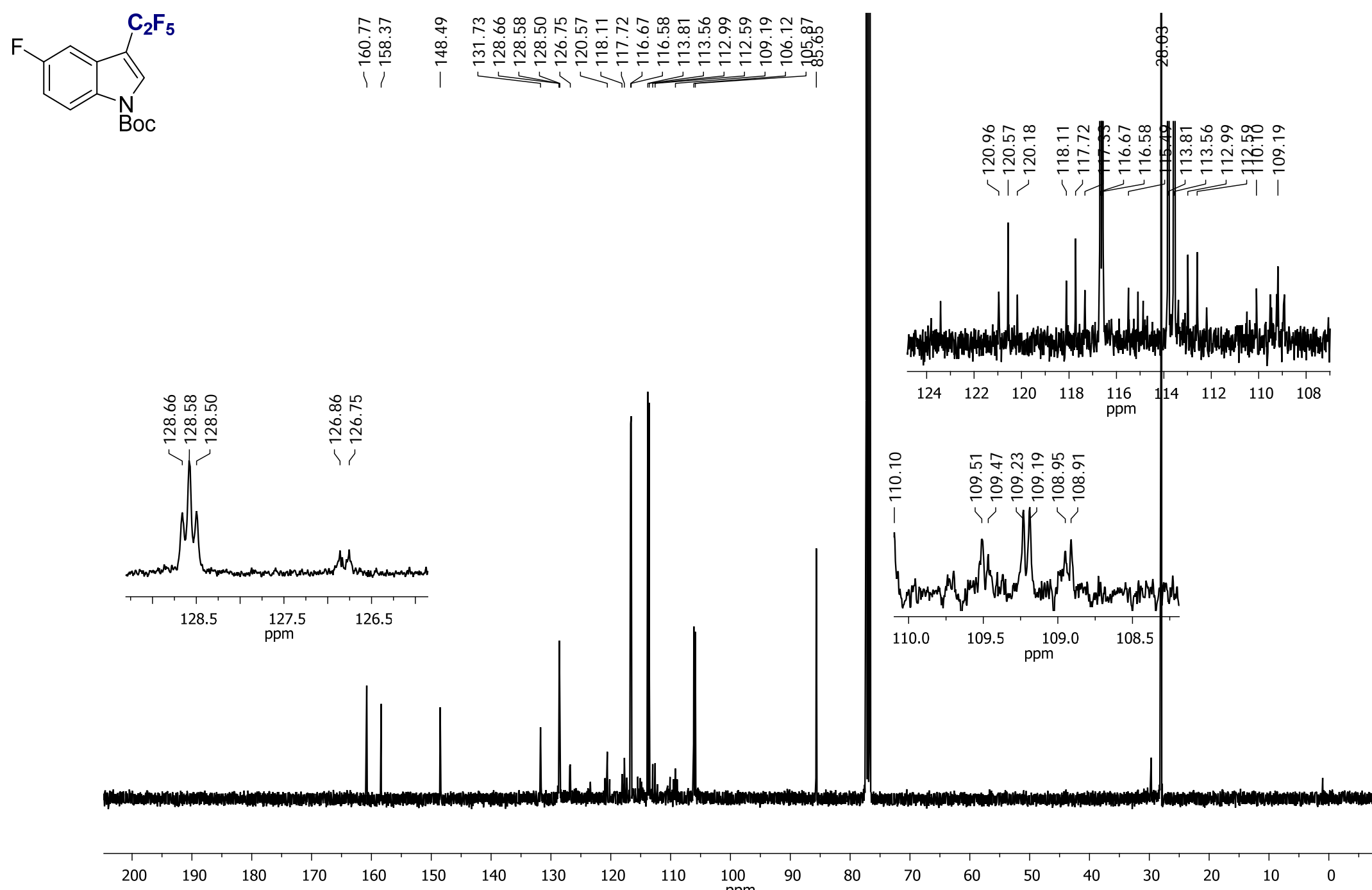

140

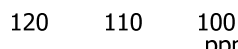

100

80

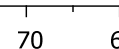

50

40

20

$10 \quad 0$

Figure S39. ${ }^{13} \mathrm{C}\left\{{ }^{1} \mathrm{H}\right\} \mathrm{NMR}\left(\mathrm{CDCl}_{3}, 100.6 \mathrm{MHz}\right)$ of $\mathbf{2 j}$ 
Supporting Information

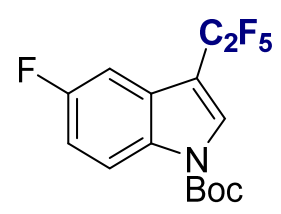

$\underbrace{\infty 0+1}$

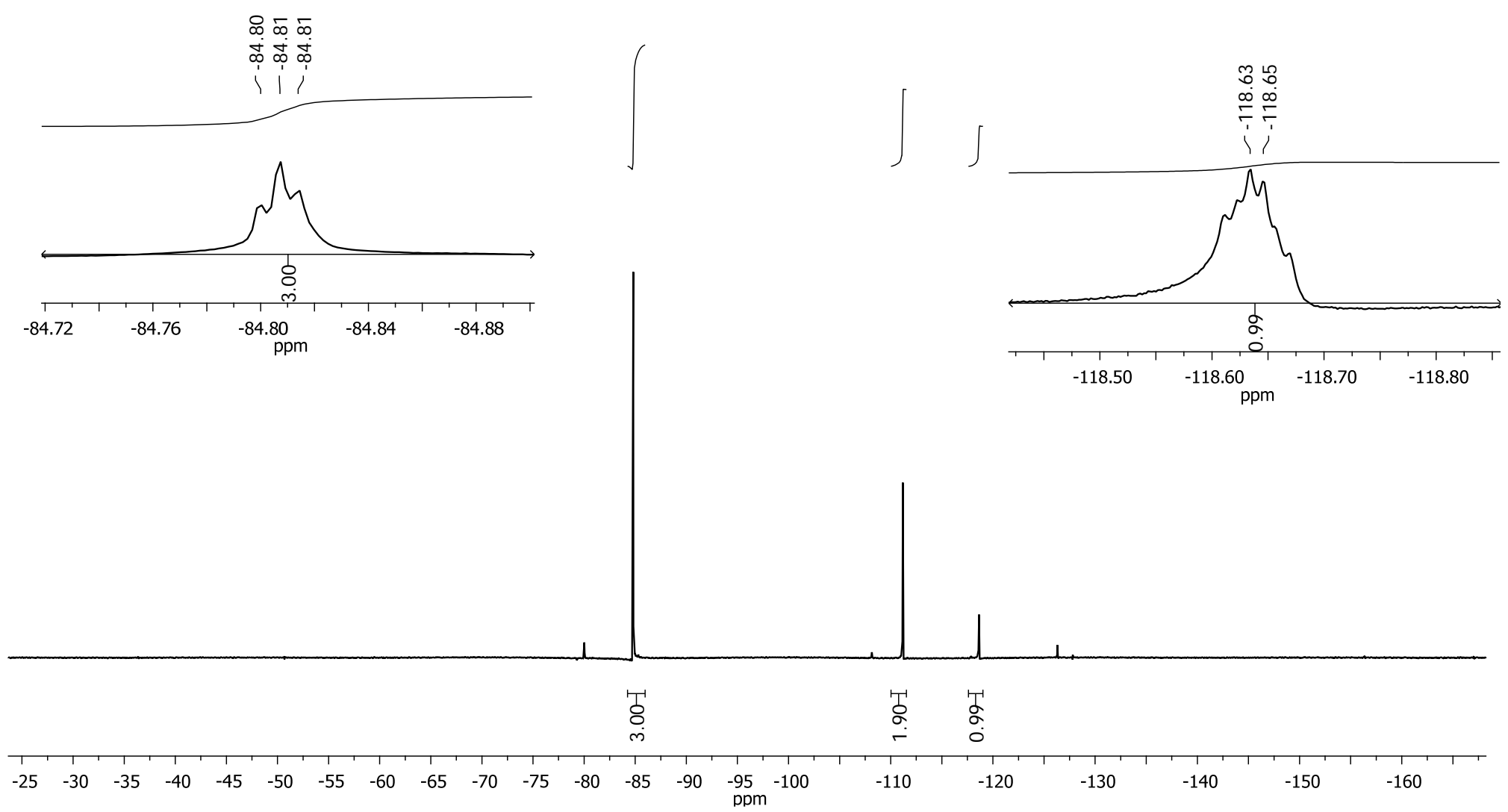

Figure S40. ${ }^{19} \mathrm{~F}$ NMR $\left(\mathrm{CDCl}_{3}, 376.5 \mathrm{MHz}\right)$ of $\mathbf{2 j}$ 
<smiles>FC(F)(F)c1ccc(C(F)(F)F)cc1</smiles>

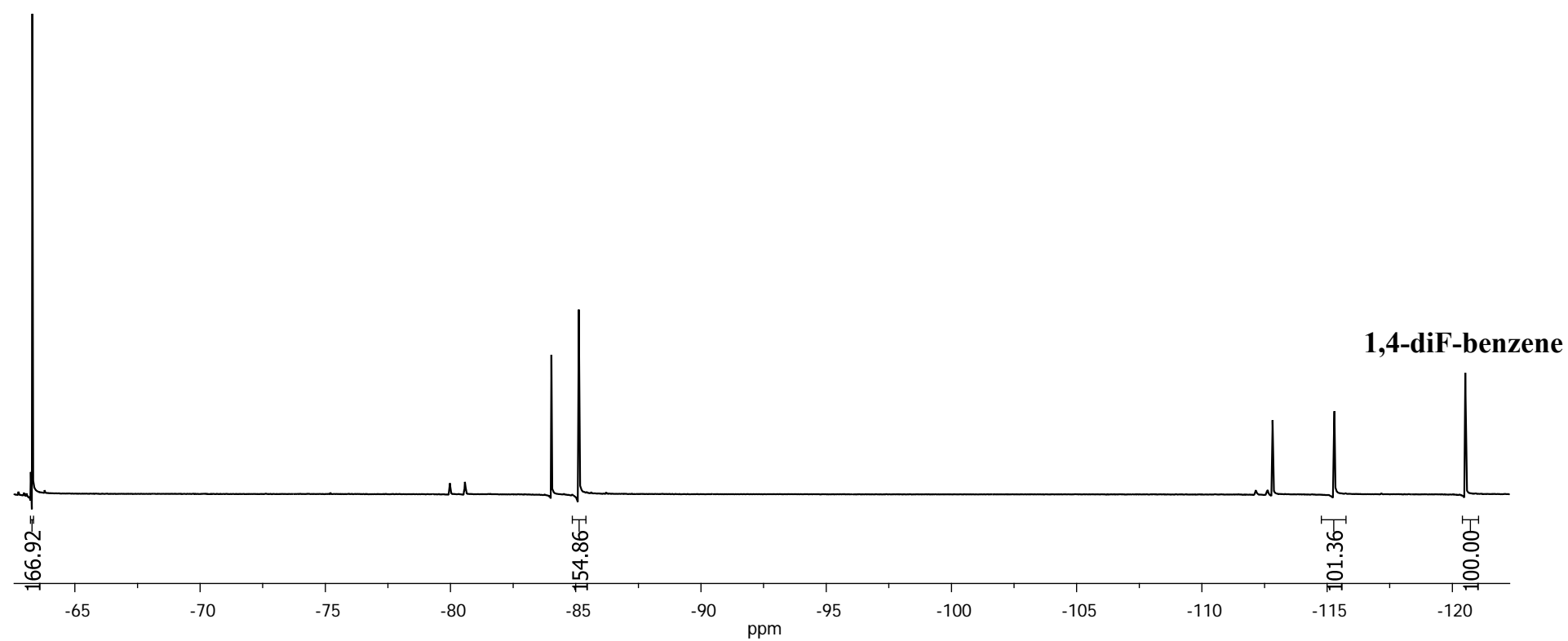

Figure S41. Quantitative ${ }^{19} \mathrm{~F}$ NMR $\left(\mathrm{CDCl}_{3}, 376.5 \mathrm{MHz}\right)$ of $\mathbf{2 k}$ 
Supporting Information

8
i
1
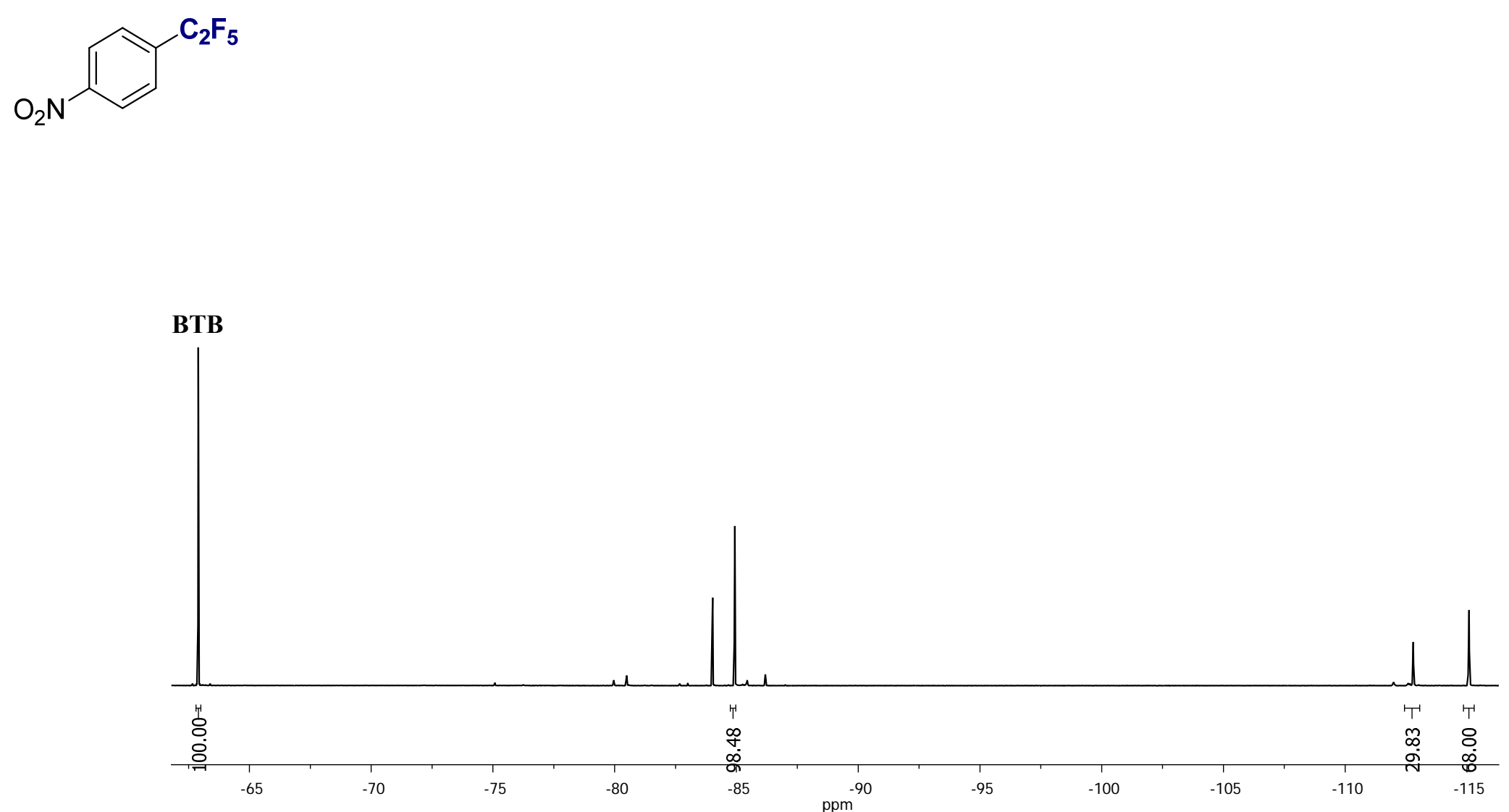

Figure S42. Quantitative ${ }^{19} \mathrm{~F} \mathrm{NMR}\left(\mathrm{CDCl}_{3}, 376.5 \mathrm{MHz}\right)$ of $2 \mathbf{l}$ 

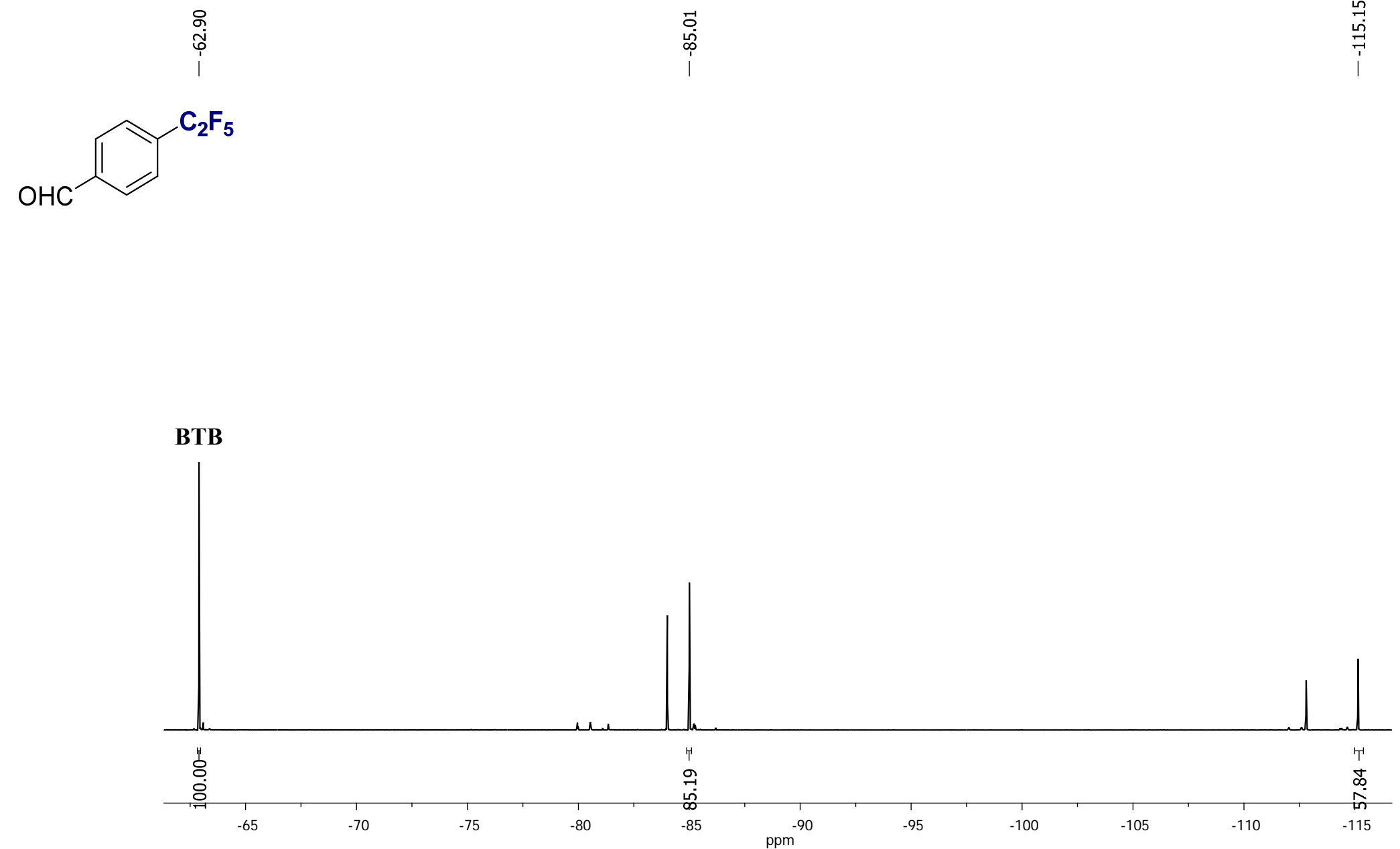

Figure S43. Quantitative ${ }^{19} \mathrm{~F}$ NMR $\left(\mathrm{CDCl}_{3}, 376.5 \mathrm{MHz}\right)$ of $\mathbf{2 m}$ 
Supporting Information

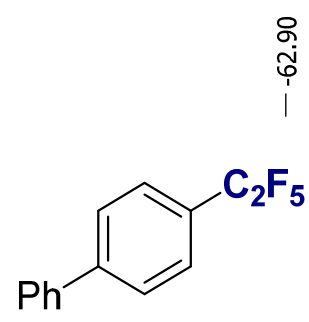

궁

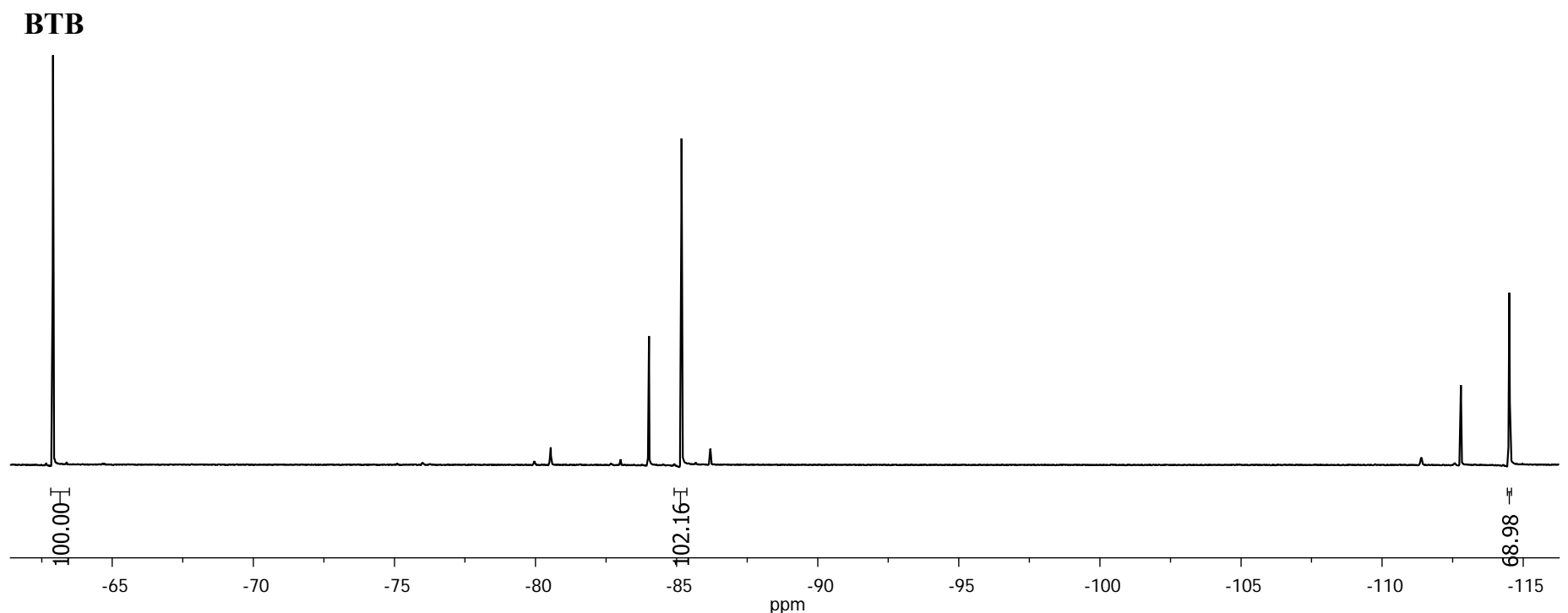

Figure S44. Quantitative ${ }^{19} \mathrm{~F}$ NMR $\left(\mathrm{CDCl}_{3}, 376.5 \mathrm{MHz}\right)$ of 2 n 
Supporting Information
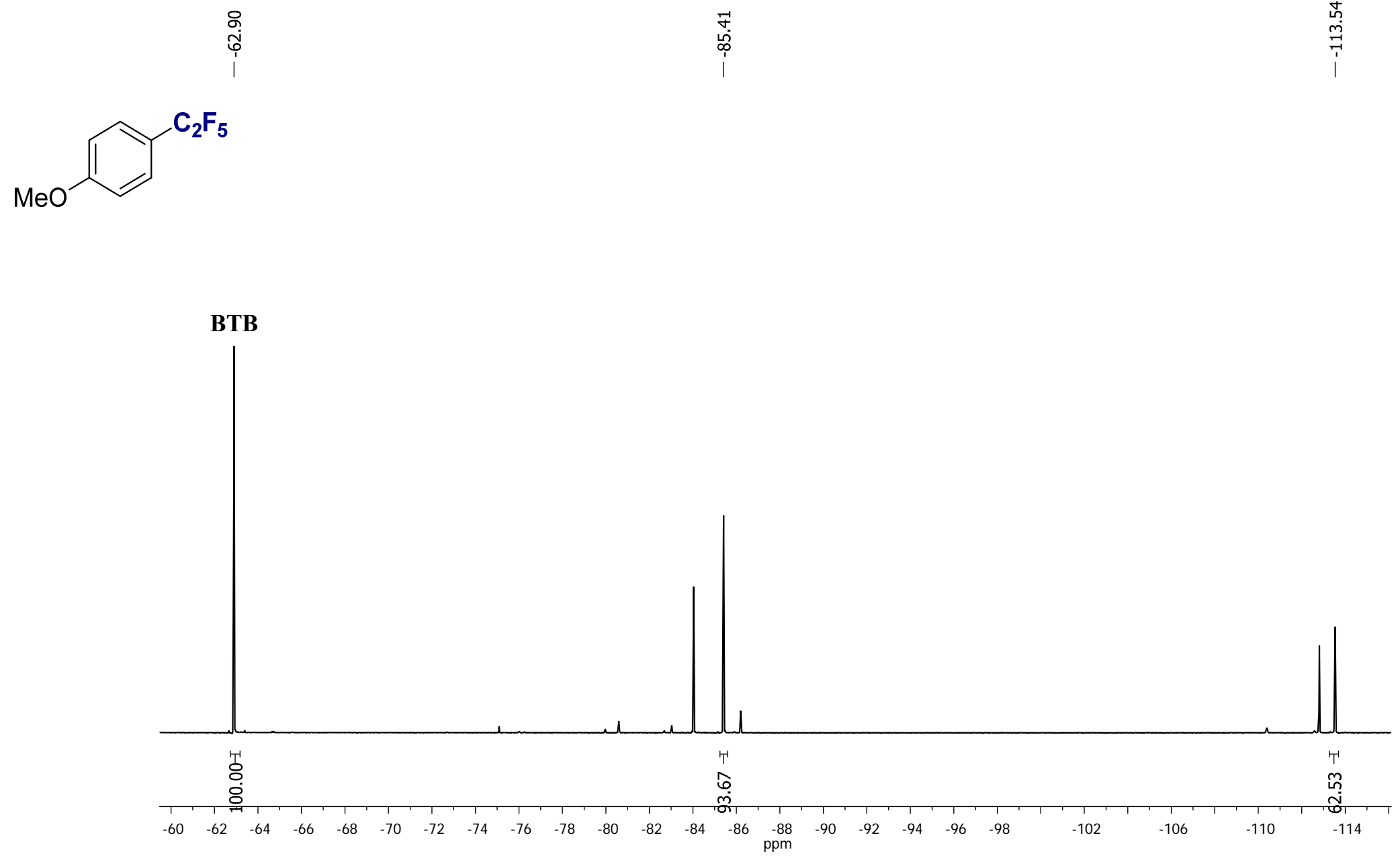

Figure S45. Quantitative ${ }^{19} \mathrm{~F} \mathrm{NMR}\left(\mathrm{CDCl}_{3}, 376.5 \mathrm{MHz}\right)$ of 20 
Supporting Information

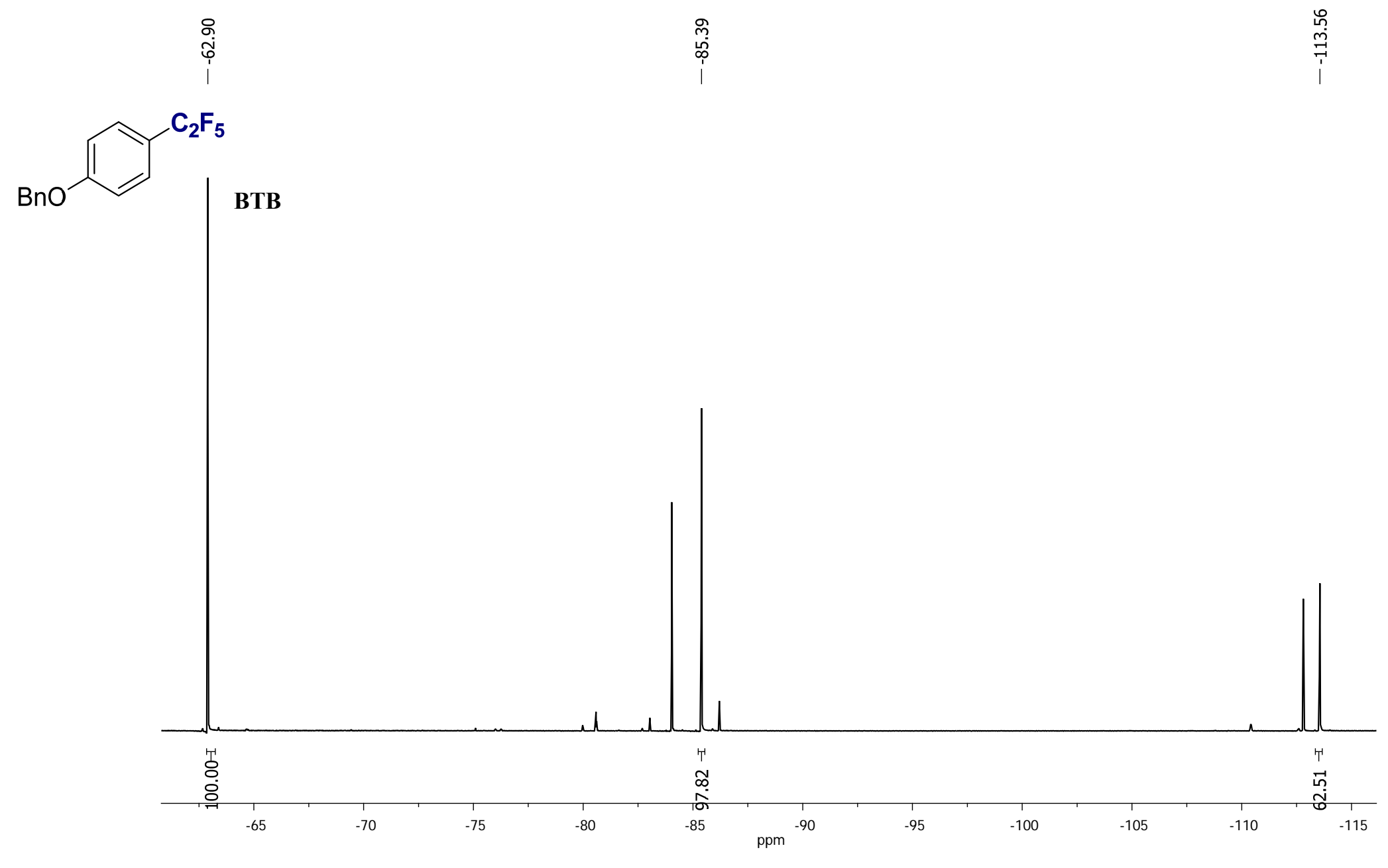

Figure S46. Quantitative ${ }^{19} \mathrm{~F} \mathrm{NMR}\left(\mathrm{CDCl}_{3}, 376.5 \mathrm{MHz}\right)$ of 2p 
Supporting Information
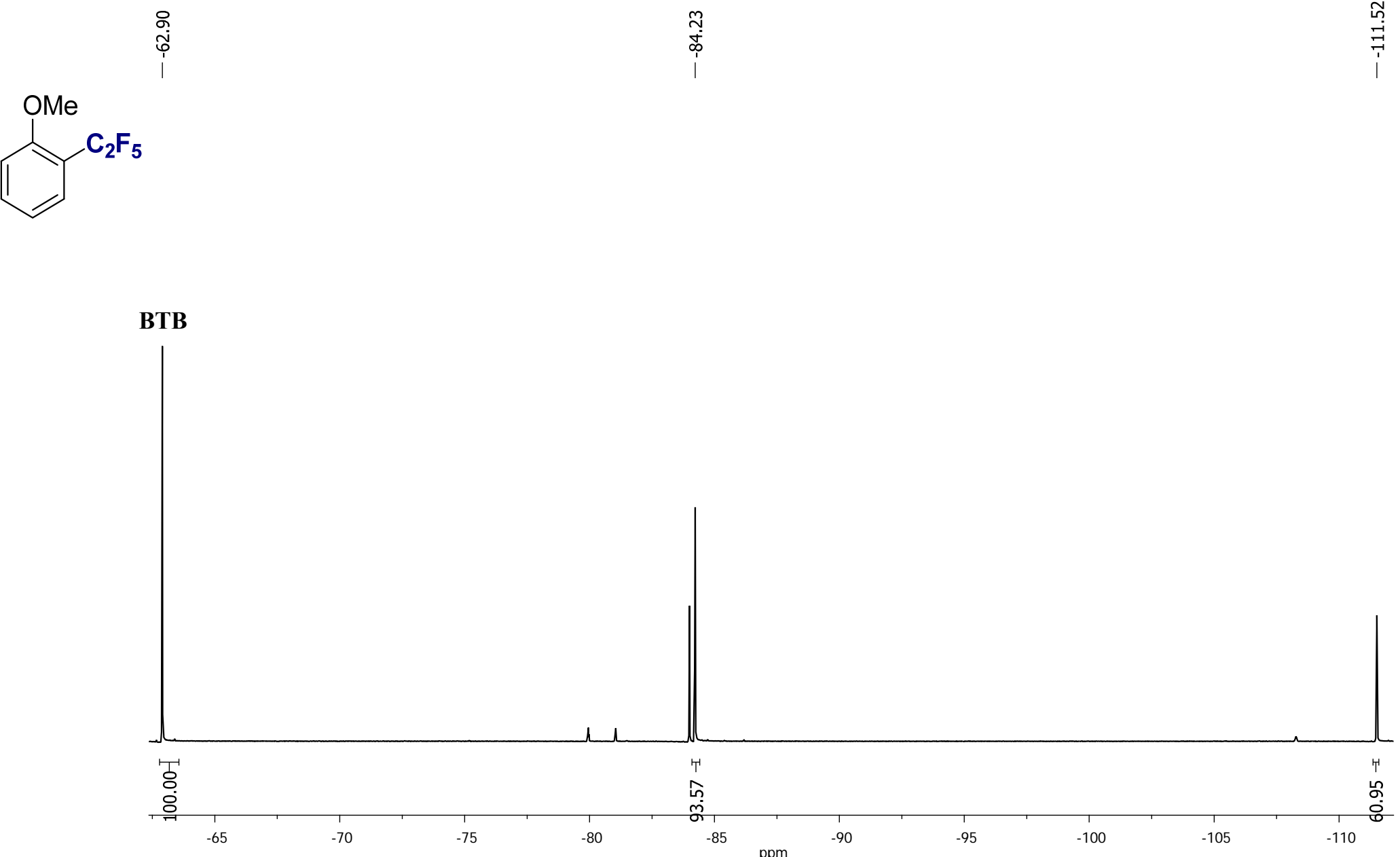

Figure S47. Quantitative ${ }^{19} \mathrm{~F} \mathrm{NMR}\left(\mathrm{CDCl}_{3}, 376.5 \mathrm{MHz}\right)$ of $\mathbf{2 q}$ 
Supporting Information

ஷ্ণ

i.

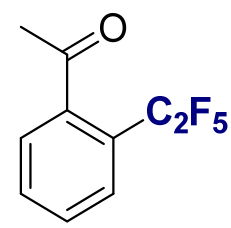

BTB

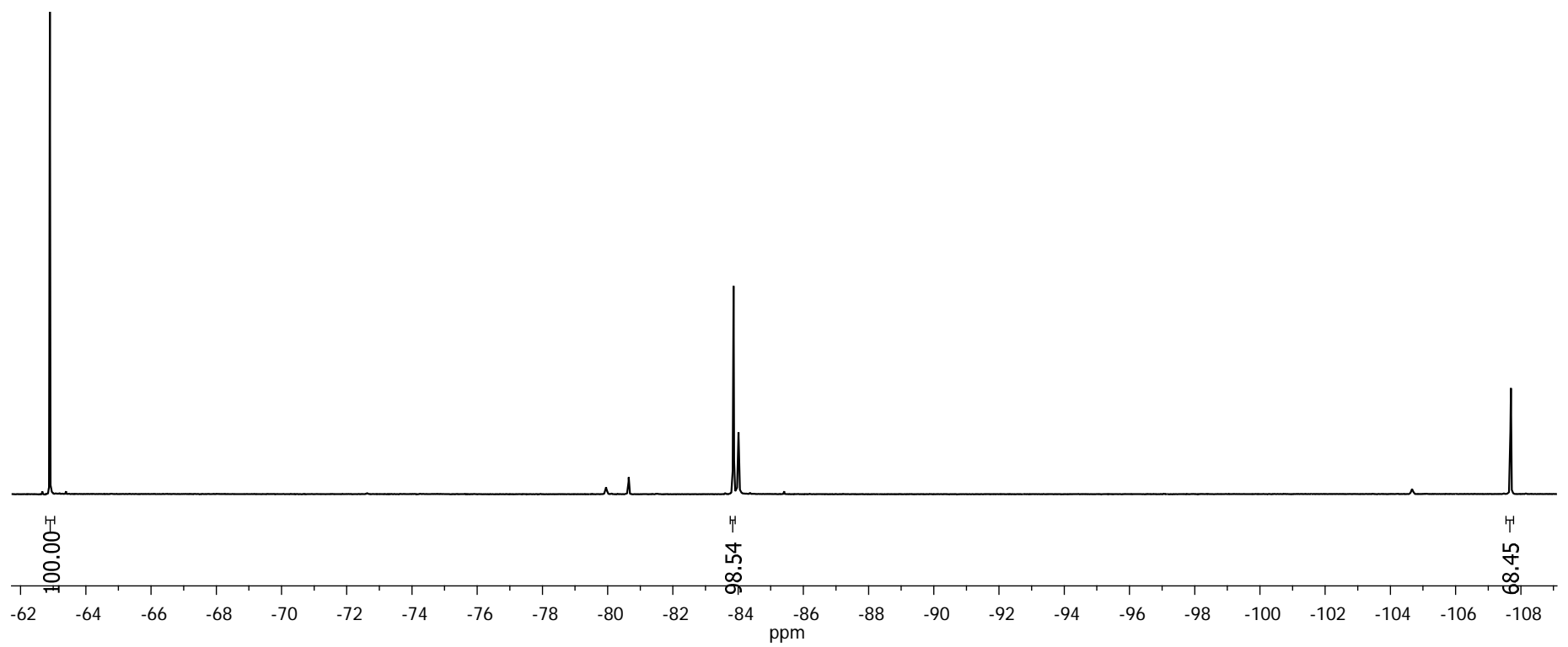

Figure S48. Quantitative ${ }^{19} \mathrm{~F}$ NMR $\left(\mathrm{CDCl}_{3}, 376.5 \mathrm{MHz}\right)$ of $\mathbf{2 r}$ 
Supporting Information

웅

웋

$\mathrm{Ph}$

$\sim \mathrm{C}_{2} \mathrm{~F}_{5}$

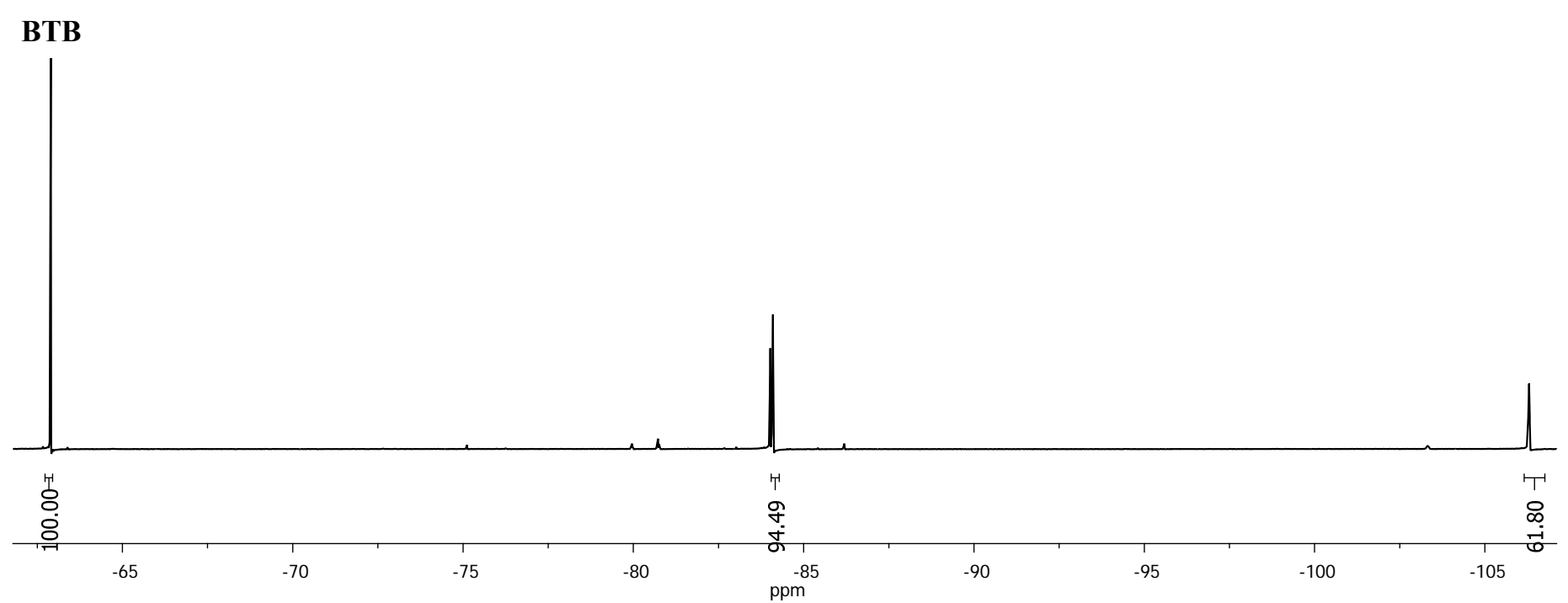

Figure S49. Quantitative ${ }^{19} \mathrm{~F} \mathrm{NMR}\left(\mathrm{CDCl}_{3}, 376.5 \mathrm{MHz}\right)$ of $2 \mathrm{~s}$ 
Supporting Information

오ํ

م.

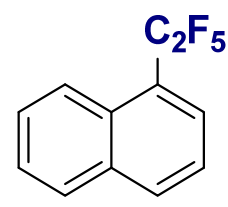

BTB

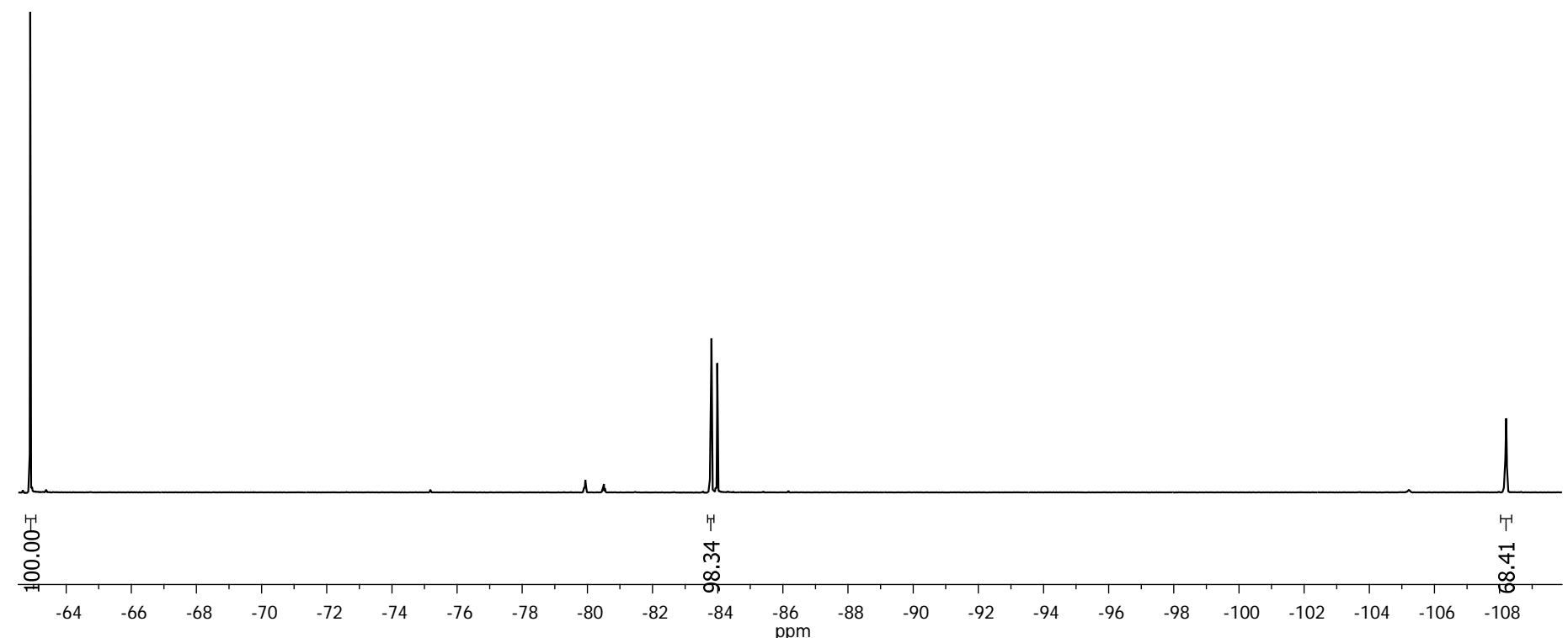

Figure S50. Quantitative ${ }^{19} \mathrm{~F}$ NMR $\left(\mathrm{CDCl}_{3}, 376.5 \mathrm{MHz}\right)$ of $\mathbf{2 t}$ 

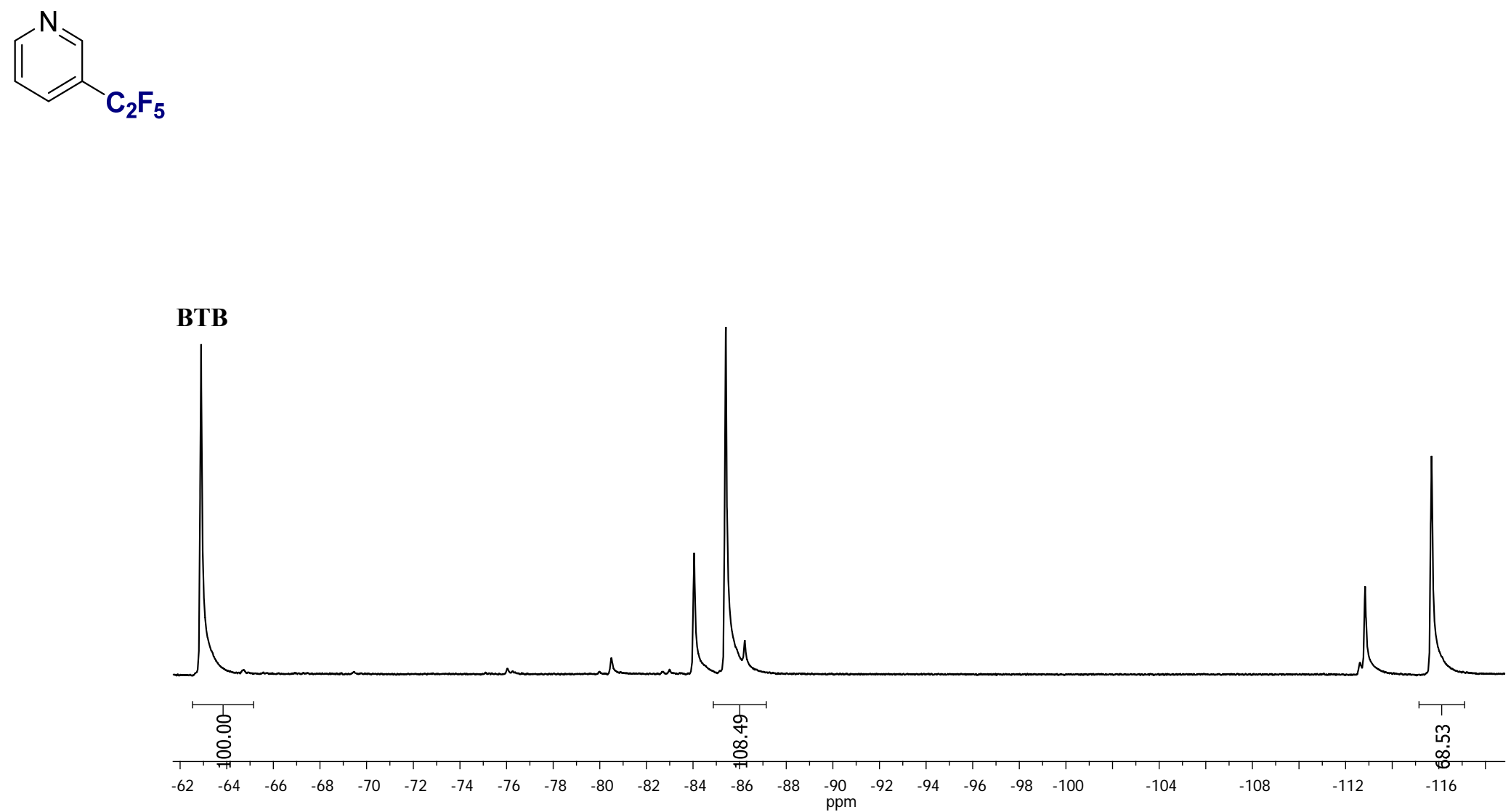

Figure S51. Quantitative ${ }^{19} \mathrm{~F}$ NMR $\left(\mathrm{CDCl}_{3}, 376.5 \mathrm{MHz}\right)$ of $\mathbf{2 u}$ 
Supporting Information

욱

$\underset{\substack{7 \\ \infty}}{+}$
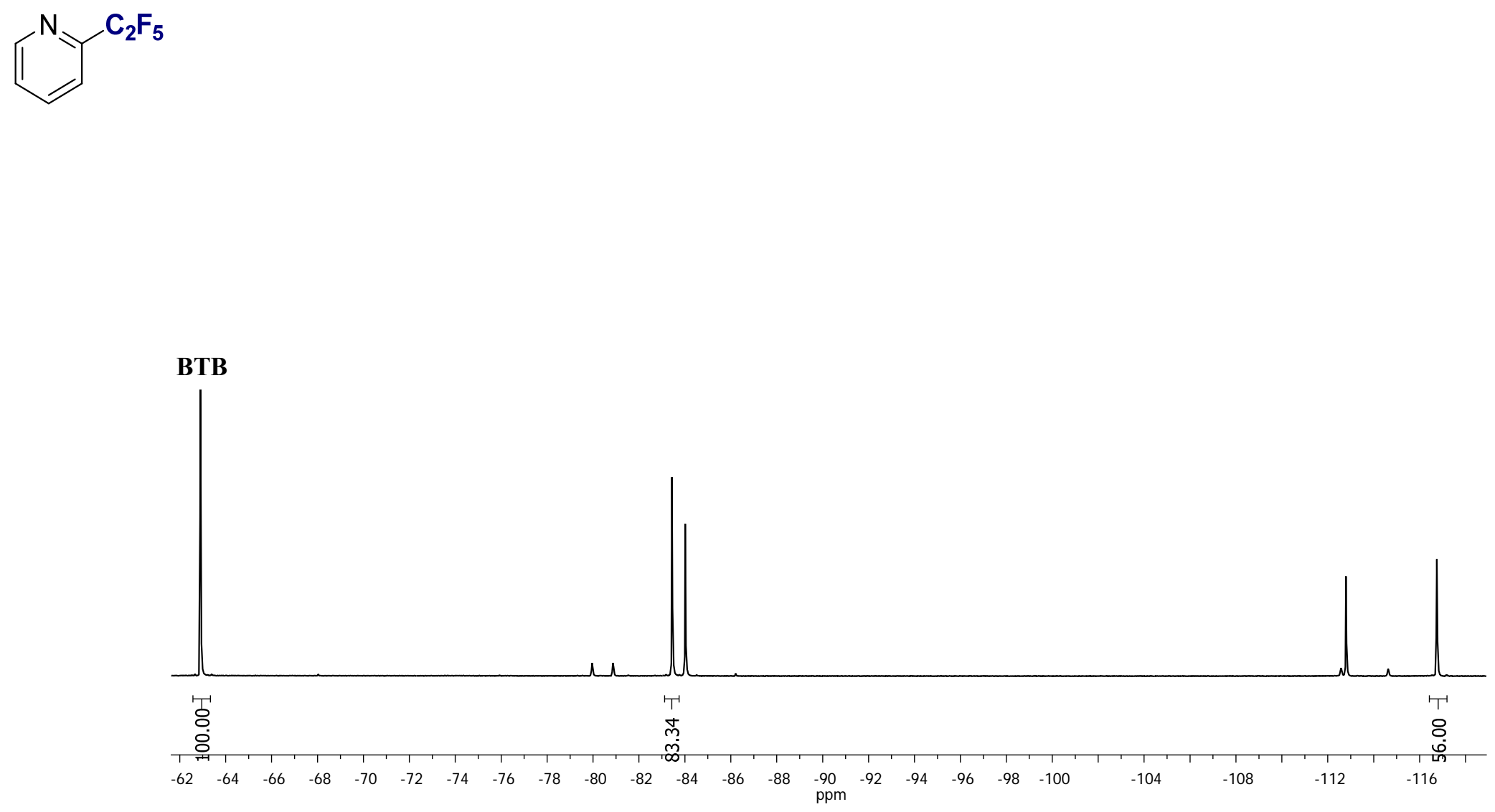

Figure S52. Quantitative ${ }^{19} \mathrm{~F}$ NMR $\left(\mathrm{CDCl}_{3}, 376.5 \mathrm{MHz}\right)$ of $\mathbf{2 v}$ 


\section{Supporting Information}

\section{References}

(1) Lishchynskyi, A.; Novikov, M. A.; Martin, E.; Escudero-Adán, E. C.; Novák, P.; Grushin.V. V. Trifluoromethylation of aryl and heteroaryl halides with fluoroform-derived $\mathrm{CuCF}_{3}$ : scope, limitations, and mechanistic features. J. Org. Chem. 2013, 78, 1112611146.

(2) Wiemers, D. M.; Burton, D. J. Pregeneration, spectroscopic detection and chemical reactivity of (trifluoromethyl)copper, an elusive and complex species. J. Am. Chem. Soc. 1986, 108, 832-834.

(3) Kremlev, M. M.; Mushta, A. I.; Tyrra, W.; Yagupolskii, Y. L.; Naumann, D.; Möller, A. $\mathrm{Me}_{3} \mathrm{SiCF}_{3} / \mathrm{AgF} / \mathrm{Cu}-\mathrm{A}$ new reagents combination for selective trifluoromethylation of various organic halides by trifluoromethylcopper, $\mathrm{CuCF}_{3}$. J. Fluorine Chem. 2012, 133, $67-71$.

(4) Kobayashi, Y.; Kumadaki, I. Studies on organic fluorine compounds. Part 27. Abnormal reactions in the trifluoromethylation of aromatic compounds with trifluoromethyl iodide and copper powder. J. Chem. Soc.; Perkin Trans. 1, 1980, 661-664.

(5) Kremlev, M. M.; Tyrra, W.; Mushta, A. I.; Naumann, D.; Yagupolskii, Y. L. The solid complex $\mathrm{Zn}\left(\mathrm{CF}_{3}\right) \mathrm{Br} \cdot 2 \mathrm{DMF}$ as an alternative reagent for the preparation of both, trifluoromethyl and pentafluoroethyl copper, $\mathrm{CuCF}_{3}$ and $\mathrm{CuC}_{2} \mathrm{~F}_{5}$. J. Fluorine Chem. 2010, $131,212-216$.

(6) Zheng, J., Lin, J.-H., Yu, L.-Y., Wei, Y., Zheng, X., Xiao, J.-C. Cross-coupling between difluorocarbene and carbene-derived intermediates generated from diazocompounds for the synthesis of gem-difluoroolefins. Org. Lett. 2015, 17, 6150-6153.

(7) Carr, G. E.; Chambers, R. D.; Holmes T. F.; Parker, D. G. Sodium perfluoroalkane carboxylates as sources of perfluoroalkyl groups. J. Chem. Soc.; Perkin Trans. 1, 1988, 921-926.

(8) Willert-Porada, M. A.; Burton, D. J; Baenziger, N. C. Synthesis and X-ray structure of bis(trifluoromethyl)(N,N-diethyldithiocarbamato)-copper; a remarkably stable perfluoroalkylcopper(III) complex. J. Chem. Soc.; Chem. Commun. 1989, 1633-1634. 
(9) Aikawa, K.; Nakamura, Y.; Yokota, Y.; Toya, W.; Mikami, K. Stable but reactive perfluoroalkylzinc reagents: application in ligand-free copper-catalyzed perfluoroalkylation of aryl iodides. Chem. Eur. J. 2015, 21, 96-100.

(10) $\mathrm{Hu}, \mathrm{M}$; Ni, C.; Hu, J. Copper-mediated trifluoromethylation of $\alpha$-diazo esters with $\mathrm{TMSCF}_{3}$ : the important role of water as a promoter. J. Am. Chem. Soc. 2012, 134, 15257-15260.

(11) Serizawa, H.; Aikawa, K.; Mikami, K. Direct synthesis of pentafluoroethyl copper from pentafluoropropionate as an economical $\mathrm{C}_{2} \mathrm{~F}_{5}$ source: application to pentafluoroethylation of arylboronic acids and aryl bromides. Org. Lett. 2014, 16, 3456-3459.

(12) Lishchynskyi, A.; Grushin, V. V. Cupration of $\mathrm{C}_{2} \mathrm{~F}_{5} \mathrm{H}$ : isolation, structure, and synthetic applications of $\left[\mathrm{K}(\mathrm{DMF})_{2}\right]\left[(t-\mathrm{BuO}) \mathrm{Cu}\left(\mathrm{C}_{2} \mathrm{~F}_{5}\right)\right]$. Highly efficient pentafluoroethylation of unactivated aryl bromides. J. Am. Chem. Soc. 2013, 135, 12584-12587.

(13) Dubinina, G. G.; Ogikubo, J.; Vicic, D. A. Structure of bis(trifluoromethyl)cuprate and its role in trifluoromethylation reactions. Organometallics 2008, 27, 6233-6235.

(14) Chalmers, A. A.; Hall, R. H. Conformational studies of D-glycals by ${ }^{1} \mathrm{H}$ nuclear magnetic resonance spectroscopy. J. Chem. Soc.; Perkin Trans. 2, 1974, 728-732.

(15) Mestre, J.; Lishchynskyi, A.; Castillón, S.; Boutureira, O. Trifluoromethylation of electron-rich alkenyl iodides with fluoroform-derived "ligandless" $\mathrm{CuCF}_{3}$. J. Org. Chem. 2018, 83, 8150-8160.

(16) Cobo, I.; Matheu, M. I.; Castillón, S.; Boutureira, O.; Davis, B. G. Phosphine-free SuzukiMiyaura cross-coupling in aqueous media enables access to 2-C-aryl-glycosides. Org. Lett. 2012, 14, 1728-1731.

(17) Qi, Q.; Shen, Q.; Lu, L. Copper-mediated aerobic fluoroalkylation of arylboronic acids with fluoroalkyl iodides at room temperature. J. Am. Chem. Soc. 2012, 134, 6548-6551.

(18) Clark, J. H.; Denness, J. E.; McClinton, M. A.; Wynd, A. J. The trifluoromethylation of chloroaromatics using the copper- $\mathrm{CF}_{2} \mathrm{Br}_{2}$ - dialkylamide reaction system. J. Fluorine Chem. 1990, 50, 411-426.

(19) Li, L.; Ni, C.; Xie, Q.; Hu, M.; Wang, F.; Hu, J. TMSCF3 as a convenient source of $\mathrm{CF}_{2}=\mathrm{CF}_{2}$ for pentafluoroethylation, (aryloxy)tetrafluoroethylation, and tetrafluoroethylation. Angew. Chem. Int. Ed. 2017, 56, 9971-9975. 